LUIZ CARLOS CARNEVALI JUNIOR

\title{
EFEITOS DO TREINAMENTO FÍSICO SOBRE O METABOLISMO LIPÍDICO NO FÍGADO DE RATOS COM CAQUEXIA ASSOCIADA AO CÂNCER: \\ PAPEL DO PPAR $\alpha$
}

Tese apresentada ao Programa de PósGraduação em Biologia Celular e Tecidual do Instituto de Ciências Biomédicas da Universidade de São Paulo; para obtenção do Título de Doutor em Ciências.

Área de Concentração: Biologia Celular e Tecidual

São Paulo 


\section{LUIZ CARLOS CARNEVALI JUNIOR}

\section{EFEITOS DO TREINAMENTO FÍSICO SOBRE O METABOLISMO LIPÍDICO NO FÍGADO DE RATOS COM CAQUEXIA ASSOCIADA AO CÂNCER: \\ PAPEL DO PPARa}

Tese apresentada ao Programa de PósGraduação em Biologia Celular e Tecidual do Instituto de Ciências Biomédicas da Universidade de São Paulo; para obtenção do Título de Doutor em Ciências.

Área de Concentração: Biologia Celular e Tecidual

Orientadora: Prof ${ }^{a}$ Dra. Marília Cerqueira Leite Seelaender

Versão Original

\section{SÃO PAULO}


DADOS DE CATALOGAÇÃO NA PUBLICAÇÃO (CIP)

Serviço de Biblioteca e Informação Biomédica do

Instituto de Ciências Biomédicas da Universidade de São Paulo

(c) reprodução total

Carnevali Junior, Luiz Carlos.

Efeito do treinamento físico sobre o metabolismo lipídico no fígado de ratos com caquexia associada ao câncer: papel do PPARa / Luiz Carlos Carnevali Junior. -- São Paulo, 2011.

Orientador: Marília Cerqueira Leite Seelaender.

Tese (Doutorado) - Universidade de São Paulo. Instituto de Ciências Biomédicas. Departamento de Biologia Celular e do Desenvolvimento. Área de concentração: Biologia Celular e Tecidual. Linha de pesquisa: Caquexia associada ao câncer - alteração do metabolismo lipídico.

Versão do título para o inglês: Effects of physical training exercise upon liver lipid metabolism of tumour-bearing rats: role of PPARa

Descritores: 1. Câncer 2. Caquexia 3. Treinamento 4. Fígado 5. Esteatose 6. Metabolismo lipídico I. Seelaender, Marília Cerqueira Leite II. Universidade de São Paulo. Instituto de Ciências Biomédicas. Programa de Pós-Graduação em Biologia Celular e Tecidual III. Título. 


\section{UNIVERSIDADE DE SÃO PAULO \\ INSTITUTO DE CIÊNCIAS BIOMÉDICAS}

Candidato(a): $\quad$ Luiz Carlos Carnevali Junior.

Título da Tese: $\quad$ Efeito do treinamento físico sobre o metabolismo lipídico no fígado de ratos com caquexia associada ao câncer: papel do PPAR $\alpha$.

Orientador(a): Marília Cerqueira Leite Seelaender.

A Comissão Julgadora dos trabalhos de Defesa da Tese de Doutorado, em sessão pública realizada a considerou

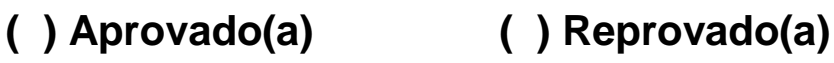

Examinador(a): Nome completo:

Instituição:

Examinador(a): Nome completo:

Instituição:

Examinador(a): Nome completo:

Instituição:

Examinador(a): Nome completo:

Instituição:

Presidente: Nome completo:

Instituição: 


\section{CerTIFICADO}

Certificamos que o protocolo registrado sob $n^{\circ} 050$ nas fls. 102 do livro 02 para uso de animais em experimentação, sob a responsabilidade do Prof(a) Dr(a)) Marilia Cerqueira Leite Seelaender, Coordenador(a) da Linha de pesquisa "Alteraçōes metabolicas e morfofuncionais mediadas pela atividade física e suplementação nutricional em ratos caquéticos" do qual participam o(s) alunos Fernando de Oliveira Rosa, Rodolfo Gonzales Camargo, Henrique Quintas Ribeiro, Luana Sabetay Oliveira Levy, Renata Silvério, Patrícia Esther Rocha, Luiz Carlos Carnevali, Lucas Maceratesi Enjiu, Felipe Fedrizzi Donatto, Michele Joana Alves, Paulo Pogério, Felipe Capel D’Ambrosio, Adriana Jaime Sbampato Assad, Marcos Pisiotano, Rodrigo Xavier das Neves, Julia Laurindo Giacomini e a pesquisadora Anelisa Magah hães, está de acordo com os Princípios Éticos de Experimentação Animal adotado pela Sociedade Brasileira de Ciência de Animais de Laboratório (SBCAL) e foi aprovado pela COMISSÃO DE ÉTICA NO USO DE ANIMAIS (CEUA) em 19.04.2011, com validade de 3 anos.

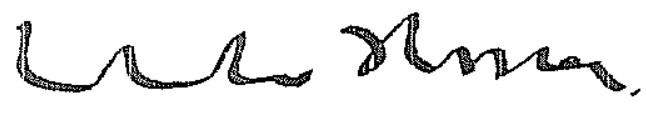

Prof.Dr.Wothan TAVARES DE LIMA Coordenador CEUA - ICB/USP
Sāo Paulo, 20 de abril de 2011.

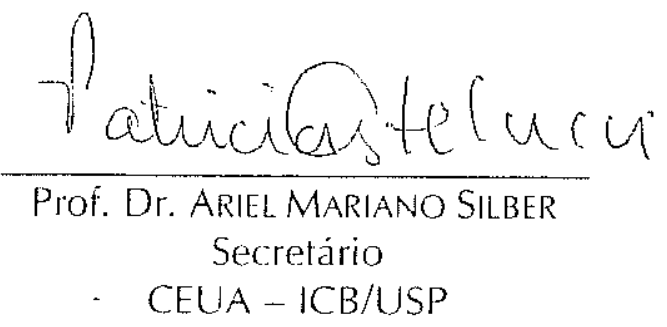


Dedico à finalização desta etapa de minha á minha família: minha mãe, Maria do Carmo, meu pai Airton (quero ser para os meus filhos o pai que você sempre foi e será para mim), por me educarem e me apoiarem no sentido mais amplo da palavra, em todos os seguimentos de minha vida. Vocês são exemplo de caráter e perseverança não somente para mim como para todos a sua volta. Obrigado por tudo.

A minha futura esposa Cíntia, que a cada dia que passa me dá exemplos de honestidade, carinho e compreensão.

As minhas irmãs Renata, Fernanda, Flávia, Giuliana, Luana e Bruna. Irmãs, são poucos que gozam do privilégio de ter muitos amigos. Eu consegui encontrar isso dentro de minha própria família. Obrigado.

À minha tia Fátima e minha Avó Palmira que durante toda a minha infância e adolescência deram suporte para que o presente sonho se realizasse.

Por último aos meus irmãos de coração Kerson Dourado e Júlio Cezar Papeschi. Irmãos, sem vocês nada disso teria acontecido. 


\section{AGRADECIMENTOS}

Primeiramente a Deus, que me abençoa e me cerca de pessoas especiais diariamente.

Agradeço à minha orientadora, Profa. Dra. Marília Seelaender, por me "orientar" e me "guiar" não somente em meu doutoramento, bem como durante toda a minha trajetória profissional.

Ao meu "padrinho" Waldecir Paula Lima", ou simplesmente Walder, o exemplo de profissional que quero ser e que depositou toda sua confiança no meu trabalho. Walder, se não fosse por você certamente não estaria finalizando esta etapa, valeu irmão.

À minha amiga, irmã e parceira profissional Dra. Daniela Caetano Gonçalves, uma das pessoas mais batalhadoras, íntegras e honestas que conheço dentro do meio acadêmico.

Ao inesquecível e inigualável Robson ou apenas "Bibi" por todos os anos de amizade, parceria e muitas risadas.

Aos meus ex-alunos e que para minha alegria tornaram-se companheiros de laboratório, Rodolfo, Henrique, Lucas e Felipe Capel, não esquecendo a Patrícia, que embora não tenha sido minha aluna, tenho muito carinho e apreço.

Á todos do laboratório da professora Alison que me acolheram nos momentos em que mais precisei e principalmente ao Dr.Marcel Benadiba. Nào tenho como agradecer. Muito obrigado.

A todos os meus colegas de laboratório que de alguma maneira me ajudaram na conclusão desta etapa e principalmente a Sra. Emília Ribeiro pelo apoio técnico.

Aos Doutores Fabio Lira, Alex Shimura e Nelo Zanchi, pela oportunidade de parcerias que me proporcionaram. Eu disse que vocês iam longe lembra?

Ao pessoal do biotério sempre disposto com boa vontade para ajudar.

Ao pessoal da secretaria, especialmente a Celiana que não cansava de tirar as minhas dúvidas.

Ao pessoal da limpeza, que muitas vezes esquecemos mais são de suma importância. 
Ao pessoal do xerox e da biblioteca pela sua eficiência e boa vontade no auxílio ao público.

A todos os professores de outros laboratórios, especialmente aqueles que participaram da minha banca de qualificação e defesa, e aqueles que de alguma maneira me ajudaram na realização desse trabalho.

Agradeço a todos os professores e funcionários da Universidade Gama Filho, que abriram as portas sempre que precisei e especialmente ao professor Fábio Mazzonetto e sua esposa Vânia Mazzonetto que me acolheram em sua família como já fizesse parte dela á muitos anos. Muito obrigado.

Aos professores da época de colégio Cláudio Sorcinelli, José Waldir Grégio e Rubens de Castro Júnior (In memoriam) que foram minha primeira referência na área de Educação Física.

A todos os professores e funcionários da Faculdade Anhanguera, especialmente os professores Sérgio Leal, Andréia Lira, Solival dos Santos Filho, Diego Ortiz Aragão, Euvas Santos, Joel Garcia, Sandra Simões e todos os professores do curso de Educação Física, que. Embora não mencionados nominalmente, sempre me apoiaram na realização de meus projetos profissionais. Posso dizer que somos uma família.

Por último e de extrema importância, agradeço a todos os meus alunos do presente e do passado. Não fossem eles, não haveria motivação de minha parte em tentar contribuir para a área de Educação Física e principalmente disseminar o orgulho que nós profissionais da saúde devemos ter por ter escolhido esta profissão maravilhosa. 


\section{RESUMO}

Carnevali JR, LC. Efeitos do treinamento em esteira sobre o metabolismo lipídico no fígado de ratos com caquexia associada ao tumor: Papel do PPARa. [Tese Doutorado em Biologia Celular e Tecidual] São Paulo - Instituto de Ciências Biomédicas da Universidade de São Paulo; 2011.

A caquexia é uma síndrome paraneoplásica caracterizada pelo comprometimento do metabolismo lipídico. O fígado, órgão responsável pelo gerenciamento do metabolismo sofre marcadas alterações em suas funções fisiológicas. Dentre as principais está o desenvolvimento da esteatose, desencadeada pela diminuição na secreção e na oxidação de gorduras por este tecido, aliada ao aumento na captação de ácidos graxos de cadeia longa. A prática de exercícios regulares é conhecida por melhorar a capacidade metabólica dos diversos tecidos, entre eles o fígado. Este trabalho verificou os efeitos do treinamento moderado realizado em esteira pelo período de 8 semanas em ratos com caquexia induzida por tumor de Walker 256. Ratos Wistar machos foram randomicamente divididos nos seguintes grupos: ratos sedentários controle (SC), ratos sedentários portadores de tumor (ST), ratos treinados controle (TC) e ratos treinados portadores de tumor controle (TT). O peso corporal, ingestão de ração, glicose, concentração de insulina plasmática, expressão gênica da carnitina palmitoiltransferase I e II (CPT I e II), da proteína ligadora de ácidos graxos (L-FABP), do receptor ativado por proliferadores de peroxissomos alfa (PPAR-alfa), do fator nuclear $\mathrm{KB}(\mathrm{NF} K \mathrm{~B})$, do inibidor do fator $\mathrm{KB}$ (IKB), do receptor do ácido cis-retinóico $(\mathrm{RXR})$, da cicloxigenase-2 (COX-2), assim como o conteúdo NFKB, PPARa e CPT II (Imunodetecção) e a atividade máxima das enzimas CPT I e II (radioensaio), foram medidos. O conteúdo de gordura no fígado foi aferido como descrito por método gravimétrico. A concentração de IL-6, TNF- $\alpha$ e IL-10 foi determinada por ELISA. Avaliou-se ainda, o efeito do treinamento sobre a concentração de $\mathrm{PGE}_{2}$ no fígado. Os resultados observados apontam restabelecimento da capacidade de oxidar e secretar lipídios do fígado através do aumento da atividade máxima do complexo CPT e da taxa de secreção de VLDLTAG nos ratos com tumor submetidos ao protocolo de treinamento. A expressão gênica do PPARa e RXR aumentou nos grupos TC e TT. A expressão gênica da FABP foi superior em TT se comparada a ST. A concentração de citocinas, bem 
como a expressão gênica e protéica do NFKB e sua capacidade de ligação ao DNA permaneceram inalteradas. Contudo, a concentração de $\mathrm{PGE}_{2}$ que notadamente aumentou no fígado e no tumor do grupo ST, foi reduzida no grupo TT. O conteúdo de gordura diminuiu em TT quando comparado a ST. O treinamento realizado por 8 semanas foi, assim, capaz de restabelecer o metabolismo lipídico no fígado e amenizar os efeitos inflamatórios induzidos pela $\mathrm{PGE}_{2}$. O PPARa, estimulado pelo treinamento aparentemente regula a capacidade de ligação do $\mathrm{NF} K \mathrm{~B}$, agindo como importante fator anti-inflamatório neste tecido. Especula-se que tal regulação tenha ocorrido através do efeito do treinamento sobre a via do PPARa, que por apresentar alterações comcomitantes na expressão gênica e protéica. Portanto, o treinamento foi capaz de atenuar os efeitos da progressão tumoral no desenvolvimento do processo de caquexia.

Palavras-chave: Câncer. Caquexia. Treinamento. Fígado. Esteatose. Metabolismo lipídico. CPT. 


\begin{abstract}
Carnevali JR, LC. Effects of physical training exercise upon liver lipid metabolism of tumour-bearing rats: role of PPARa. [Ph. D. Thesis - Molecular Biology of the Cell Group] São Paulo: Instituto de Ciências Biomédicas da Universidade de São Paulo; 2011.
\end{abstract}

Cancer Cachexia is a paraneoplastic syndrome characterised by marked disruption of lipid metabolism. The liver is responsible for metabolic control and suffers marked physiological alterations during Cancer cachexia. Among these, hepatic steatosis, triggered by impaired lipid secretion, augmented uptake and decrease oxidation. Regular exercise training is well known to induce improvement of metabolic capacity in several tissues, including the liver. We adressed the effects of 8 weeks treadmill training upon liver of Walker 256 tumor-bearing rats. Male Wistar rats were randomly assigned to the following groups: sedentary control (SC), sedentary tumour-bearing (ST), trained control (TC) and trained tumour-bearing rats (TT). Body weight, dietary intake, plasma glucose and plasma insulin concentrations were evaluated. Gene expression of liver carnitine palmitoyltransferase I and II (CPT I and II), liver fatty acid-binding protein (L-FABP), peroxisome proliferator-activated receptor-alpha (PPAR-alpha), Nuclear factor kappaB (NFkB), kappa B inhibitor (IKB), cis-retinoic acid receptor (RXR), ciclooxygenase-2 (COX-2), as well as NFKB, PPARalpha and CPT II protein content and the maximal activity of CPT I and II (radioassay), were assessed. The fat content was also measured, and IL-6, TNF- $\alpha$ and IL-10 content in the liver assessed by ELISA. Moreover, the role of exercise training upon $\mathrm{PGE}_{2}$ content was also evaluated. Results: The results indicate the reestablishment of lipid oxidation and secretion capacity by the liver, with increased CPT complex activity and VLDL secretion rate enhancement as promoted by exercise training. PPARa and RXR gene expression increased in TC and TT. FABP mRNA content was higher in TT than ST. Cytokine content and NFKB gene and protein expression did not change neither NFKB DNA binding capacity. However, liver fat content was decreased in TT in comparison to ST.

In conclusion, exercise training performed for 8 weeks was able to reestablish lipid metabolism in the liver and attenuate the pro- inflammatory effect, as there was decreased $\mathrm{PGE}_{2}$ tissue content. PPARa through exercise training seems to act as an 
important anti-inflammatory factor in such tissue. Therefore, exercise training was able to prevent the development of cachexia. The mechanisms involved, require, nevertheless further investigation.

Keywords: Exercise training. Cachexia. CPT. Steatosis. Lipid metabolism. Liver. 


\section{LISTA DE ABREVIATURAS E SIGLAS}

ACC: Acetil CoA carboxilase

AG: ácidos graxos

AGCL: Ácidos graxos de cadeia longa

apoB: apoliproteina B

ATP: adenosina Trifosfato

CACT: carnitina Acil carnitina transferase

COX-2: Ciclooxigenase-2

CPT I: Carnitina Palmitoil transferase 1

CPT II: Carnitina Palmitoil transferase 2

CRH: Hormônio liberador de corticotrofina

CS: Citrato sintase

DGAT 1: Diacilglicerol Aciltransferase 1

DGAT 2: Diacilglicerol Aciltransferase 2

ELISA: Ensaio de imunoabsorbância ligado a enzima

FABP: Proteína ligadora de ácidos graxos

HDL: Lipoprotein de alta densidade

IGF-1: Fator de crescimento ligado à insulina-1

IKKa: Modulador essencial de IKB quinase alfa

IKKß: Modulador essencial de IKB quinase beta

IL-1: Interleucina-1

IL-10: Interleucina-10

IL-6: Interleucina-6

IкB: Inibidor do fator nuclear kappaB 
LDL: Lipoproteina de baixa densidade

L-FABP: Proteína ligadora de ácidos graxos

LPL: Lipase de lipoproteina

MTP: Proteína de transferência microssomal

NFкB: Fator nuclear kappaB

PCR: Reação da cadeia de polimerase

$\mathrm{PGE}_{2}$ : Prostaglandina $\mathrm{E}_{2}$

PPAR $\beta$ : Receptor ativado por proliferadores de peroxissomos beta PPAR $\alpha$ : Receptor ativado por proliferadores de peroxissomos alfa PPAR $\gamma$ : Receptor ativado por proliferadores de peroxissomos gama PPAR: Receptor ativado por proliferadores de peroxissomos

PPRE: Elemento responsive do PPAR

RIP: Protéina de interação ao receptor

RT: Transcriptase reversa

RXR: Receptor do ácido cis-retinóico

SC: Sedentário controle

ST: Sedentário tumor

TAG: Triacilglicerol

TC: Treinado controle

TNFa: Fator de necrose tumoral alfa

TRADD: Receptor associado ao domínio de morte protéica do TNF TRAF2: Fator associado ao TNF-2

TT: Treinado tumor

VLDL: Lipoproteína de densidade muito baixa 


\section{LISTA DE ILUSTRACÕES}

Figura 1 - Sistema de treinamento em Esteira para ratos........................... 37

Figura 2 - Carcinossarcoma de Walker 256 desenvolvido no flanco direito....... 37

Figura 3 - Progressão do peso corporal absoluta no período de 8 semanas...... 48

Figura 4 - Média do consumo semanal de ração.............................................. 49

Figura 5 - Média do consumo semanal de ração.............................................. 49

Figura 6 - Consumo de ração acumulado 21 antes do sacrifício dos ratos........ 50

Figura 7 - Concentração plasmática de insulina............................................. 51

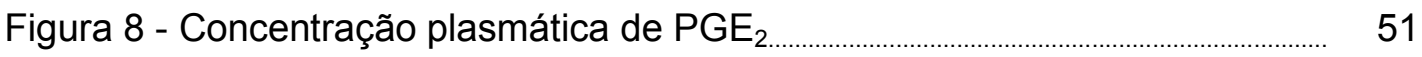

Figura 9 - Taxa se secreção de VLDL-TAG........................................... 52

Figura 10 - Conteúdo de TAG no fígado..................................................... 53

Figura 11 - Atividade máxima da CPT I e CPT II no fígado ............................ 54

Figura 12 - Expressão gênica da FABP, CPT I e CPT II no fígado................... 55

Figura 13 - Expressão gênica do PPARa, RXR, NFкB e IкB no fígado.............. 56

Figura 14 - Expressão gênica da proteína COX-2 no fígado.......................... 57

Figura 15 - Expressão protéica das proteínas PPARa, CPT II e NFkB............ 58

Figura 16 - Ensaio de ligação ao DNA das subunidades NFkB p65 e p50, no fígado...................................................................................................... 59

Figura 17 - Concentração de PGE2 no fígado.............................................. 60

Figura 18 - Atividade máxima da CPT I e CPT II no músculo sóleo................... 61

Figura 19 - Atividade máxima da enzima Citrato Sintase no músculo sóleo...... 62

Figura 20 - Expressão gênica da CPT I, CPT Ile FABP no músculo sóleo........ 63

Figura 21 - Concentração das citocinas IL-10, IL-6, TNFa IL-B no músculo

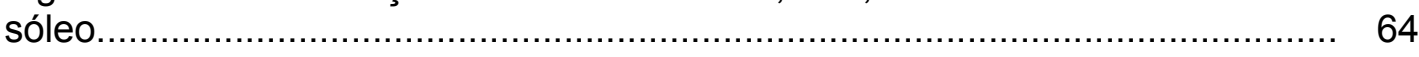

Figura 22 - Peso absoluto do tumor após 14 dias da injeção............................ 65

Figura 23 - Concentração de PGE2 e TNFa no tecido tumoral......................... 66 


\section{LISTA DE TABELAS}

Tabela 1 - Protocolo de treinamento........................................................... 36

Tabela 2 - Sequência de primers para realização de PCR tempo real............... 43

Tabela 3 - Concentração das citocinas IL-6, IL-10 e TNFa no fígado............... 60 


\section{SUMÁRIO}

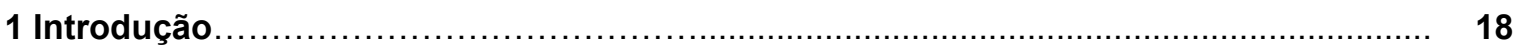

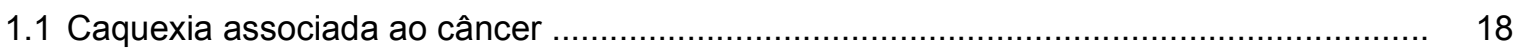

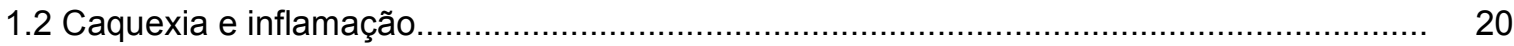

1.3 Distúrbios metabólicos induzidos pela caquexia associada ao tumor.............................. 23

1.4 Papel do fígado no metabolismo lipídico e alterações induzidas pela caquexia associad. ac câncer

1.5 PPARs (receptores ativados por proliferadores de peroxissomos..................................... $\quad 29$

1.6 Exercício como estratégia para o tratamento da caquexia............................................ 30

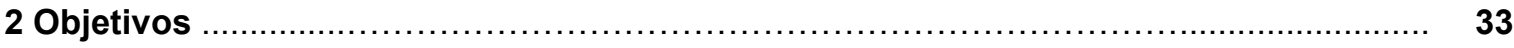

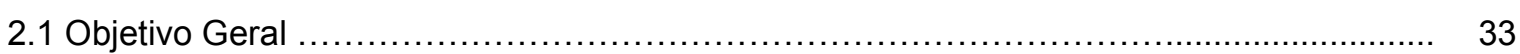

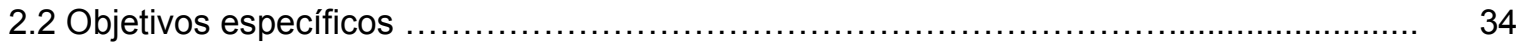

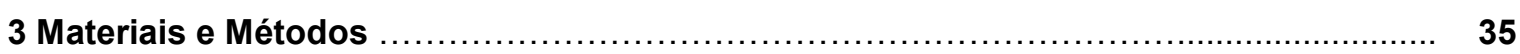

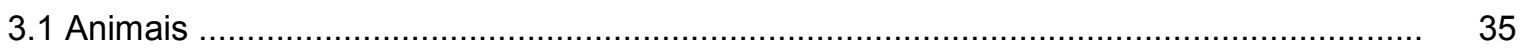

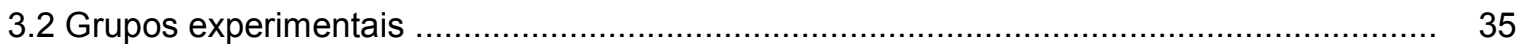

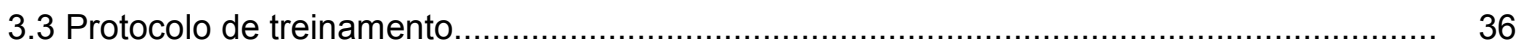

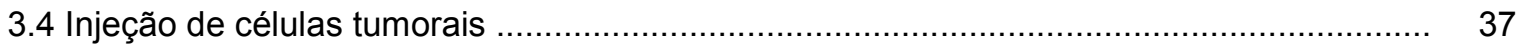

3.5 Peso corporal e ingestão alimentar..................................................................... 38

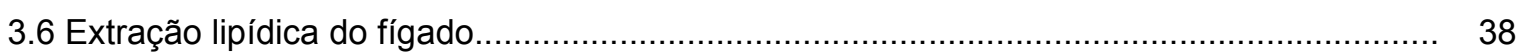

3.7 Avaliação da taxa de secreção plasmática de VLDL......................................................... 38

3.8 Determinação da concentração plasmática de insulina.................................................... 39

3.9 Medida da atividade máxima da carnitina Palmitoil Transferase (CPT-I) e (CPT-II) no

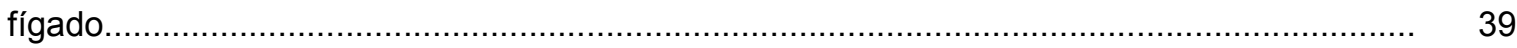

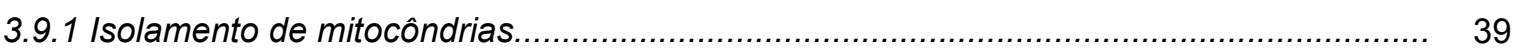

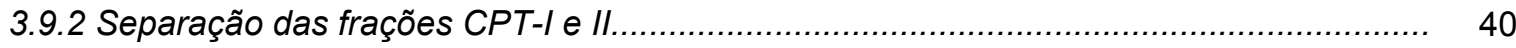

3.9.3 Ensaio para medida da atividade máxima CPT-I e II................................................ 40

3.9.4 Extração da fase orgânica........................................................................................ 41

3.10 Análise da expressão gênica da CPT I, CPT II, FABP, PPARa, RXR, IKB, NFkB e COX-

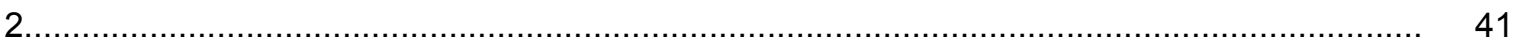

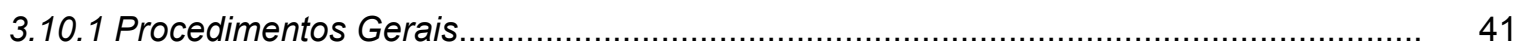

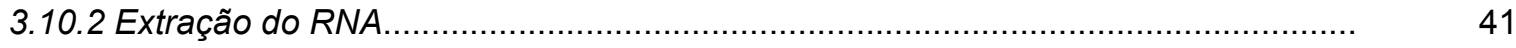

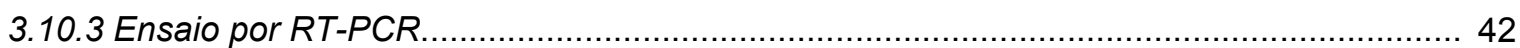

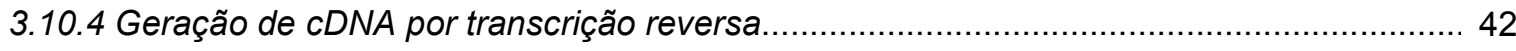

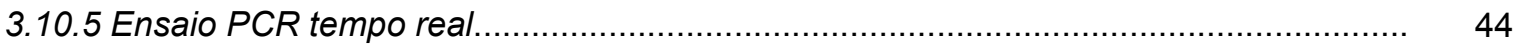

3.11 Análise semi-quantitativa do conteúdo protéico para PPARa, CPT I e NFKB por meio de

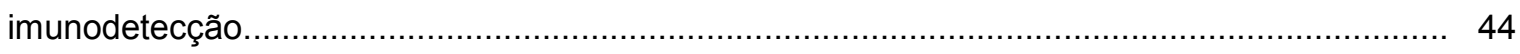

3.12 Determinação da concentração de proteína nas amostras................................................... 45 


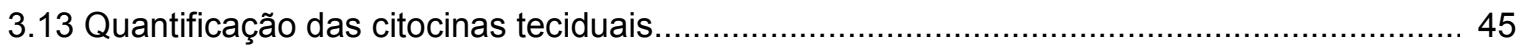

3.13.1 Ensaio de imunoabsorbância ligado a enzima (ELISA)................................................ 45

3.14 Ensaio de ligação do NFkB ao DNA ................................................................ 46

3.15 Análise estatística ............................................................................................ 47

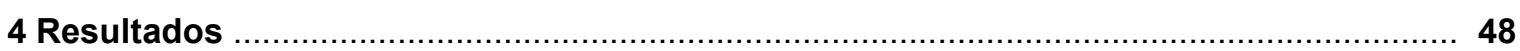

4.1 Progressão do peso corporal e consumo de ração............................................................ 48

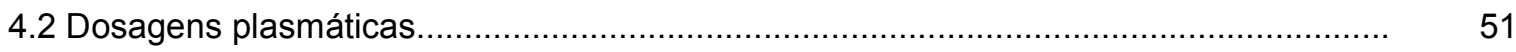

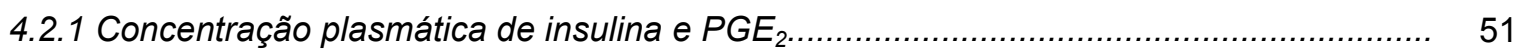

4.2.2 Taxa de secreção de VLDL-TAG.................................................................. 52

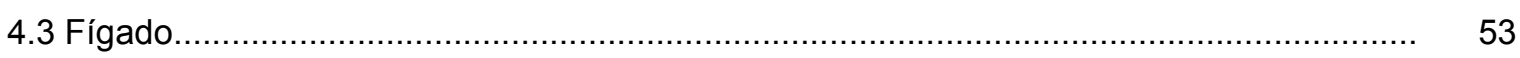

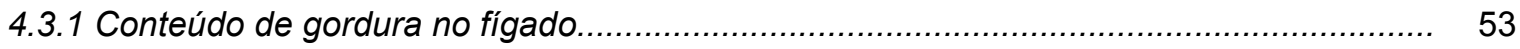

4.3.2 Medida da atividade máxima das enzimas CPT I e CPT II no fígado............................. $\quad 54$

4.3.3 Medida da expressão gênica das proteínas CPT I,CPT I/ e L-FABP no fígado.................... 55

4.3.4 Medida da expressão gênica das proteínas PPARa, RXR, NFKB e IKB no fígado ........... 56

4.3.5 Medida da expressão gênica da COX-2 no fígado ....................................................... 57

4.3.6 Medida da expressão protéica de PPARa, CPT I/ e NFKB no fígado ............................. 58

4.3.7 Ensaio de ligação do NFKB ao DNA no fígado ...................................................... 59

4.3.8 Concentração de citocinas (IL-10, IL-e, TNFa) no fígado............................................. 60

4.3.9 Concentração de prostaglandina $E_{2}\left(P G E_{2}\right)$ no fígado ............................................. 60

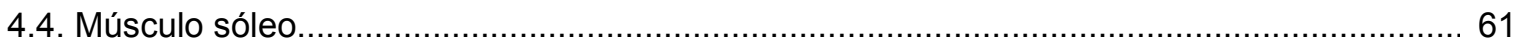

4.4.1 Medida da atividade máxima das enzimas CPT I e CPT I/ no músculo sóleo.................. 61

4.4.2 Medida da atividade máxima da enzima Citrato Sintase (CS) no músculo sóleo................. 62

4.4.3 Medida da expressão gênica das proteínas CPT I,CPT II e FABP no músculo sóleo ..... 63

4.4.4 Concentração de citocinas (IL-10, IL-6, TNFa) no músculo sóleo ................................ 64

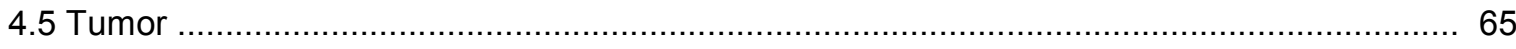

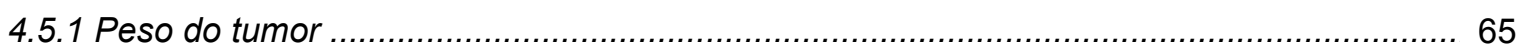

4.5.2 Concentração plasmática de $P G E_{2}$ e TNFa no tecido tumoral ...................................... 66

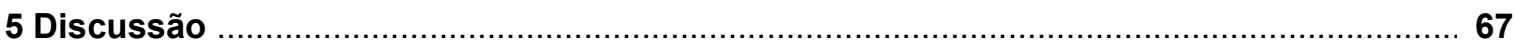

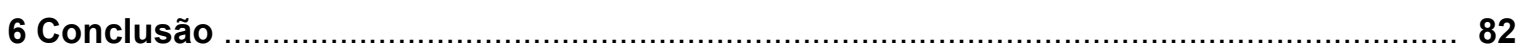

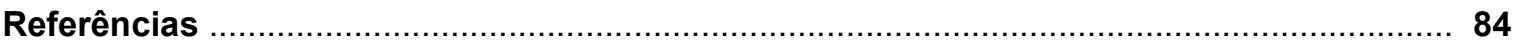




\section{Introdução}

\subsection{Caquexia associada ao câncer}

A caquexia é definida como uma síndrome multifacetada resultante da redução na ingestão de alimentos e a uma variedade de anormalidades metabólicas (incluindo hipermetabolismo), sendo mais freqüente uma combinação desses fatores (Fearon e Moses, 2002). Recentemente, entre os anos de 2010 e 2011 uma definição consensual atualizada define caquexia como "Síndrome multifatorial que desencadeia perda contínua de massa muscular esquelética (com ou sem perda de massa gorda) que não pode ser completamente revertida através de suporte nutricional convencional e leva à um prejuízo funcional progressivo do organismo. A fisiopatologia é caracterizada pela combinação da redução de consumo energético e distúrbios no metabolismo energético" (Argilés et al., 2010; Fearon et al., 2011; Muscaritoli et al., 2010).

A denominação "caquexia" deriva do termo "kakos" má e "hexis" condição. Embora não exista apenas uma definição de caquexia, um recente consenso estabelecido por pesquisadores aponta que a caquexia ocorre em mais de $80 \%$ dos pacientes com câncer e é a maior contribuinte para a morbidade e mortalidade desses (Evans et al., 2008). Contudo, apesar de constituir causa direta da mortalidade em até $40 \%$ dos pacientes com câncer (Fox et al., 2009), na maioria dos casos, não é diagnosticada ou tratada (Evans et al., 2008; Springer et al., 2006).

A perda rápida e acentuada de peso é o sintoma mais notável da caquexia e afeta mais da metade dos pacientes com câncer, em sua maioria aqueles em estado avançado (Argilés et al., 1997; Fearon et al., 2006; Fearon e Moses, 2002). Tal diminuição do peso corporal não está associada somente a perda de massa gorda, mas também de massa magra, visto que na vigência desta síndrome há uma importante degradação protéica muscular motivada por diversas alterações fisiológicas (McMillan, 2009). Contudo, a ausência de uma resposta uniforme neste processo e a imprecisão na detecção de outros sintomas em pacientes com câncer dificulta o diagnóstico da síndrome (Blum et al., 2010).

Bozzetti et al. (2009) propõem a divisão da síndrome em pré-caquexia e caquexia, adotando como critério, a redução de peso corporal maior ou menor que 
10\%. Mais recentemente Fearon et al. (2011) propuseram a classificação da caquexia de acordo com a gravidade em pré-caquexia (perda de peso inferior a $5 \%$, anorexia e alterações metabólicas), caquexia (perda de peso superior a $5 \%$ ou IMC<20) e caquexia refratária, na qual o processo catabólico é intenso, os tratamentos anti-câncer não mais obtêm resposta e o tempo de sobrevida é inferior a três meses. Cerca de $23 \%$ dos pacientes com câncer recebem o diagnóstico de caquexia, o que representa sem dúvida uma subestimação na incidência da síndrome (Fox et al., 2009).

Entre os mecanismos indutores para a perda de peso no quadro caquético está a anorexia, que leva a redução da ingestão nutricional, em virtude de fatores que induzem obstrução do trato intestinal, náusea, depressão e uma maior morbidade ao tratamento químio e radioterápico (Revisão de Brown, 2002; Fearon e Moses, 2002). Contudo, o desenvolvimento da caquexia em pacientes com câncer não está relacionado apenas com a diminuição do consumo alimentar, envolvendo também um aumento na taxa metabólica basal e no dispêndio energético, resultando em um balanço energético e nitrogenado negativo (Blum et al., 2010). Além da exacerbada perda involuntária de peso, outros sintomas clínicos caracterizam a caquexia. Dentre estes se destacam a anorexia, alterações no paladar, vômito, má absorção intestinal, astenia, fadiga, perda de habilidades motoras e físicas, apatia, perda da imuno-competência, caos metabólico, desequilíbrio iônico, alteração no perfil hormonal plasmático e disfunção hipotalâmica (Concenso Brasileiro de Caquexia e Anorexia em Cuidados Paliativos, 2011).

Embora tenha sido descrita há mais de dois mil anos atrás, a caquexia passou a receber maior atenção dos pesquisadores há poucos anos, e sem dúvida, existem ainda muitas questões não esclarecidas, bem como, a necessidade da descoberta de uma terapia capaz de reverter tal quadro (Anker e Coats, 1999; Mustafá et al., 2001; Von Haeling et al., 2002). Pela razão de tal complexidade existem ainda muitas dúvidas e divergências sobre os mecanismos fisiológicos e moleculares que induzem alterações metabólicas na vigência da caquexia.

\subsection{Caquexia e inflamação}

Entre os mecanismos propostos no desenvolvimento da caquexia em pacientes com câncer, diversos mediadores incluindo citocinas, eicosanóides, 
neurotransmissores e produtos relacionados ao tumor e ao hospedeiro são postulados como contribuintes (Tisdale, 2008). Propõe-se que a presença do tumor e as citocinas pró-inflamatórias por ele produzidas e/ou liberadas pelo sistema imunológico em resposta à vigência deste participam do desenvolvimento e progressão da caquexia associada ao câncer, induzindo a inflamação crônica (Argilés et al., 2003; Ramos et al., 2004). Atualmente, a própria definição da síndrome enfatiza o papel desta inflamação crônica. As citocinas pró-inflamatórias são o sinal chave para a lipólise e a proteólise nos diversos tecidos e a elevação na concentração de tais citocinas é um sintoma comum no quadro caquético, (Argilés et al., 2010; Anker et al., 1999; Levine et al., 1990). Assim, estas são capazes de alterar o perfil hormonal (glicocorticóides, catecolaminas, hormônio do crescimento, entre outros), diminuir a produção de diversos agentes anabólicos, como o IGF-1 e a insulina e comprometer o metabolismo energético em geral, afetando o funcionamento do fígado, músculos e tecido adiposo (Skipworth et al., 2007).

O TNF $\alpha$ (Fator de necrose tumoral alfa) em conjunto com a IL-10 (interleucina-10) são considerados entre as diversas citocinas existentes, elementos chave para desenvolvimento da caquexia-anorexia associada ao câncer, por estimularem o aumento nas concentrações de CRH (hormônio liberador de corticotropina), neurotransmissor este responsável por suprimir a ingestão alimentar (Argilés et al., 2009). Além das citocinas inflamatórias tais como o TNF $\alpha$ e a IL-6, a leptina, hormônio capaz de regular o metabolismo lipídico, a atividade do sistema complemento e homeostasia e os hormônios adiponectina e resistina ( também produzidos pelo tecido adiposo) são mediadores envolvidos na caquexia associada ao câncer. Em pacientes caquéticos é observada redução na concentração de leptina entre outras alterações (Smiechowska et al., 2010; Tessitore et al., 2000).

Já no músculo esquelético o aumento da concentração de TNF $\alpha$, a IL-6 apresenta claro efeito sobre o processo de controle da síntese protéica e proteólise (Durham et al., 2009). De fato, esta perda de massa muscular esquelética representa um dos pontos chave do processo inflamatório induzido pela caquexia. Mudanças significativas nas concentrações de citocinas inflamatórias ocorrem na vigência da caquexia associada ao câncer (Revisão de Silvério et al., 2011), destacando-se o aumento nas concentrações do já supracitado TNF $\alpha$ e seus receptores (Tracey et al., 1988). 
Além da presença das citocinas, produtos originários do metabolismo do ácido araquidônico, também estão ligados ao desenvolvimento da caquexia (McCarthy, 2003). Através de processos metabólicos catalisados principalmente pela ação dos complexos cicloxigenase (COX) e lipoxigenases, este ácido presente em abundância nas membranas biológicas é liberado pelas enzimas fosfolipases, e convertido em prostaglandinas e leucotrienos (Tilley et al., 2001). As prostaglandinas, especialmente as da série $2\left(\mathrm{PGE}_{2}\right)$ são potentes mediadores parácrinos da resposta inflamatória local. Além disso, a $\mathrm{PGE}_{2}$, é capaz de induzir a síntese de TNF- $\alpha$, IL-6 e IL-1 em macrófagos e outros tipos celulares (Willians e Schacter, 1997). Modelos animais e estudos com humanos traçam paralelo entre a concentração plasmática de $\mathrm{PGE}_{2}$ e a de citocinas inflamatórias no processo de caquexia associada ao câncer (Lira et al., 2010; McCarthy, 2003).

Nos últimos anos, o fator nuclear de transcrição қڤ (do inglês: nuclear factor kappa B) tem sido apontado como o principal responsável pelo controle da inflamação em tecidos como músculo esquelético, tecido adiposo e fígado (Mantovani, 2010). Tal controle seria exercido através da modulação da produção de diversas citocinas pró-inflamatórias, destacando-se entre estas o TNF $\alpha$ e IL-6 (Revisão de Lira et al., 2010).

Em células de mamíferos o NFKB apresenta-se composto por cinco subunidades: RelA (p65), RelB, c-Rel, p50/p105 (NFкB-1) e p52/p100 (NFкB-2) (Gilmore \& Herscovitch, 2006). Tais subunidades demonstram capacidade em formar uma variedade de homo e heterodímeros que controlam de maneira diferente a expressão gênica, mediante a presença de estímulos estressores, tais como vírus, bactérias, fatores de crescimento e as próprias citocinas que de maneira cíclica, tem sua expressão por estes dímeros regulada (Hayden e Ghosh, 2004).

Baseando-se na regulação de processos celulares regulados pela "família NFкB", suas subunidades podem ser dividas em dois grupos distintos: as proteínas NFKB (p50/p105, p52/p100), e as proteínas Rel (RelA, RelB, c-Rel). Enquanto as proteínas Rel possuem domínios de transativação C-terminal não presente nas subunidades p50 e p52, estas últimas apresentam capacidade de ligar-se com o DNA e formarem heterodímeros com outras subunidades de NFKB conhecidas por contribuírem na regulação da expressão gênica de citocinas inflamatórias (Revisao de Bassères e Baldwin, 2006). Além disso, a formação de heterodímeros p52/p52 e p50/p50, com ênfase neste último, pode regular negativamente a expressão de genes alvo do 
NFкB por recrutar co-repressores transcricionais, contribuindo assim para a finalização/controle do processo inflamatório (Kim et al., 2005a).

Em revisão realizada por Viatour et al. (2005), três vias de sinalização da atividade transcricional do NFKB foram apresentadas, todas baseadas na ativação de uma cascata de quinases. Dentre estas destacamos a via denominada "clássica", ativada pela ação do TNFa, que sequencialmente recruta diversos receptores e proteínas tais como a TRADD (do inglês "TNF-receptor-associated death domai protein"), RIP (receptor interacting protein) e TRAF2 (TNF-receptor associated factor 2) (Hsu et al., 1995). A partir do recrutamento e ativação do complexo ІкB-quinase (IKK), composto por IKKa, IKKß e NEMO (do inglês "IKB kinase alfa e beta e $N F K B$ essential modulator" respectivamente). Posteriormente esta ativação leva à fosforilação e degradação do ІкBa, permitindo que o heterodímero p50-p65 esteja livre e migre para o núcleo, onde ao ligar-se em sítios $\mathrm{\kappa B}$ específicos, ativa a transcrição de uma série de genes alvos para o desenvolvimento do processo inflamatório, incluindo IL-6, IL-8, TNFa, COX, entre outros (Viatour et al., 2005).

Entre os trabalhos existentes na literatura científica, boa parte credita à diversas vias de fosforilação e ativação da subunidade p65 a responsabilidade pela sinalização e desencadeamento do processo inflamatório (Sakurai et al., 1999; Zhong et al., 1998, 2002;). A fosforilação pode ocorrer tanto no citoplasma quanto no núcleo, sendo estímulo-específico e provavelmente tipo celular-específico (Viatour et al., 2005). De fato, a concentração aumentada de p65 no espaço nuclear decorrente da ativação do complexo IKK, vem sendo descrita em diversas doenças de origem inflamatória tais como a caquexia (Bassères e Baldwin, 2006; Marok et al., 1996). Dessa forma, a visão atual da caquexia é de que se trata de uma síndrome de inflamação branda crônica e progressiva mediada pela ação de diversos sinalizadores inflamatórios, potencialmente gerenciados pela via do NFKB (Argilés, 2008).

\subsection{Distúrbios metabólicos induzidos pela caquexia associada ao tumor}

Como citado anteriormente, por não relacionar a diminuição do consumo alimentar a um menor gasto energético, o desenvolvimento da caquexia em pacientes com câncer não está apenas relacionado com a anorexia. Hyltander et al. (1991) em um estudo clássico realizado com um grande número de sujeitos, 
verificou que pacientes com caquexia associada ao câncer apresentam um maior gasto energético em repouso se comparados com indivíduos normais. Um dos mecanismos que contribuem para o aumento deste gasto é a atividade de ciclos fúteis, tais como o Ciclo de Cori (glicose-lactato-glicose). De fato, a utilização do lactato derivado do tumor é um processo metabólico ineficiente que consome 6 moléculas de ATP por ciclo e é essencial para compensação da acidose tumoral (Argilés et al., 1997). O fluxo pelo Ciclo de Cori adicional contribui com aproximadamente a perda de $300 \mathrm{Kcal} / \mathrm{dia}$ em pacientes com câncer (Eden et al., 1984).

Além disso, o metabolismo de carboidratos é profundamente alterado, levando ao estado de resistência e insulina, intolerância a glicose e indução de diabetes do tipo II (Tayek et al., 1992). Tal resistência promove alterações que envolvem o fígado, tecido adiposo e o músculo esquelético, está presente em pacientes com câncer e foi a primeira anomalia metabólica associada à caquexia (Argilés et al., 1997).

Os efeitos da caquexia sobre o metabolismo lipídico são menos conhecidos do que os incidentes sobre o metabolismo de carboidratos e proteínas, principalmente nos que diz respeito aos mecanismos envolvidos. Isso se justifica por acreditar-se que a perda de proteínas é mais prejudicial que a perda de gorduras para o funcionamento do organismo. Contudo, atualmente sabe-se que mesmo em situações de jejum voluntário e em presença de doenças ocorre preservação e até mesmo expansão dos depósitos de gordura na tentativa de manutenção da homeostase (Pond, 2001). Nos últimos anos, o metabolismo lipídico na caquexia associada ao câncer vem sendo amplamente estudado na tentativa de compreender os fenômenos que levam a perda de peso (principalmente o tecido adiposo), seguido de hiperlipidemia (Evans et al., 2008). Tal perda de massa gorda é resultado de três diferentes processos: $O$ aumento da atividade lipolítica, diminuição da atividade da enzima LPL (lipase de lipoproteínas) e redução da lipogênese que resulta em esterificação de lipídios diminuída (Bing e Trayhurn, 2009; Thompson et al., 1991). A hiperlipidemia decorrente da diminuição da atividade da LPL resulta ainda na queda da remoção de triacilglicerol plasmático (TAG) endógeno (VLDL) e exógeno (quilomícron) (Lira et al., 2010). Em animais portadores de tumor com caquexia agressiva associada existe uma importante relação entre a diminuição da atividade da LPL e o desenvolvimento de hipertrigliceridemia (Bing e Trayhurn, 2009; Evans e 
Willianson, 1988; López-Soriano et al., 1996). Por se tratar do órgão alvo do presente estudo, as funções metabólicas deste tecido, bem como as alterações promovidas pela caquexia neste processo são discutidas a seguir.

\subsection{Papel do fígado no metabolismo lipídico e alterações induzidas pela caquexia associada a câncer}

O fígado possui uma função central no controle do metabolismo intermediário, pois é responsável por aceptar e determinar o direcionamento das gorduras nele presentes de acordo com as condições metabólicas e hormonais do indivíduo (Spassiani e Kuk, 2008). O tráfego dos lipídios no fígado é bidirecional, podendo estes ser secretados pelo fígado, re-captados e/ou reutilizados pelo próprio (Zammit, 1996). Ainda, as gorduras que chegam neste tecido podem ser armazenadas, oxidadas ou ainda direcionadas para secreção e utilização por tecidos periféricos tais como o músculo esquelético e o tecido adiposo através das lipoproteínas (Gibbons, 1990). As lipoproteínas são estruturas esféricas compostas de apolipoproteínas, triacilglicerol, fosfolipídios e ester colesterol (Sheperd, 1992). O fornecimento de triacilglicerol a partir do fígado para os tecidos extra-hepáticos ocorre através da lipoproteína de muito baixa densidade (VLDL) (Durstine et al., 2002). Além da VLDL, o fígado é responsável pela síntese da lipoproteína de baixa densidade (LDL), partícula rica em colesterol e representa uma fração remanescente de VLDL (Durstine e Thompson, 2001) e a lipoproteína de alta densidade (HDL) cuja função é realizar o transporte reverso de colesterol da periferia para o fígado (Stefanik et al., 1998).

A montagem da partícula de VLDL é um mecanismo complexo que envolve diversas moléculas regulatórias tais como a Diacilglicerol Aciltransferase 1 e 2 (DGAT 1 e 2) fosfolipase $D$ e a proteína de transferência microssomal (MTP) (Gibbons et al., 2004). A MTP possui papel fundamental na montagem e secreção de VLDL. Especificamente, esta proteína heterodimérica localizada no lúmen do retículo endoplasmático transfere o TAG para a apoB (apoliproteína B), proteína esta intraluminal necessária para produzir a partícula de VLDL (Chapados et al, 2008). A maturação total da VLDL é dependente da ação da fosfolipase $D$, enzima 
responsável pela transferência de grandes gotículas de TAG para a partícula intermediaria (Asp et al., 2000).

O fígado utiliza ácidos graxos de cadeia longa (AGCL) para manutenção do turnover de ATP necessário para seu próprio funcionamento (Murthy e Pandi, 1994). Na mitocôndria ocorrem eventos metabólicos tais como o ciclo de Krebs e a Beta-oxidação, responsáveis pela re-síntese de ATP, onde os AGCL, devido à sua composição química, contribuem de maneira significante (Lima et al., 2005). O processo de entrada desses ácidos graxos na mitocôndria é realizado pela ação de um complexo enzimático dependente de carnitina e que por esse motivo recebe o nome de complexo Carnitina Palmitoil Transferase (CPT). (Lira et al., 2010)

O complexo CPT tem a responsabilidade de conduzir os AGCL por entre as membranas mitocondriais e encaminhá-lo para a Beta-oxidação/Ciclo de Krebs (Lira et al., 2010). A CPT I é uma proteína integral de membrana localizada na membrana externa da mitocôndria, enquanto a CPT II é uma proteína periférica ancorada no lado interno da membrana mitocondrial (Kerner e Hoppel, 2000). A capacidade da enzima CPT I em converter Acil-CoA em acilcarnitina e a catálise inversa promovida pela enzima CPT II na matriz mitocondrial resulta na efetiva transferência da molécula de AGCL para dentro da matriz mitocondrial (Zamitt e Costhorphine, 1985). Devido à sua localização na membrana externa mitocondrial, a CPT I é suscetível a regulação alostérica pela ação do Malonil-CoA (Witters et al., 1988). A principal função do Malonil CoA é regular a participação relativa entre carboidratos e lipídios no processo de obtenção de energia. A inibição por malonilCoA representa uma das formas de regular, em condições fisiológicas, a atividade da CPT I e portanto, a oxidação de ácidos graxos (McGarry et al., 1987). A CPT I difere ainda da CPT II, por requerer a integridade da membrana à qual está associada para manutenção de sua atividade catalítica; já a CPT II preserva sua atividade enzimática após solubilização (Woeltje et al., 1990). Ainda, o glucagon (Bjornsson et al., 1992), o estrogênio (Weinstein et al., 1986), os hormônios tiroideanos (Saggerson e Carpenter, 1986, 1982), a vasopressina e as catecolaminas (Siddiqui, 1987) entre outros, são hormônios que regulam a atividade da CPT I. 
A produção e secreção da VLDL, bem como a ação do complexo CPT podem ser reguladas através da dieta e por fatores endócrinos (Bjornsson et al, 1992; Windmueller e Spaeth, 1988; Weinstein et al., 1986; Saggerson e Carpenter, 1986,1982)

Nos últimos 15 anos estudos realizados pelo grupo de Seelaender têm demonstrado que tanto a montagem e secreção de lipoproteínas, bem como a capacidade oxidativa do fígado de ratos caquéticos portadores do tumor Walker 256, sofrem interferência direta das alterações metabólicas e fisiológicas promovidas pela caquexia associada ao câncer, levando ao desenvolvimento de esteatose. Este quadro hepático patológico está relacionado a fatores como: incorporação aumentada de ácidos graxos de cadeia longa ( $A G C L)$ de origem exógena, mudança no perfil de VLDL secretada, diminuição da oxidação lipídica no fígado, aumento da síntese de novo (Kazantzis e Seelaender, 2005; Lira et al., 2010, 2008; Rosa et al., 1998; Seelaender et al., 1999, 1998, 1996).

O primeiro trabalho, realizado com 14 [c] oleato marcado, mostrou resultados que indicavam um quadro de esteatose em ratos caquéticos portadores de tumor, uma vez que estes apresentaram maior conteúdo de gotículas lipídicas e de TAG incorporado à VLDL, quando comparados ao grupo controle (Seelaender et al., 1996). Mais recentemente (Lira et al., 2008) outro estudo de nosso grupo verificou aumento da concentração de TAG plasmático e TAG presente na VLDL de ratos caquéticos quando comparados ao grupo controle. Além disso, a diminuição da secreção de VLDL sugeriu uma possível diminuição na produção desta lipoproteína pelo fígado de animais caquéticos portadores de tumor. Ainda no mesmo trabalho, esses resultados foram acompanhados da análise da expressão gênica da apoB e MTP, proteínas relacionadas com a montagem da VLDL (descritas acima), verificando-se uma diminuição da expressão dos respectivos RNAm no grupo portador de tumor em relação ao grupo controle (Lira et al., 2008).

O complexo CPT, processo chave no controle do transporte e oxidação de AG no fígado, tem sua atividade reduzida na caquexia ( $56 \%$ para a CPT II), além de haver redução da CPT II da região periportal (Kazantzis e Seelaender, 2005). O ácino hepático é considerado a unidade funcional do fígado e prevê populações distintas de hepatócitos: os presentes na zona periportal, que estão envolvidos com a maior oxidação de ácidos graxos, e os hepatócitos perivenosos, relacionados à montagem da VLDL e processos lipogênicos (Guzman e Castro, 1989). 
A redução de atividade no complexo CPT no fígado de ratos caquéticos verificada nos experimentos de Kazantzis e Seelaender (2005) ocasiona redução de transporte mitocondrial de AGCL e concomitante diminuição da síntese de corpos cetônicos (também demonstradas nesse trabalho), o que por sua vez agrava a proteólise no músculo esquelético; sintoma também característico da caquexia. De fato, o acetil-CoA proveniente da beta-oxidação pode ser utilizado para geração de energia ou formação de corpos cetônicos em uma série de reações da enzima HMG-CoA (Hidroximetilglutaroil coenzima $A$ ), que resultam em acetoacetato ou betahidroxibutirato (McGarry e Foster, 1980). No jejum prolongado, a maior produção de corpos cetônicos é agente protetor no organismo contra a proteólise, além de fornecer substrato para geração de energia em outros órgãos (Wasserman et al., 1989).

Nos últimos anos, tem-se tornado claro que os distúrbios metabólicos relacionados com o acúmulo de lipídios no fígado estão associados com o desenvolvimento do processo inflamatório (Bruunsgaard, 2005; Lira et al., 2010). Cai et al. (2005), demonstraram que o aumento da expressão gênica de agentes inflamatórios no fígado está relacionado com o aumento do conteúdo de gordura no mesmo. De fato, o NFkB é ativado nos hepatócitos pela ação de citocinas pró inflamatórias, contribuindo para o desenvolvimento da esteatose hepática (Shoelson et al., 2006).

Além da possível associação do desenvolvimento da esteatose a concentração de citocinas pró e antiinflamatórias, o aumento da produção de Prostaglandina $E_{2}\left(\mathrm{PGE}_{2}\right)$ pelas células de Kupffer também está envolvido na etiologia da esteatose (Lira et al., 2010; Siddiqui e Willians, 1989). Tanto as citocinas quanto a $\mathrm{PGE}_{2}$ afetam o processo de sinalização da insulina e por esta razão exercem papel importante do desenvolvimento da resistência a este hormônio no fígado (Henkel et al., 2009; Anderson e Borlak, 2008; Bugianesi et al., 2002).

\subsection{PPARs (receptores ativados por proliferadores de peroxissomos)}

$\mathrm{Na}$ última década estabeleceu-se que diversas alterações no metabolismo lipídico são mediadas por receptores ativados por lípides, que atuam como mensageiros-chave na transdução de estímulos nutricionais, farmacológicos e metabólicos na modulação da expressão gênica (Schoonjans et al., 1996). Esses 
receptores são conhecidos como receptores ativados por proliferadores de peroxissomos (PPARs) e foram identificados pela primeira vez em 1990, quando a isoforma alfa mostrou ser um receptor de xenobiontes capaz de induzir a proliferação de peroxissomas no fígado de ratos (Bocher et al., 2002). Subsequencialmente, dois outros tipos de PPARs, gama e beta, foram identificados (Delerive et al.,2001).

O PPAR $\alpha$ é altamente expresso no músculo esquelético, coração e fígado; enquanto o PPAR $\gamma$ é preferencialmente expresso no tecido adiposo e em macrófagos, e o PPAR é encontrado na maioria das células do organismo (revisão de Smith, 2002). Sabe-se que no fígado, o PPAR $\alpha$ regula a proliferação de peroxissomos e modula a oxidação de ácidos graxos (revisão de Peluso et al., 2000). Assim, os genes para a proteína ligadora de ácidos graxos (FABP), e para a CPT I (carnitina palmitoil transferase), por exemplo, são sujeitos á modulação imposta por este receptor nuclear. A proteína de transferência de triglicérides microssomal (MTP), responsável pela transferência de triglicérides para a apolipoproteína $B$ na formação de lipoproteína de muito baixa densidade (VLDL) também é regulada pelo PPAR $\alpha$ (revisão de Rakhshandehroo et al., 2010; Staels et al., 1998).

Dessa maneira, credita-se ao PPAR $\alpha$ um papel crucial no reconhecimento e no influxo de ácidos graxos nos casos de restrição alimentar, uma vez que em tal situação, esse receptor induz a ativação de todos os sistemas de oxidação de ácidos graxos prevenindo a incorporação do estado de esteatose hepática, que usualmente ocorre em indivíduos caquéticos (Reddy e Rao, 2006). Outros fatores adicionais podem ainda estar envolvidos na modulação da capacidade de transativação do PPARa, como o receptor do ácido Cis-retinóico $(R X R)$, que se dimeriza com o PPARa, tornando possível a ligação com o elemento responsivo ao PPAR (PPRE) presente no gene alvo a ser transcrito (Van Bilsen et al., 2002).

Além disso, existe a possibilidade do PPARa ter a capacidade de gerenciar o processo inflamatório através da regulação negativa ou transrepressão de genes envolvidos na produção de citocinas inflamatórias no fígado, tais como NFқB e ІқB (Hebbachi et al., 1997). Tal hipótese embora seja meramente especulativa, sem dúvida necessita de mais estudos para ser comprovada. 


\subsection{Exercício como estratégia para o tratamento da caquexia}

No que diz respeito aos efeitos do exercício no tratamento da caquexia associada ao câncer, a manipulação do treinamento físico como estratégia para superar a inflamação sistêmica ganhou destaque nos últimos anos. O treinamento de endurance parece uma escolha adequada dada a extensão das respostas fisiológicas e metabólicas associadas a esse tipo de esforço (Concenso Brasileiro de Caquexia e Anorexia em Cuidados Paliativos, 2011). A American Cancer Society recomenda aos pacientes manter atividade física, preferencialmente de intensidade moderada, tanto quanto o tratamento com quimioterapia, podendo ser seguramente realizado imediatamente após quimioterapia de alta dose (Dimeo et al., 1997)

De fato, prática de exercícios regulares é um fator de proteção contra diabetes do tipo 2, câncer de cólon e de mama (Blair et al., 2001), e em se tratando do câncer, pode atenuar os efeitos adversos da quimio e radioterapia e ainda, prevenir, atenuar e/ou reverter o quadro caquético e os processos de sinalização crônica inflamatória a ele associados (Lira et al., 2009, 2008; Murray Ardies, 2002).

Corneya (2003), através de uma revisão da literatura verificou que indivíduos com câncer praticantes de atividade física regular apresentam melhora expressiva na composição e peso corporal, flexibilidade, retardamento da fadiga central, satisfação e melhora na qualidade de vida (Courneya e Friedenreich, 1997; Kolden et al., 2002; Segal et al., 2001; Schwartz, 1999). Além disso, o treinamento promove efeitos positivos nas funções fisiológicas e imunológicas (Pedersen e Hoffman, 2000; Thorén et al., 1990). Tal efeito esta associado ao aumento na concentração de citocinas com propriedades anti-inflamatórias (Petersen et al., 2005) e concomitante diminuição na concentração de citocinas pró-inflamatórias como o TNF $\alpha$. (Dinarello, 1992).

Estudos recentes publicados por nosso grupo de pesquisa demonstraram que a prática crônica de exercícios modula negativamente a produção de citocinas envolvidas na regulação e manutenção do processo inflamatório (Lira et al., 2010, 2009a, 2009b, 2009c). A relação entre a produção de TNF $\alpha$ / IL-10 (citocinas consideradas pró e anti-inflamatórias respectivamente), vem sendo recentemente utilizada como um parâmetro confiável na detecção do nível de avanço do processo inflamatório em tecidos como adiposo e músculo esquelético (Rosa Neto et al., 2009). Por outro lado, embora existam estudos que mostrem melhora do processo 
inflamatório no fígado por meio da relação TNF $\alpha$ / IL-10 (Pighon et al., 2010), em ratos caquéticos portadores de tumor praticantes de exercício, tal relação ainda não fora demonstrada.

Além do efeito anti-inflamatório, a atividade física induz alterações na mobilização e utilização de ácidos graxos nos diversos tecidos (Horowitz e Klein, 2000). No treinamento de endurance ocorre um maior aumento na captação e utilização de ácidos graxos durante (Holloszy et al., 1973; Henriksson et al., 1977) e após o término do exercício (Pearsall et al., 1990; Kimber et al., 2003).

A prática de exercícios promove o aumento da atividade catalítica do complexo CPT no fígado (Lira et al., 2010), a queda na concentração de insulina e a maior atividade da lipase hormônio sensível, potencializando a formação de corpos cetônicos. Essa maior produção protege o organismo contra a proteólise durante a atividade física prolongada (Van Dijk et al., 1994). Já no estado caquético, tal proteólise está potencializada pela diminuição na produção de corpos cetônicos imposta pela redução na atividade catalítica do complexo CPT, como verificado anteriormente em trabalho publicado por nosso grupo de pesquisa (Kazantzis e Seelaender, 2005). Tal resultado demonstra que o fígado atua como órgão aferente e contribuinte para regulação metabólica durante e após a prática de exercícios (Cardin et al., 1994). 


\section{Objetivos}

\subsection{Objetivo Geral}

É de conhecimento que na vigência do quadro caquético associado à presença do tumor ocorre um processo de inflamação sistêmica que altera o metabolismo intermediário e leva o fígado ao desenvolvimento de esteatose. Entendendo-se que o treinamento é uma estratégia anti-inflamatória modulando a produção de citocinas anti e pró-inflamatórias respectivamente, e favorecendo o aumento na expressão e atividade de proteínas e enzimas chave do metabolismo lipídico no fígado, o objetivo do presente projeto foi verificar o efeito do treinamento físico em esteira no restabelecimento do metabolismo hepático de ratos portadores de tumor, bem como suas propriedades anti-inflamatórias. Ainda, pretende-se verificar a possível implicação do PPARa na modulação dos efeitos do exercício. 


\subsection{Objetivos Específicos}

1-Confirmar os efeitos da caquexia sobre o organismo e em particular o fígado. 2-Verificar o efeito do treinamento físico sobre os parâmetros abaixo afetados pela caquexia

a-Peso corporal e ingestão de ração

b-Metabolismo intermediário no fígado

-Capacidade de oxidação de ácidos graxos pelo fígado através da atividade máxima e expressão gênica do complexo enzimático CPT (etapa chave da oxidação lipídica) -Expressão gênica e protéica do receptor nuclear PPARa (modula a expressão gênica de enzimas oxidativas do metabolismo lipídico) e expressão gênica do RXR (auxiliar na ativação transcricional do PPARa)

-Conteúdo hepático de triacilglicerol, taxa de secreção de VLDL-TAG e expressão gênica da L-FABP no fígado

c-No plasma

- Concentração de triacilglicerol,colesterol e lipoproteínas

- Concentração de insulina

d-Inflamação no fígado

-Perfil de citocinas (IL-1 $\beta$, IL-6 e IL-10)

-Produção de prostaglandinas no fígado através da expressão gênica da COX-2 e do conteúdo de PGE2 presente no tecido.

e- Parâmetros inflamatórios no tumor

-Avaliar a concentração de PGE2 e TNFa.

-Avaliar a progressão do peso tumoral 


\section{Materiais e Métodos}

\subsection{Animais}

Foram utilizados ratos machos adultos da linhagem Wistar (Rattus norvegicus), fornecidos pelo Biotério da faculdade de Medicina/USP. Os animais foram mantidos no Biotério de Experimentação do departamento de Biologia Celular e do Desenvolvimento (ICB/USP) em regime de fotoperíodo $12 \mathrm{~h}$ claro:12 h escuro (período claro iniciando-se às $7 \mathrm{~h}$ ), temperatura de $23 \pm 1{ }^{\circ} \mathrm{C}$, recebendo ração granulada comercial (NUVILAB ${ }^{\circledR}$ CR1- Nutrivital Nutrientes Ltda) ad libitum.

O sacrifício dos animais foi realizado por decapitação, após oito semanas de treinamento, precedido de jejum de 12 horas. Foram coletados imediatamente após o sacrifício o plasma e os tecidos para a realização das determinações descritas a seguir.

Os procedimentos de manipulação experimental dos animais foram realizados de acordo com as normas estabelecidas no Guide to the care and use of experimental animals of the Canadian Council on Animal Care e Colégio Brasileiro de Experimentação Animal (COBEA) e aprovados pela Comissão de Ética do Instituto de Ciências Biomédicas - USP (certificado número: 148/2001 de 14/11/2001).

\subsection{Grupos Experimentais.}

Os animais foram divididos nos seguintes grupos:

- Grupo de ratos sedentários controle - SC

- Grupo de ratos sedentários portadores de tumor - ST

- Grupo de ratos treinados controle - TC

- Grupo de ratos treinados portadores de tumor - TT

\subsection{Protocolo de treinamento}

O protocolo de treinamento dos animais foi desenvolvido a partir do protocolo desenvolvido por Bacurau (2000). 
O grupo de animais treinados em intensidade moderada (60 - $65 \%$ do $\mathrm{VO}_{2}$ $\max$ ), como supracitado, exercitaram-se diariamente em esteira por 60 minutos, 5 vezes ao dia, seguindo o esquema abaixo (Tabela 1):

Tabela 1 - Protocolo de Treinamento

$\begin{array}{lccccc} & \text { 2a.feira } & \text { 3a. feira } & \text { 4a. feira } & \text { 5a. feira } & \text { 6a. feira } \\ & \text { 30 min } & 40 \mathrm{~min} & 30 \mathrm{~min} & 35 \mathrm{~min} & 30 \mathrm{~min} \\ \text { Adaptação } & 10 \mathrm{~m} / \mathrm{m} & 10 \mathrm{~m} / \mathrm{m} & 15 \mathrm{~m} / \mathrm{m} & 15 \mathrm{~m} / \mathrm{m} & \mathbf{2 0 \mathrm { m } / \mathrm { m }} \\ \text { 1a semana } & 35 \mathrm{~min} & 45 \mathrm{~min} & 50 \mathrm{~min} & 55 \mathrm{~min} & 60 \mathrm{~min} \\ \text { 2a semana } & 60 \mathrm{~min} & 60 \mathrm{~min} & 60 \mathrm{~min} & 60 \mathrm{~min} & 60 \mathrm{~min} \\ \text { 3a semana } & 50 \mathrm{~min} & 55 \mathrm{~min} & 60 \mathrm{~min} & 60 \mathrm{~min} & 60 \mathrm{~min} \\ \text { 4a semana } & 60 \mathrm{~min} & 60 \mathrm{~min} & 60 \mathrm{~min} & 60 \mathrm{~min} & 60 \mathrm{~min} \\ \text { 5a semana } & 50 \mathrm{~min} & 55 \mathrm{~min} & 60 \mathrm{~min} & 60 \mathrm{~min} & 60 \mathrm{~min} \\ \text { 6a semana } & 60 \mathrm{~min} & 60 \mathrm{~min} & 60 \mathrm{~min} & 60 \mathrm{~min} & 60 \mathrm{~min} \\ \text { 7a semana } & 50 \mathrm{~min} & 55 \mathrm{~min} & 60 \mathrm{~min} & 60 \mathrm{~min} & 60 \mathrm{~min} \\ \text { 8a semana } & 60 \mathrm{~min} & 60 \mathrm{~min} & 60 \mathrm{~min} & 60 \mathrm{~min} & 60 \mathrm{~min}\end{array}$

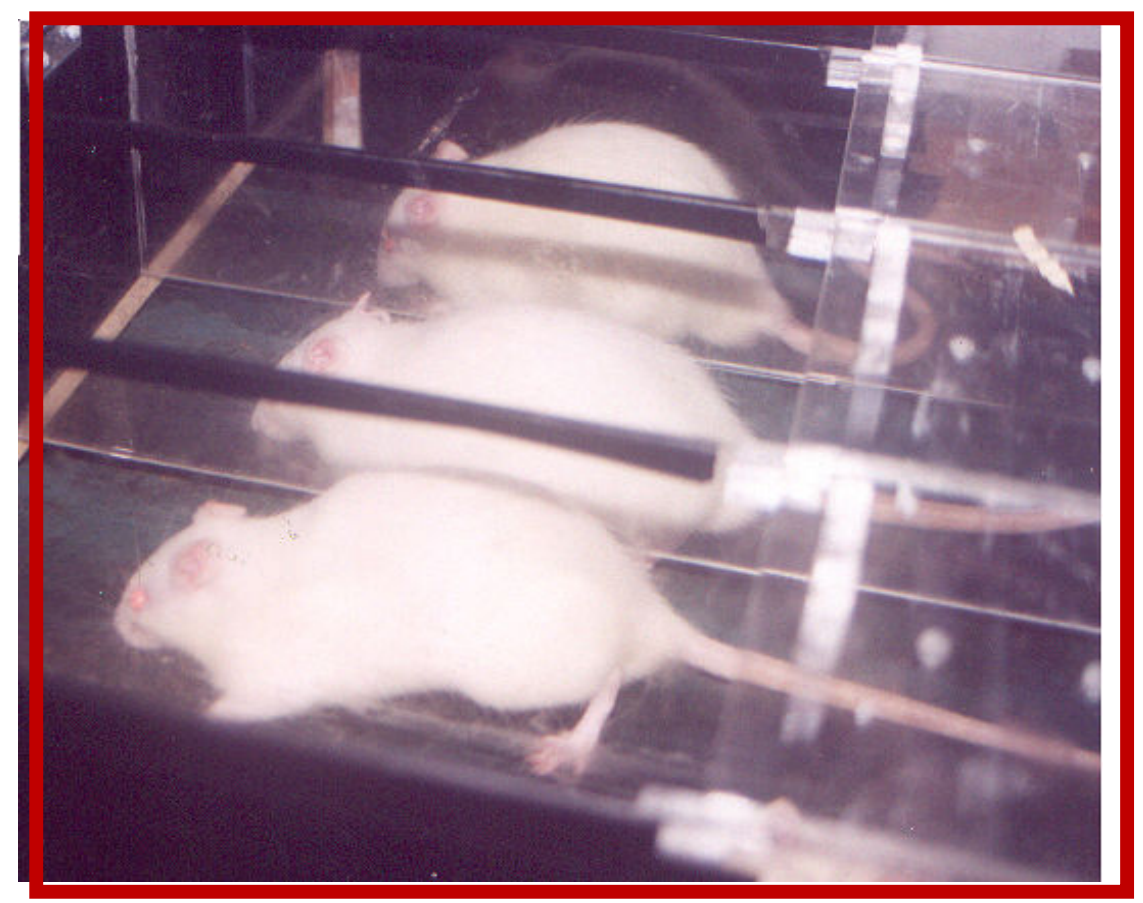

Figura 1: Sistema de treinamento em Esteira para ratos 


\subsection{Injeção de células tumorais}

As células $\left(2,0 \times 10^{7}\right)$ do carcinossarcoma de Walker 256 foram injetadas em suspensão salina, no flanco direito, como descrito em Machado et al. (2004).

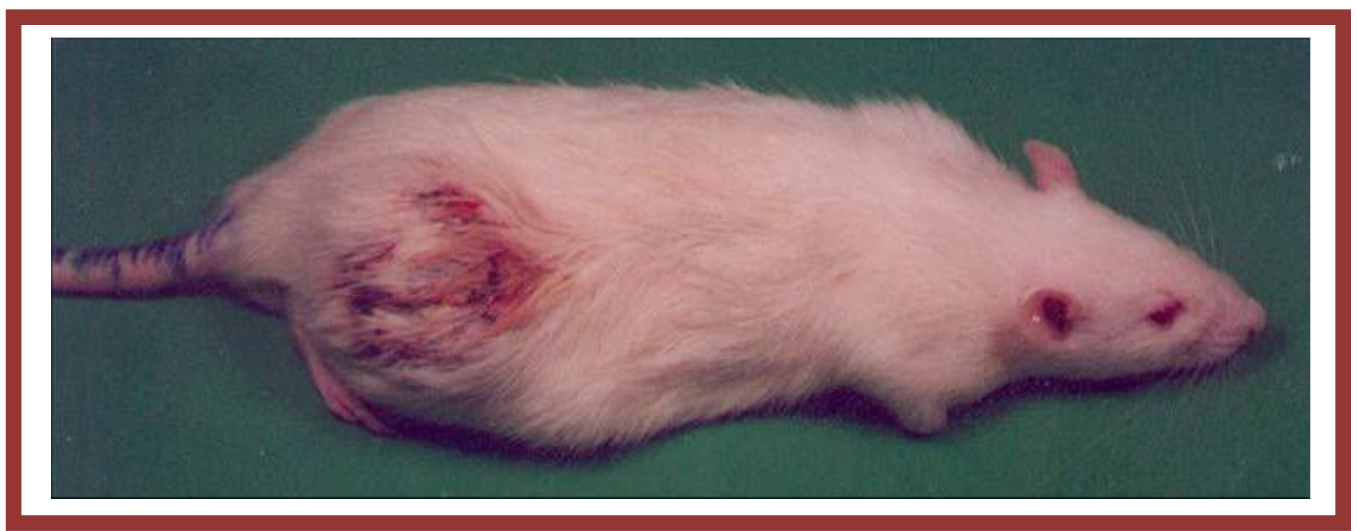

Figura 2: Carsinosarcoma de Walker 256 desenvolvido no flanco direito

\subsection{Peso corporal e ingestão alimentar}

Os animais foram pesados semanalmente durante todo o período do experimento. $O$ consumo de ração foi aferido diariamente durante a progressão tumoral.

\subsection{Extração lipídica do fígado}

Amostras de pesos conhecidos do fígado foram analisadas para quantificação de gordura, pelo método gravimétrico, após extração lipídica conforme Folch et al. (1957). Os tecidos foram pesados e colocados em Beckers individuais. O conteúdo equivalente ao peso de cada tecido em água foi adicionado ao Becker e os mesmos foram tampados com papel pardo. Os tecidos foram para a autoclave por uma hora. Após esfriamento, o conteúdo dos Beckers foi homogeneizado $15 \mathrm{~mL}$ utilizados como amostra. As amostras do tecido foram incubadas com KOH 30\% (p/v) por 15 minutos e, a seguir, acrescidas de $3 \mathrm{~mL}$ de etanol absoluto em banho maria por $2 \mathrm{~h}$, a $70{ }^{\circ} \mathrm{C}$. A fração dos lipídios neutros foi então extraída três vezes com éter de 
petróleo, e lavada com $2 \mathrm{~mL}$ de água destilada. Feito isso, as amostras foram transferidas para vials de vidro, nos quais após evaporação do éter de petróleo, determinou-se a massa de gordura presente por amostra, em relação a sua massa total.

\subsection{Avaliação da taxa de secreção plasmática de VLDL}

O experimento foi realizado 12 horas após a última sessão de exercícios. Os ratos sofreram privação alimentar por $12 \mathrm{~h}$ para minimizar a contribuição das lipoproteínas intestinais no soro. Pela manhã, os ratos foram anestesiados com quetamina (80mg kg1) e xilazina (10mg kg) e então Tiloxapol diluído em $1 \mathrm{ml}$ de salina , como descrito por Joles et al.(600 mg kg1; Triton WR1339; Sigma) foi injetado de forma endovenosa. O sangue foi coletado da cauda á 0, 60, 120 e 180 min. O soro foi removido a partir de centrifugação. O triacilglicerol plasmático foi quantificado usando kits comerciais (Labtest1, Brazil) a partir de duplicatas em cada um dos períodos acima indicados e a taxa de secreção para cada animal foi determinada a partir do slope da massa versus a curva de tempo.

\subsection{Determinação da concentração plasmática de insulina.}

A concentração plasmática de insulina foi determinada por RIA (radioimmunoassay) utilizando kit comercial (Coat-A-Count (DPC), Los Angeles, CA, USA). O método consiste no princípio de reação antígeno/anticorpo marcado por ${ }^{125}$ (radiação gama). A leitura e quantificação dos hormônios foi realizada em equipamento Packard® - modelo Cobra II . Todas as amostras foram analisadas em duplicatas. 


\subsection{Medida da atividade máxima da carnitina Palmitoil Transferase (CPT I e CPT II)}

\subsubsection{Isolamento de mitocôndrias}

Utilizou-se o método descrito por Curi et al. (1988). Após a perfusão o fígado e o músculo sóleo foram removidos e então fragmentados com o auxílio de tesouras, lavados com tampão de isolamento (Manitol $220 \mathrm{mM}$; sacarose $70 \mathrm{mM}$; EDTA $0,1 \mathrm{mM}, \mathrm{pH} 7,4)$ e homogeneizados manualmente. Os tecidos fragmentados no tampão foram filtrados com gaze e, a seguir, submetidos a duas centrifugações de baixa velocidade (1000 rpm, $12 \mathrm{~min}$ ), e duas outras de alta rotação (8000 rpm, 15 $\min )$.

\subsubsection{Separação das frações CPT-I e II}

A separação das frações contendo CPT-I e II foi realizada conforme metodologia de Woltje et al. (1987). As mitocôndrias isoladas foram ressuspensas em tampão (KCL 0,15 mM e Tris HCL 5 mM , pH 7,2), centrifugadas (17000 g, 15

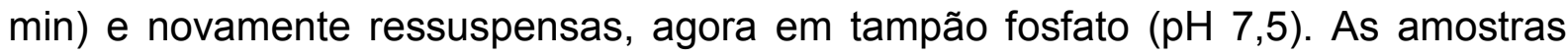
foram congeladas em nitrogênio líquido, sofrendo, a seguir, uma ultracentrifugação (100000 g, 1 h). O precipitado obtido foi ressuspenso em tampão fosfato e Tween 20 (solução 1\% p/v). A mistura foi levada ao banho de gelo com agitação, por $30 \mathrm{~min}$, e centrifugada $(100000 \mathrm{~g}, 1 \mathrm{~h}$ ). Ao final das centrifugações, foram obtidas as frações da CPT-I e II.

\subsubsection{Ensaio para medida da atividade máxima CPT-I e II}

Utilizou-se a técnica de Bremer (1981), adaptada por Seelaender et al. (1996). O meio de incubação foi composto por meio de ensaio correspondente a $80 \%$ do volume total (KCL $75 \mathrm{mM}$, Manitol $50 \mathrm{mM}$, Hepes $25 \mathrm{mM}$, EGTA 0,2 mM, pH $7,3), 5 \%$ de albumina de soro bovino livre de gordura; palmitoil CoA $42 \mu \mathrm{M} ; 0,25 \mu \mathrm{M}$ 
de ${ }^{3} \mathrm{H}$-metilcarnitina e 25 ou $50 \mu \mathrm{L}$ de fração enzimática isolada. Os controles receberam água destilada em substituição à amostra de CPT-I ou II. As amostras foram incubadas por $6 \mathrm{~min}$, a $37^{\circ} \mathrm{C}$.

\subsubsection{Extração da fase orgânica}

Utilizou-se o método de Bremer e Norum (1967) adaptado por Seelaender et al. (1996). A reação enzimática foi interrompida pela adição de ácido perclórico $7 \%$ (v/v). As amostras foram centrifugadas a $3000 \mathrm{rpm}$ por 10 minutos. O precipitado obtido foi lavado com 2,0 mL de ácido perclórico e dissolvido em 1,6 mL de água destilada deionizada. Acrescentou-se à essa solução, 1,0 mL de butanol, 0,4 mL de ácido perclórico $0,1 \mathrm{~mL}$ de sulfato de amônia saturado. Uma nova centrifugação foi realizada (1500 rpm, $20 \mathrm{~min}$ ), e a fase orgânica transferida para frascos contendo líquido de cintilação Brays. A leitura da radioatividade contida nas amostras foi realizada com o auxílio de um contador de cintilação (Hitache, C60ß). Os resultados foram expressos em nmoles/min/mg de proteína.

\subsection{Análise da expressão gênica da CPT I, CPT II, FABP, PPAR alfa, RXR, IKB, NFKB e COX-2}

\subsubsection{Procedimentos Gerais}

Para reduzir a presença de RNAses, foram adotados os seguintes cuidados em todos os procedimentos: utilização de material esterilizado descartável; esterilização da vidraria (em forno a $250^{\circ} \mathrm{C}$ por 4 horas); manipulação de amostras e materiais com luvas; utilização de água tratada com dietil-pirocarbonato (água Sigma-DEPC 0,01\% vol/vol em 3 vezes de $200 \mathrm{~mL}$, sob agitação magnética por 12 horas, autoclavada) (Sambrook et al., 1989).

\subsubsection{Extração do RNA}

Para a análise da expressão gênica das proteínas CPT I, CPT II, PPARa, FABP, PPARa, RXR, IKB, NFKB e COX-2 o RNA total do fígado, foi extraído com o reagente Trizol $^{\circledR}\left(100 \mathrm{mg}\right.$ de tecido/ml Trizol $\left.^{\circledR}\right)$, após homogeneização dos tecidos em 
aparelho Politron e incubação por 10 minutos à temperatura ambiente. As amostras foram precipitadas com cerca de $200 \mu$ de clorofórmio e centrifugadas por 15 minutos a $12000 \mathrm{~g}\left(4^{\circ} \mathrm{C}\right)$ para a obtenção do RNA total (a fase superior) que foi precipitada com $500 \mu \mathrm{l}$ de álcool isopropílico e incubação por 10 minutos à temperatura ambiente. Os pellets, agora visíveis, foram lavados com etanol $75 \%$ e as amostras centrifugadas por 5 minutos a $7500 \mathrm{~g}$, a $4{ }^{\circ} \mathrm{C}$. O álcool foi removido e os pellets secos à temperatura ambiente por 15 minutos. As amostras foram solubilizadas em água-DEPC. Para avaliação da concentração e pureza do RNA total, foram realizados ensaios espectrofotométricos sob comprimento de onda de 260 e $280 \mathrm{~nm}$. A razão $A_{260 / 280}$ é proporcional à concentração de RNAtot na amostra (SAMBROOK et al, 1989).

\subsubsection{Ensaio por RT-PCR}

Remoção de DNA genômico: O RNAtotal extraído de fígado dos grupos experimentais foi colocado em presença de Deoxiribonuclease I, DNAse altamente purificada, para a remoção de DNA genômico. Para tanto, o RNAtotal foi incubado por 15 minutos à temperatura ambiente, em tubo de polipropileno juntamente com $2 \mu \mathrm{l}$ de DNAse I, e $2 \mu \mathrm{l}$ de solução tampão Dnase 10X, completando com água-DEPC para 20 $\mu l$ de volume total de reação. Em seguida foi bloqueada a reação com EDTA 25 mM incubado por 10 minutos a $65^{\circ} \mathrm{C}$. O RNAtot foi seco em centrífuga a vácuo.

\subsubsection{Geração de cDNA por transcrição reversa}

O cDNA foi gerado pela incubação de $2 \mu \mathrm{g}$ de RNA total na presença de $2 \mu \mathrm{l}$ de OligoDTs $(0,05 \mu \mathrm{g} / \mu \mathrm{l})$ e $2 \mu \mathrm{l}$ de transcriptase reversa (M-MLV Reverse Transcriptase 20 U, Gibco), completando com Água-DEPC para $20 \mu$ de volume total de reação, por 10 minutos à $21^{\circ} \mathrm{C}, 30$ minutos à $42^{\circ} \mathrm{C}$ e 10 minutos, em termociclador (Gene Amp $\AA$, PCR system 9700). 
Os primers foram desenhados conforme sequência Genebank, representado pela tabela 2:

Tabela 2: Sequência de primers para realização do PCR Tempo Real

\begin{tabular}{|c|c|c|}
\hline Proteína & Sense & Antisense \\
\hline $\begin{array}{l}\text { CPT I } \\
\text { (NM_031559.2) }\end{array}$ & CCAAGCTGTGGCCTTCCAGT & GGACGCCGCTCACAATGTTC \\
\hline $\begin{array}{l}\text { CPT II } \\
\text { (NM_012930.1) }\end{array}$ & GATAAGCAGAATAAGCACACC & GGAGGAACAAAGCGAATGAGT \\
\hline $\begin{array}{l}\text { PPAR } \alpha \\
(\text { NM_0131961) }\end{array}$ & GAACCTGGCCACATCATTTC & CAGCAAAACCTTTGTGGTGA \\
\hline $\begin{array}{l}\text { FABP } \\
(\text { NM_012556.1) }\end{array}$ & TTCTCCGGCAAGTACCAAGTG & CCCAGTGTCATGGTATTGGTG \\
\hline $\begin{array}{l}\text { NFкB } \\
\text { (AF079314.1) }\end{array}$ & CCGAGCTCAGTGAGGACCTA & ATCTGTTTGAGGGCTTCGTG \\
\hline $\begin{array}{l}\text { I кВ } \\
\text { (AF246634.1) }\end{array}$ & ACCTCATTGCCACCATGAAC & СTTCCCTTCATGCACGATTT \\
\hline $\begin{array}{l}\text { GAPDH } \\
\text { (NM_017008.3) }\end{array}$ & ACATCATCCCTGCATCCACT & GGGAGTTGCTGTTGAAGTCA \\
\hline $\begin{array}{l}\text { COX-2 } \\
(\text { NM_017232.3) }\end{array}$ & AGAGAAAGAAATGGCTGCAGAGTT & AGCAGGGCGGGATACAGTT \\
\hline $\begin{array}{l}\text { RXR } \\
\text { (NM_012805.2) }\end{array}$ & ACTGCCGATACCAGAAGTG & CATGTTTGCCTCCACGTATG \\
\hline
\end{tabular}

3.10.5 Ensaio PCR tempo real

Os resultados da concentração de mRNA foram expressos pela razão Gene alvo/GAPDH (gliceraldeído 3 fosfato desidrogenase). Para cada amostra a amplificação foi realizada em triplicata em 25- $\mu$ l por reação, volume de 5-20 de of cDNA, $12.5 \mu$ S Syber Green Master Mix (Applied Biosystems), e $200 \mathrm{nM}$ de cada primer. A análise (PCR) foi realizada segundo os parâmetros: $50{ }^{\circ} \mathrm{C}$ por 2 min., $95{ }^{\circ} \mathrm{C}$ por 10 min., seguido de 40 ciclos de $95^{\circ} \mathrm{C}$ por $15 \mathrm{~s}$, e $60{ }^{\circ} \mathrm{C}$ por $1 \mathrm{~min}$. A fluorescência foi quantificada e analisada no equipamento AB 7300 Sequence Detector System 
(Applied Biosystems). Os resultados foram expressos usando em unidades arbitrárias e segundo método descrito pelo fabricante.

\subsection{Análise semi-quantitativa do conteúdo proteíco para PPARa, CPT II e NFKB por Imunodetecção}

As amostras de fígado foram homogeneizadas em tampão de lise $(\mathrm{PH} \mathrm{7,6)} \mathrm{e}$ a quantidade de proteína determinada pelo método de Bradford et al.(1976) As amostras foram adicionadas ao marcador (4X SDS) na concentração de $90 \mu \mathrm{de}$ amostra e submetidas a uma temperatura de $95^{\circ} \mathrm{C}$ por 5 minutos, a e em seguida as amostras foram transferidas para o gel de acrilamida e bis-acrilamida $4 \%$ correndo por duas horas em uma voltagem de $20 \mathrm{~mA}$. Após o término, as proteínas contidas no gel foram transferidas para membrana de nylon (Hybond extra ${ }^{\circledR}$ ) em sistema de transferência semi seco por uma hora. A confirmação da transferência foi confirmada com corante Ponceau na membrana. Após as lavagens com TBS $+0,1 \%$ Tween, realizou-se o bloqueio com incubação de albumina por uma hora. Após o bloqueio e a novas lavagens, incubou-se a membrana com o anticorpo primário para apoB antisheep (Bristol Myers Squibb) na diluição de 1:1000 em TBS +0,1\% tween, overnight. No dia seguinte, após as lavagens, incubou-se a membrana com o anticorpo secundário Santa Cruz (antigoat), na diluição de 1:5000 por duas horas. Após a incubação seguida de lavagens, revelou-se a membrana em acetato por 1 minuto com kit de ECL (GE).

As membranas foram digitalizadas e quantificou-se as bandas através do programa Scion Image. Utilizou-se como controle interno a proteína a-tubulina.

\subsection{Determinação da concentração de proteína nas amostras}

Utilizou-se o método de Bradford et al. (1976), modificado ( $\mathrm{mg} / \mathrm{mL})$. As amostras foram lidas contra curva padrão de albumina. A leitura foi realizada em espectrofotômetro (Beckman Coulter, DU 640) a 750 nm, após adição do reagente de Folin às amostras diluídas em solução contendo $\mathrm{Na}_{2} \mathrm{CO}_{3}, \mathrm{NaOH}$, tartarato de sódio e potássio e sulfato de cobre. Para a determinação do conteúdo proteíco nos tecidos dos animais preparou-se homogenato na proporção de 1:5 (peso/ volume). 


\subsection{Quantificação das citocinas teciduais}

\subsubsection{Ensaio de imunoabsorbância ligado a enzima (ELISA)}

Para dosagem das citocinas TNF- $\alpha$, IL-1 $\beta$, IL-10 e IL-6 foi utilizado o método enzyme-linked immunoabsorbent assay (DuoSet ELISA) de captura (R\&D System, Inc., Minneapolis, USA). Este ensaio foi realizado em amostras homogeneizadas de acordo com o ítens (4.7), proveniente dos diferentes grupos experimentais. Placas com 96 poços foram sensibilizadas com $100 \mu \mathrm{L}$ de anticorpo monoclonal anti-rato IL10 , IL-1 $\beta$ e ou TNF- $\alpha$ (anticorpo de captura) e incubadas overnight em temperatura ambiente. Após este período, os poços foram lavados por 3 vezes com tampão para lavagem $\left(0,05 \%\right.$ Tween ${ }^{\circ} 20$ em PBS, pH 7,2 - 7,4). Posteriormente, a placa foi bloqueada para evitar ligações inespecíficas com $300 \mu \mathrm{L}$ de solução de bloqueio (1\% BSA em PBS, pH 7,2 - 7,4, 0,2 $\mu \mathrm{m}$ filtrado) e incubada por 1 hora em temperatura ambiente. Findo este prazo, os poços foram lavados novamente como descrito acima.

Após o bloqueio, foram adicionados $100 \mu \mathrm{L}$ por poço das amostras e dos padrões diluídos previamente em reagente de diluição (1\% BSA em PBS, pH 7,2 $7,4,0,2 \mu \mathrm{m}$ filtrado), e cobertos com fita adesiva. Em dois poços foram colocados somente o reagente de diluição para caracterização do branco. A placa foi incubada por 2 horas em temperatura ambiente. Após este período, os poços foram lavados por 3 vezes com tampão de lavagem (0,05\% Tween ${ }^{\circledR} 20$ em PBS, pH 7,2 - 7,4).

Após as lavagens, adicionou-se $100 \mu \mathrm{L}$ do anticorpo de detecção (Anticorpo anti-rato IL-10, IL-1 $\beta$, IL-6 e TNF- $\alpha$ Biotinilado) diluídos previamente em reagente de diluição (1\% BSA em PBS, pH 7,2 - 7,4, 0,2 $\mu \mathrm{m}$ filtrado) na concentração estabelecida, os poços foram cobertos com fita adesiva e procedeu-se a incubação por 2 horas, em temperatura ambiente. Os poços foram lavados novamente como descrito anteriormente. Posteriormente, adicionou-se $100 \mu \mathrm{L}$ de Streptoavidina-HRP $(1: 250)$ por poço, então cobertos com papel laminado e incubados por 30 minutos, à temperatura ambiente. Findo este prazo, os poços foram lavados novamente como descrito anteriormente. Posteriormente, a solução de substrato (mistura dos reagentes de cores $\mathrm{A}-\mathrm{H}_{2} \mathrm{O}_{2}$ e $\mathrm{B}$ - Tetrametilbenzidina) foi adicionado na diluição de 1:1 por poço, seguido de incubação por 30 minutos à temperatura ambiente, evitando-se contato direto da placa com a luz. A reação foi interrompida com $50 \mu \mathrm{L}$ 
de $\mathrm{H} 2 \mathrm{SO} 430 \%$ por poço sob agitação lenta. A leitura foi realizada em leitor de ELISA (Power Wave, Bio-tek,USA), utilizando-se filtro de $450 \mathrm{~nm}$.

\subsection{Ensaio de ligação do NFkB ao DNA}

Inicialmente as amostras de fígado foram removidas imediatamente após o sacrifício dos ratos, homogeneizadas e seus núcleos extraídos conforme instruções dos fabricantes dos Kits de extração nuclear (Panomics Extraction Nuclear Kits (AY2002)), e armazenadas à $-80^{\circ} \mathrm{C}$. A localização nuclear da subunidade p65 do NFKB foi avaliada utilizando um kit de fator de transcrição ELISA para detectar a ligação desta subunidade ao DNA (Panomics, Fremont, CA; EK 1120). Todos os reagentes requeridos para o preparo dos extratos nucleares e para a realização dos ensaios ELISA foram incluídos, e todos foram utilizados conforme descrição do fabricante.

\subsection{Análise Estatística}

Os resultados foram analisados no programa ANOVA two way e comparados através do Teste de Bonferroni. O nível de significância adotado de, pelo menos $\mathrm{P}<0,05$. 


\section{Resultados}

\subsection{Progressão do peso corporal e consumo de ração}

Na figura 3 observa-se o valor absoluto de progressão do peso corporal dos ratos. Os grupos TC e TT apresentaram diminuição significativa em relação aos grupos SC e ST $(111,0 \pm 10,0 \mathrm{~g}$ vs $229,0 \pm 9,0 \mathrm{~g}$ e $121,0 \pm 11,0$ vs $202,0 \pm 12,0 \mathrm{~g}$ respectivamente). ${ }^{* *} p<0,001$.

\section{Progressão do peso corporal}

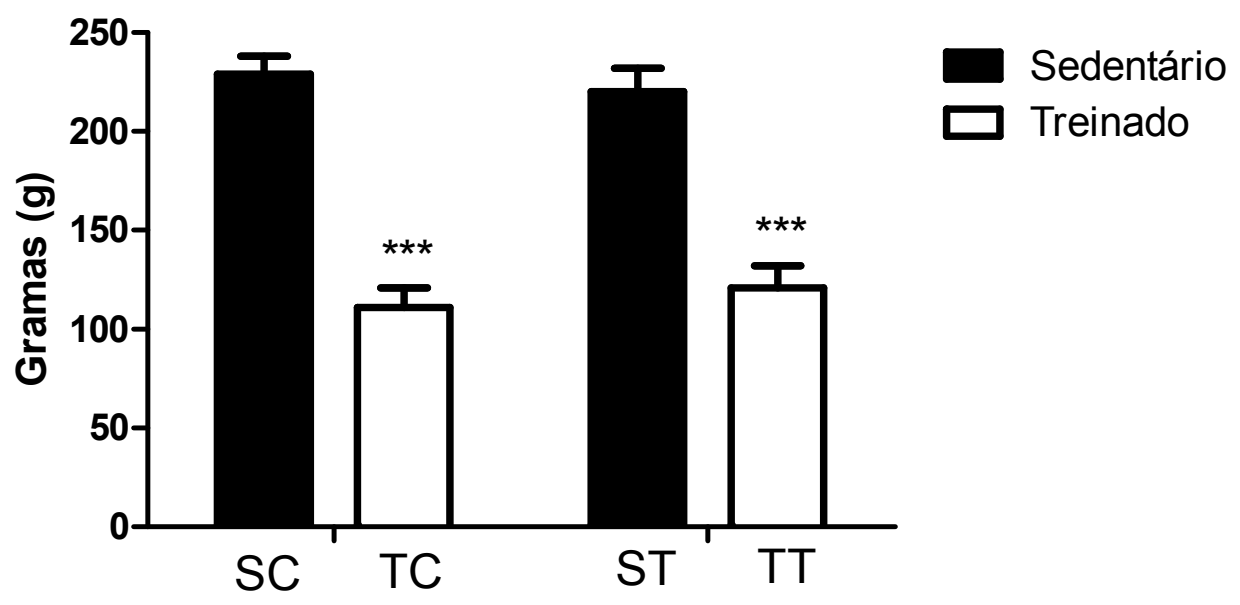

Figura 3: Progressão do peso corporal absoluta no período de 8 semanas. Resultados expressos em média \pm EPM. $n=5$ para todos os grupos. ${ }^{* * *} P<0,001$ em relação a $S C,{ }^{* * *} P<0,001$ em relação a ST. SC (sedentário controle), ST (sedentário tumor), TC (treinado controle), TT (treinado tumor). 
Na figura 4 observa-se diminuição no consumo de ração dos ratos de todos os grupos em relação ao grupo controle, porém apenas os ratos do grupo TC apresentaram diferença estatisticamente significante quando comparados ao grupo SC $(p<0,01)$. Contudo, os resultados demonstram efeito do treinamento em comparação aos ratos sedentários independente da presença ou não do tumor de $18,48 \%(p<0,05)$.

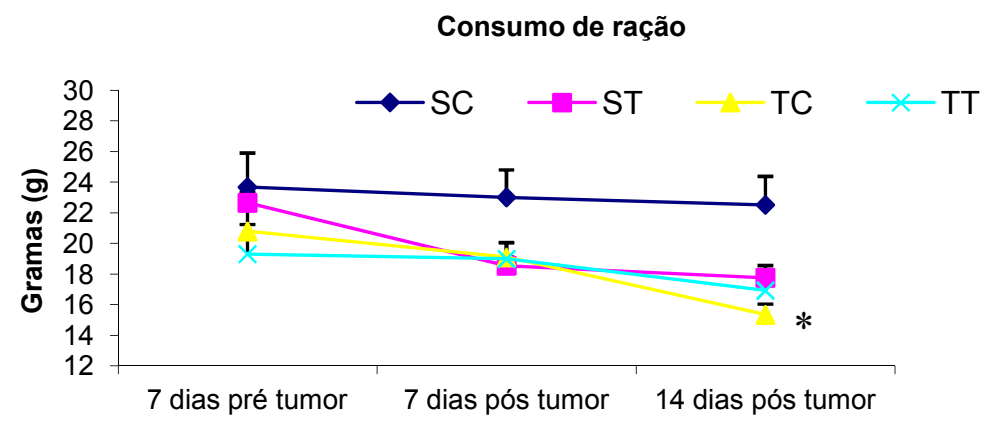

Figura 4: Média do consumo semanal de ração. Resultados expressos em média \pm EPM. $n=5$ para todos os grupos. $P<0,01$ entre SC e TC e $p<0,05$ para o efeito do treinamento entre os grupos (14 dias pós- tumor). SC (sedentário), ST (sedentário tumor), TC (treinado), TT (treinado tumor).

Na figura 5 observa-se diminuição no consumo de ração quando observado o efeito do tumor a partir do sétimo dia, sendo este efeito mais pronunciado após 14 dias de implante tumoral ( $p<, 0,05$ entre SC e ST).

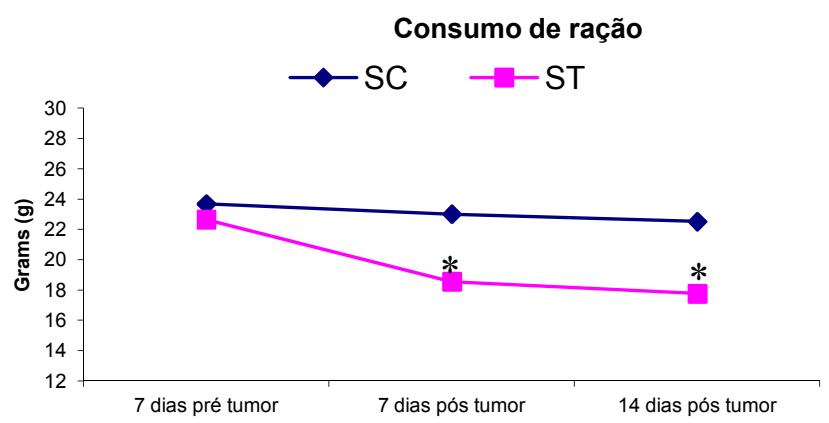

Figura 5: Média do consumo semanal de ração. Resultados expressos em média \pm EPM. $n=5$ ratos por grupo. ${ }^{*} \mathrm{P}<0,05$ entre SC e ST. S (sedentário), ST (sedentário tumor). 
O consumo acumulado de ração 21 dias antes do sacrifício descrito na figura 6 apresenta um menor consumo de ração nos grupos SC e TC em relação ao grupo $S\left({ }^{* *} p<0,01\right)$.

Consumo cumulativo de ração

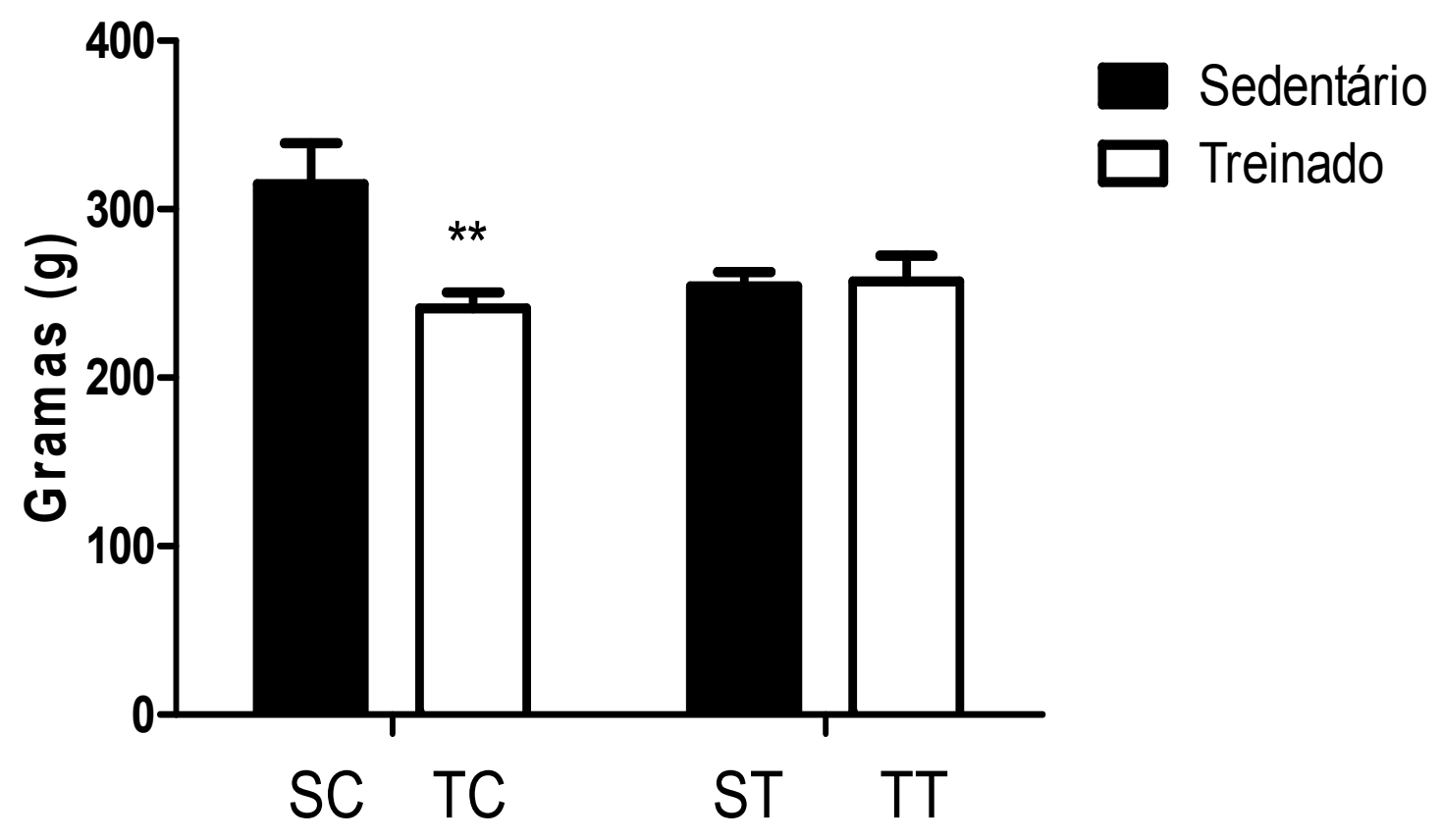

Figura 6: Consumo de ração acumulado 21 dias antes do sacrifício dos ratos. Resultados expressos em média \pm EPM. $n=5$ para todos os grupos. ** $P<0,01$ em relação ao grupo sedentário controle. SC (sedentário controle), ST (sedentário tumor), TC (treinado controle), TT (treinado tumor). 


\subsection{Dosagens plasmáticas}

4.2.1 Concentração plasmática de insulina e $P G E_{2}$

Insulina

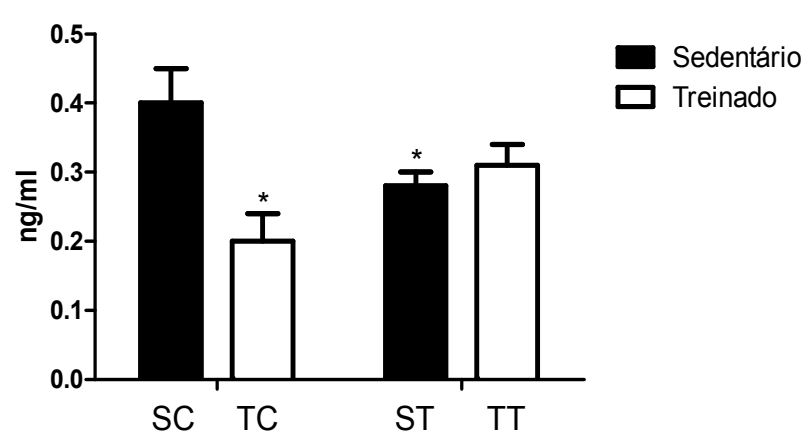

Figura 7: Concentração plasmática de insulina. Resultados expressos em média \pm EPM. $n=7 \mathrm{SC}$ e ST e $n=5$ TC e TT. * $P<0,05$ em relação a SC. SC (sedentário controle), ST (sedentário tumor), TC (treinado controle), TT (treinado tumor).

$\mathrm{Na}$ figura 7 apresentamos a concentração plasmática de insulina nos diferentes grupos. Observa-se que os grupos TC e ST apresentaram diminuição significativa das concentrações de insulina plasmática (30 e 50\% respectivamente) em relação ao grupo SC $(P<0,05)$. A figura 8 abaixo apresenta os resultados para as concentrações plasmáticas de $\mathrm{PGE}_{2}$. Observa-se que $\mathrm{ST}$ apresentou maior concentração de $\mathrm{PGE}_{2}$ em ST se comparado a SC $(4,4 \pm 0,74 \mathrm{pg} / \mathrm{ml}$ vs. 2,2 $\pm 0,67$ $\mathrm{pg} / \mathrm{ml}$ respectivamente; $\mathrm{p}<0,05$ )

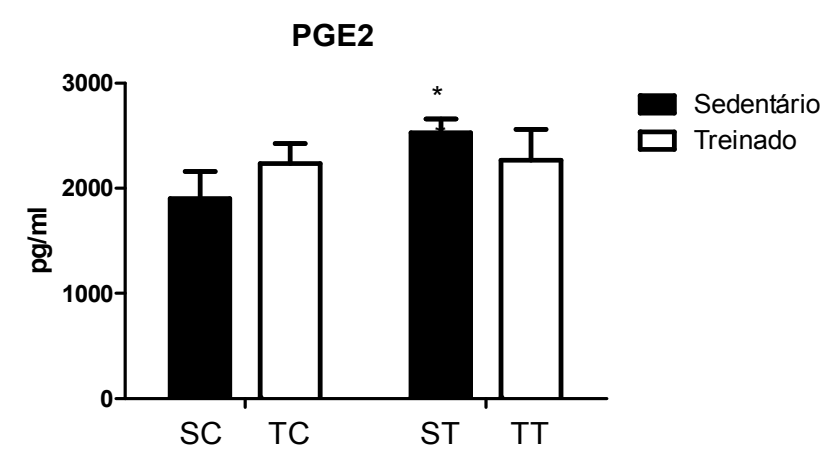

Figura 8: Concentração plasmática de $\mathrm{PGE}_{2}$. Resultados expressos em média $\pm E P M . n=8$ para $S C$ e ST e $\mathrm{n}=5$ para TC e TT. * $\mathrm{P}<0,05$ em relação a SC. SC (sedentário controle), ST (sedentário tumor), TC (treinado controle), TT (treinado tumor). 


\subsubsection{Taxa de secreção de VLDL-TAG}

Conforme ilustrado na figura 9, a taxa de secreção de VLDL-TAG para os grupos ST e TT apresentou redução aos 60min quando comparados com SC (ST: $1.1 \pm 5.6$ $\mathrm{mg} / \mathrm{dl}$ e TC: $39.4 \pm 24.2 \mathrm{mg} / \mathrm{dl}$ vs. SC: $523.3 \pm 82.9 \mathrm{mg} / \mathrm{dl} ; \mathrm{p}<0.001)$. A secreção de VLDL-TAG em TT aumentou em comparação a ST $(77.0 \pm 16.0 \mathrm{mg} / \mathrm{dl}$ em TT vs. 1.1 $\pm 5.6 \mathrm{mg} / \mathrm{dl}$ em ST; $p<0.001)$. Aos 120 minutos, TC apresentou menor taxa de secreção de VLDL-TAG quando comparado com SC $(205.8 \pm 29.4 \mathrm{mg} / \mathrm{dl}$ vs. $419.5 \pm$ $56.4 \mathrm{mg} / \mathrm{dl} \mathrm{em} ; \mathrm{p}$ < 0.01) e em TT observa-se diminuição nos valores quando comparado com ST $(104.2 \pm 9.9 \mathrm{mg} / \mathrm{dl}$ vs. $338.1 \pm 81.2 \mathrm{mg} / \mathrm{dl} ; \mathrm{p}<0.01)$. ST e TC apresentaram redução na taxa de secreção de VLDL-TAG aos 180 minutos quando comparados à SC $(22.8 \pm 98.0 \mathrm{mg} / \mathrm{dl} \mathrm{em} \mathrm{ST} \mathrm{and} 440.3 \pm 69.8 \mathrm{mg} / \mathrm{dl} \mathrm{em} \mathrm{EC} \mathrm{vs.} 478.4$ $\pm 84.2 \mathrm{mg} / \mathrm{dl} \mathrm{em} \mathrm{SC} ; \mathrm{p}<0.05$ ). Ainda, o treinamento nos ratos portadores de tumor aumentou a taxa de secreção de VLDL-TAG em comparação a ST (477.3 \pm 80.6 $\mathrm{mg} / \mathrm{dl}$ em TT vs. $22.8 \pm 98.0 \mathrm{mg} / \mathrm{dl}$ em ST < 0.01), restabelecendo a secreção de VLDL-TAG a valores próximos aos de repouso.

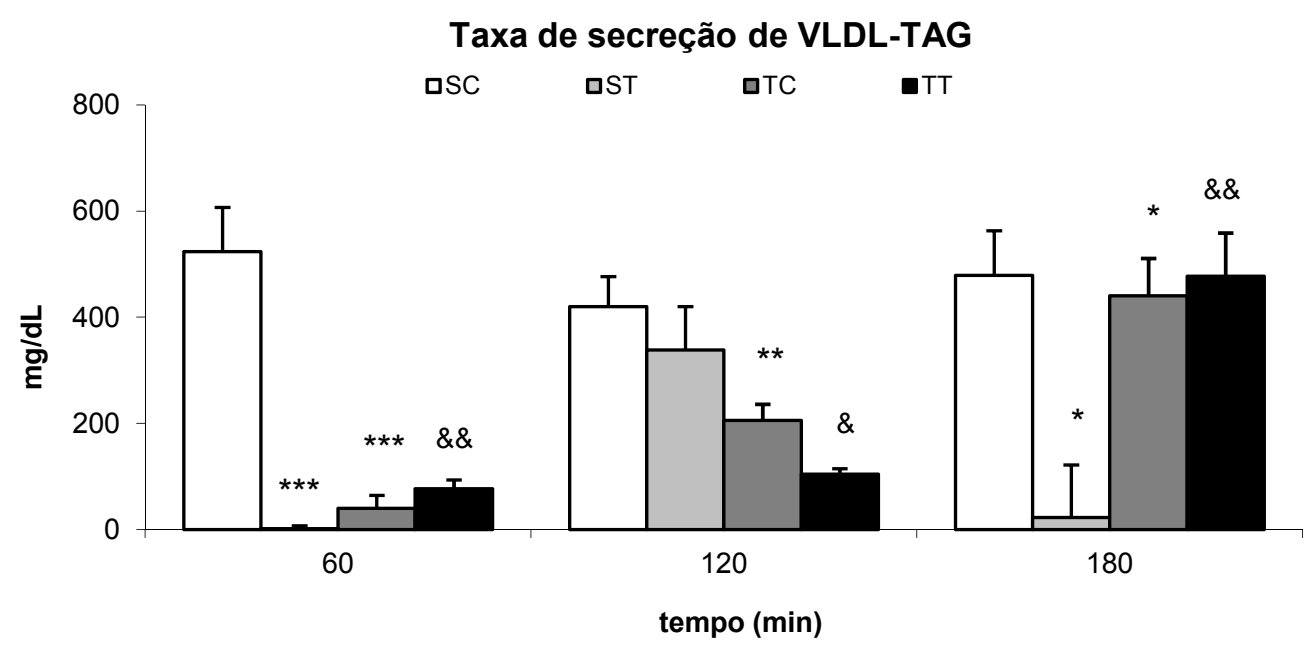

Figura 9: Taxa de secreção de VLDL-TAG. ${ }^{* * *} p<0.001$ vs. SC no tempo respectivo; ${ }^{* *} p<$ 0.01 vs. SC no tempo respectivo; ${ }^{\& \&} p<0.001$ vs. ST no tempo respectivo; ${ }^{\&} p<$ 0.01 vs. ST no tempo respectivo. SC (sedentário controle), ST (sedentário tumor), TC (treinado controle), TT (treinado tumor) $n=7$ para todos os grupos. 


\subsection{Fígado}

\subsubsection{Conteúdo de gordura no fígado}

Na figura 10 observa-se que o grupo ST apresentou aumento significativo no conteúdo de TAG quando comparado ao grupo SC $(26,6 \pm 4,5 \mathrm{mg}$ vs. 9,7 $\pm 0,7 \mathrm{mg} p$ < 0.05). O treinamento reduziu significativamente o conteúdo de TAG em TC e TT quando comparado com os grupos SC e ST respectivamente $(6,7 \pm 0,8 \mathrm{mg}$ em TC vs. 9,7 $\pm 0,1 \mathrm{mg}$ em SC e 2,6 $\pm 0,2 \mathrm{mg}$ em TT vs. $26,6 \pm 4,5 \mathrm{mg}$ em ST; $p<0,05$ ).

\section{Conteúdo de TAG no fígado}

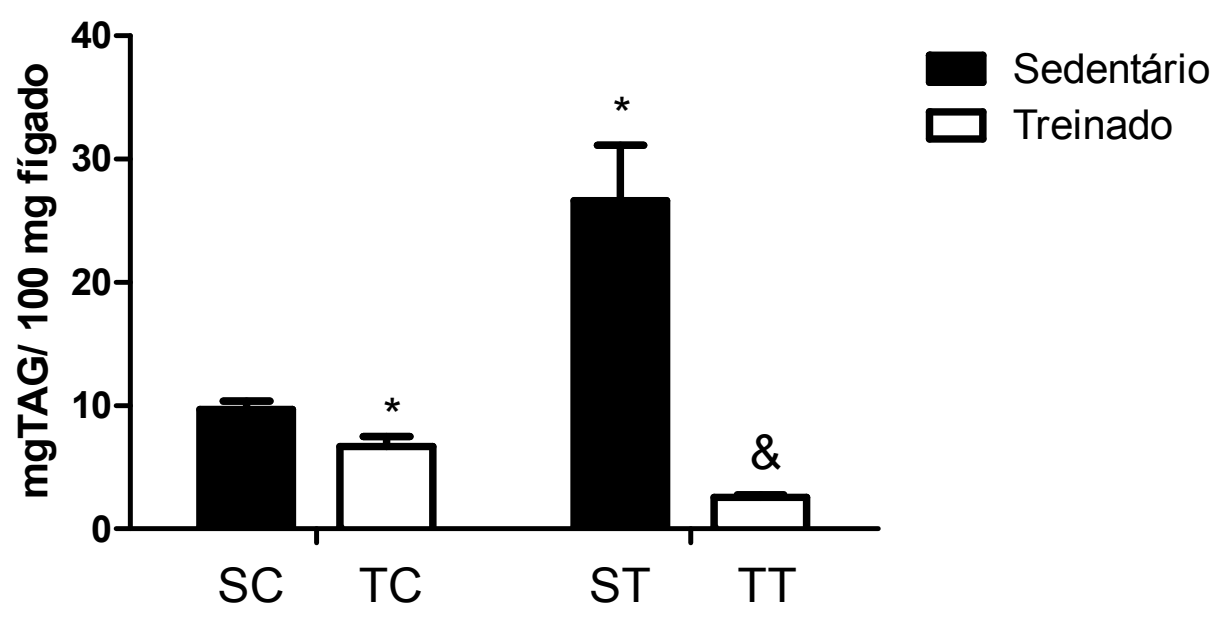

Figura 10: Conteúdo de TAG no fígado. Resultados expressos em média \pm EPM. $n=7$ para SC e ST e $\mathrm{n}=5$ para TC e TT. SC (sedentário controle), ST (sedentário tumor), TC (treinado controle), TT (treinado tumor). ${ }^{*} p<0.05$ vs. SC; ${ }^{\alpha} p<0.05$ vs. ST. 
4.3.2 Medida da atividade máxima das enzimas CPT I e CPT II no fígado

A Figura 11 apresenta os resultados para atividade máxima das enzimas CPT I e CPT II para o fígado. Observa-se que ST apresentou diminuição na atividade máxima tanto de CPT I, como de CPT II comparado ao grupo SC (2,66 \pm 0,30 vs. $3,66 \pm 0,30 \mathrm{nmol} / \mathrm{min} / \mathrm{mg}$ proteína e $0,16 \pm 0,10$ vs $1,68 \pm 0,16 \mathrm{nmol} / \mathrm{min} / \mathrm{mg}$ proteína respectivamente $p<0,01)$. Os grupos TC e TT por sua vez aumentaram a capacidade máxima de ambas CPT I e CPT II quando comparados a SC (TC: 9,96 \pm 1,02 vs. $3,66 \pm 0,30 \mathrm{nmol} / \mathrm{min} / \mathrm{mg}$ proteína e 14,79 $\pm 2,74$ vs 1,68 $\pm 0,16$ $\mathrm{nmol} / \mathrm{min} / \mathrm{mg}$ proteína e TT: 10,61 $\pm 1,62$ vs. 3,66 \pm 0,30 nmol/min/mg proteína e $9,25 \pm 1,12$ vs $1,68 \pm 0,16 \mathrm{nmol} / \mathrm{min} / \mathrm{mg}$ proteína, respectivamente, $\mathrm{p}<0,01)$.
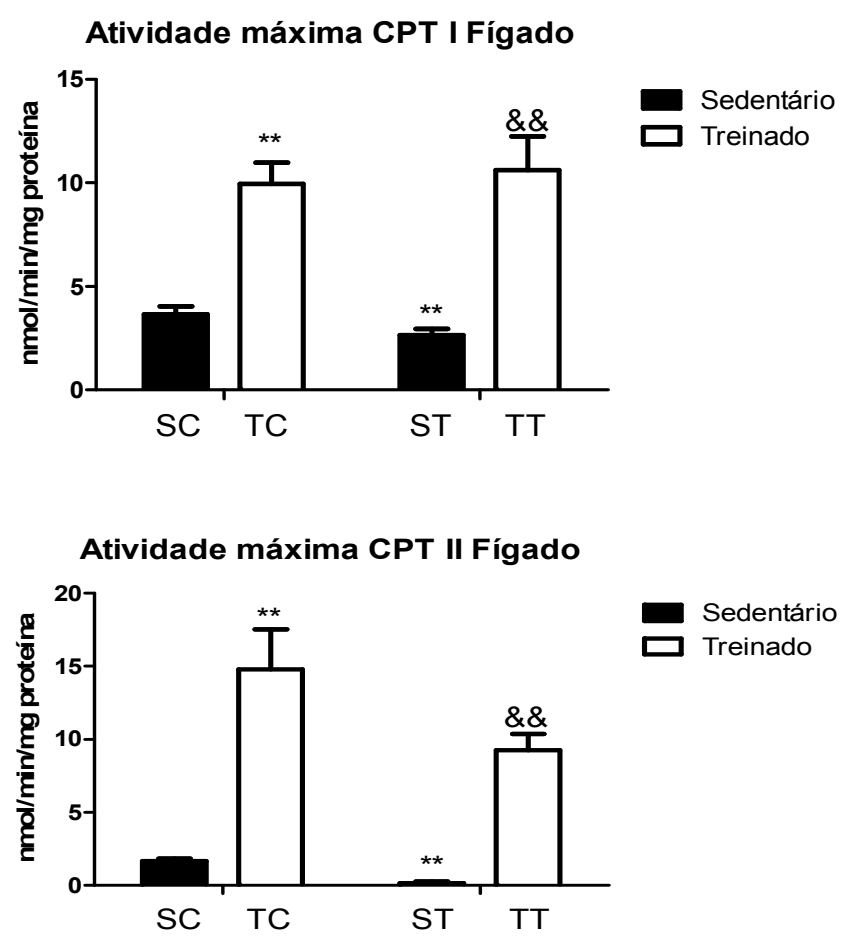

Figura 11: Atividade máxima da CPT I e CPT II no fígado. Resultados expressos em média \pm EPM. $n=10$ para SC e ST e $n=8$ para TC e TT. ${ }^{* *} p<0,01$ em relação a SC e \&\& $p<0,01$ em relação a ST. SC (sedentário controle), ST (sedentário tumor), TC (treinado controle), TT (treinado tumor). 
Na figura 12 observa-se que a expressão gênica da FABP diminui em TC $(43 \% \# p<0,05)$ quando comparado com SC. Contudo, TT apresentou aumento na expressão gênica da FABP se comparado à TC e ST (2.03 \pm 0.05 vs. $1.46 \pm 0.23 \mathrm{UA}$ e $2 . \pm 0.05$ vs. $1.31 \pm 0.17 \mathrm{UA} \quad * \& p<0.05$ respectivamente). A expressão gênica da CPT II aumentou em TT $\left(39 \%\right.$; ${ }^{*} p<0,05$ e $\left.54 \% ;{ }^{\&} p<0,01\right)$ respectivamente em comparação à TC e ST.
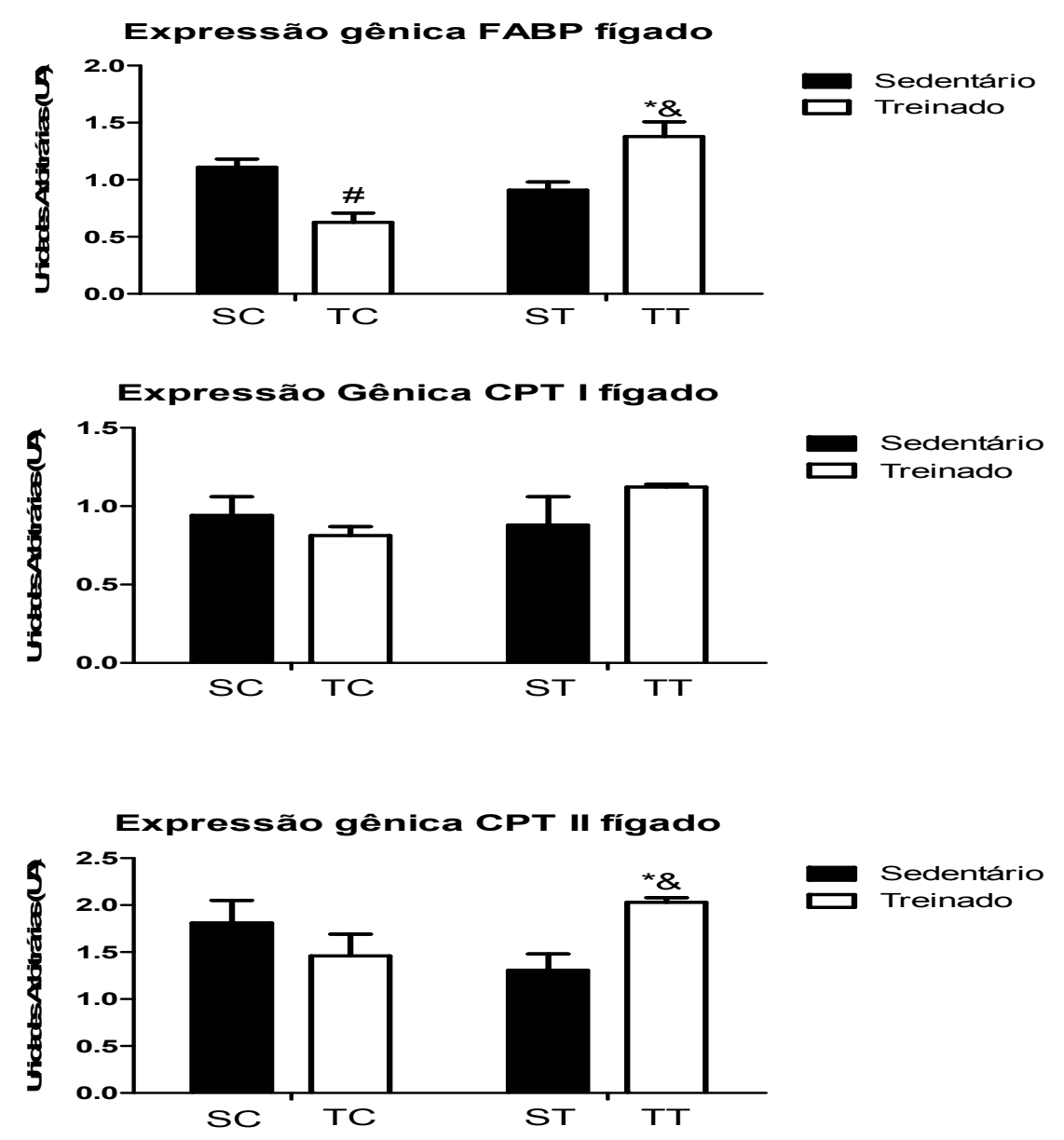

Figura 12: Expressão gênica das proteínas FABP, CPT I e CPT II no fígado. Resultados expressos em média \pm EPM. $n=10$ para SC e ST e $n=8$ para TC e TT. ${ }^{p}<<0,05$ em relação a SC; ${ }^{*} p<0,05$ em relação a TC; ${ }^{*} p<0,05$ em relação a ST. SC (sedentário controle), ST (sedentário tumor), TC (treinado controle), TT (treinado tumor). 
4.3.4 Medida da expressão gênica de PPARa, $R X R$, NFKB e IKB no fígado

Com relação aos resultados obtidos para a expressão gênica no fígado na figura 13 observa-se que RNAm do RXR aumentou 83\% ( $\left.{ }^{*} p<0,05\right)$ em TC e $250 \%$ ( $\left.{ }^{\&} p<0.01\right)$ em TT quando comparado com SC e ST respectivamente. A expressão gênica do PPAR-a mRNA apresentou o mesmo padrão de resultado, aumentando $103 \%\left({ }^{*} \mathrm{p}<0.05\right)$ em TC e 106\% ( $\left.{ }^{\&} \mathrm{p}<0.01\right)$ em TT quandd com SC e ST respectivamente. O grupo TC apresentou diminuição na expressão gênica do IKB em relação à $S C\left({ }^{* *} p<0,01\right)$ e TT em ${ }^{\S}$ relação à $S T\left({ }^{\star} p<0,01\right)$. O NFKB não apresentou diferença entre os grupos estudados ( $p>0,05)$.

A

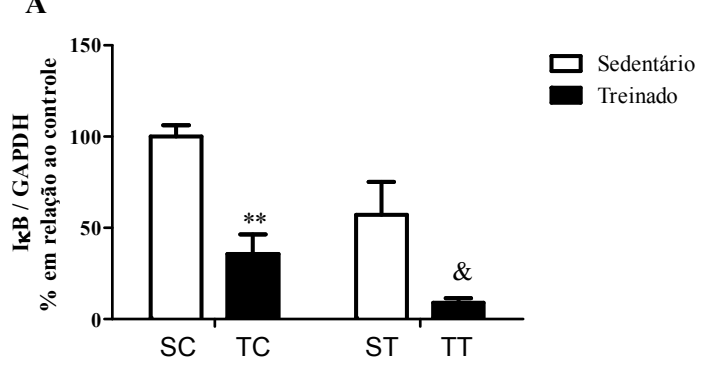

C

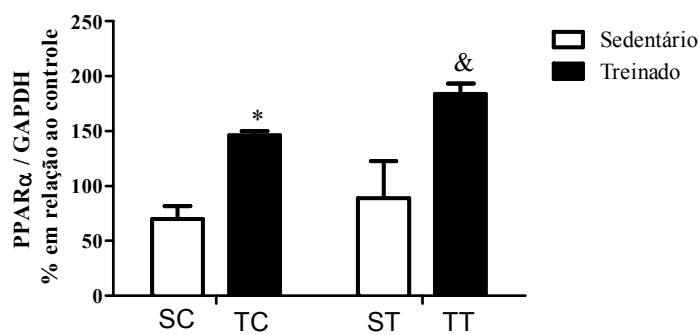

B

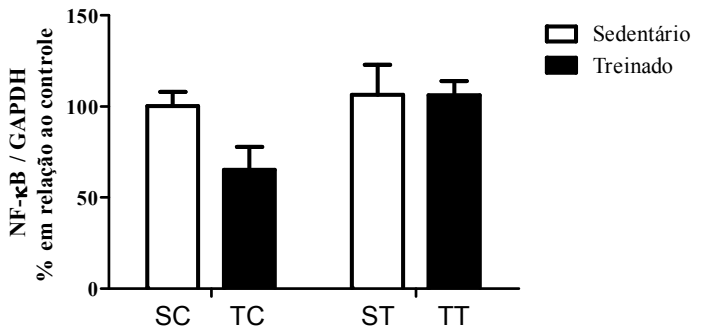

D

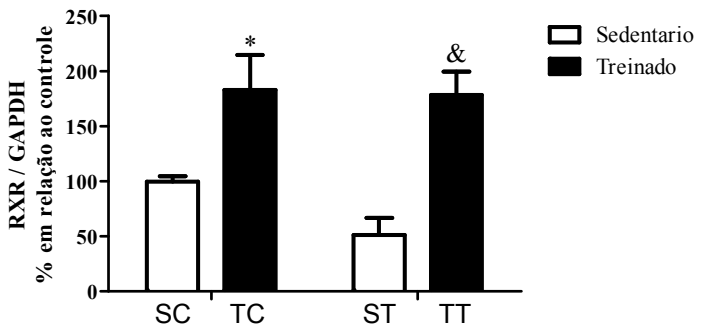

Figura 13: Expressão gênica das proteínas PPARa, RXR, NFkB e IkB no fígado. Resultados expressos em média \pm EPM. $n=5$ para todos os genes e grupos. (A) Ikappa B RNAm. ** $p<0.01$ vs. SC e ${ }^{\&} p<0.01$ vs. ST. (B) NF-kappa B p65 RNAm. (C) PPAR- $\alpha$ RNAm. * $p<$ 0.05 vs. SC $e^{\&} p<0.01$ vs. ST. (D) RXR RNAm. ${ }^{*} p<0.05$ vs. SC $e^{\&} p<0.01$ vs. ST. SC (sedentário controle), ST (sedentário tumor), TC (treinado controle), TT (treinado tumor). 
4.3.5 Medida da expressão gênica da COX-2 (cicloxigenase-2) no fígado

A figura 14 abaixo representa a expressão gênica da enzima COX-2. Observa-se que o conteúdo de RNAm da COX-2 aumentou 333\% em TC ( ${ }^{*} p<$ $0.05)$ e $209 \%$ in ST $(p<0.05)$ em comparação à SC. Inversamente.TT apresentou $58 \%\left({ }^{\#} \mathrm{p}<0.01\right)$ menos RNAm quando comparado a ST.

\section{Expressão gênica COX-2 fígado}

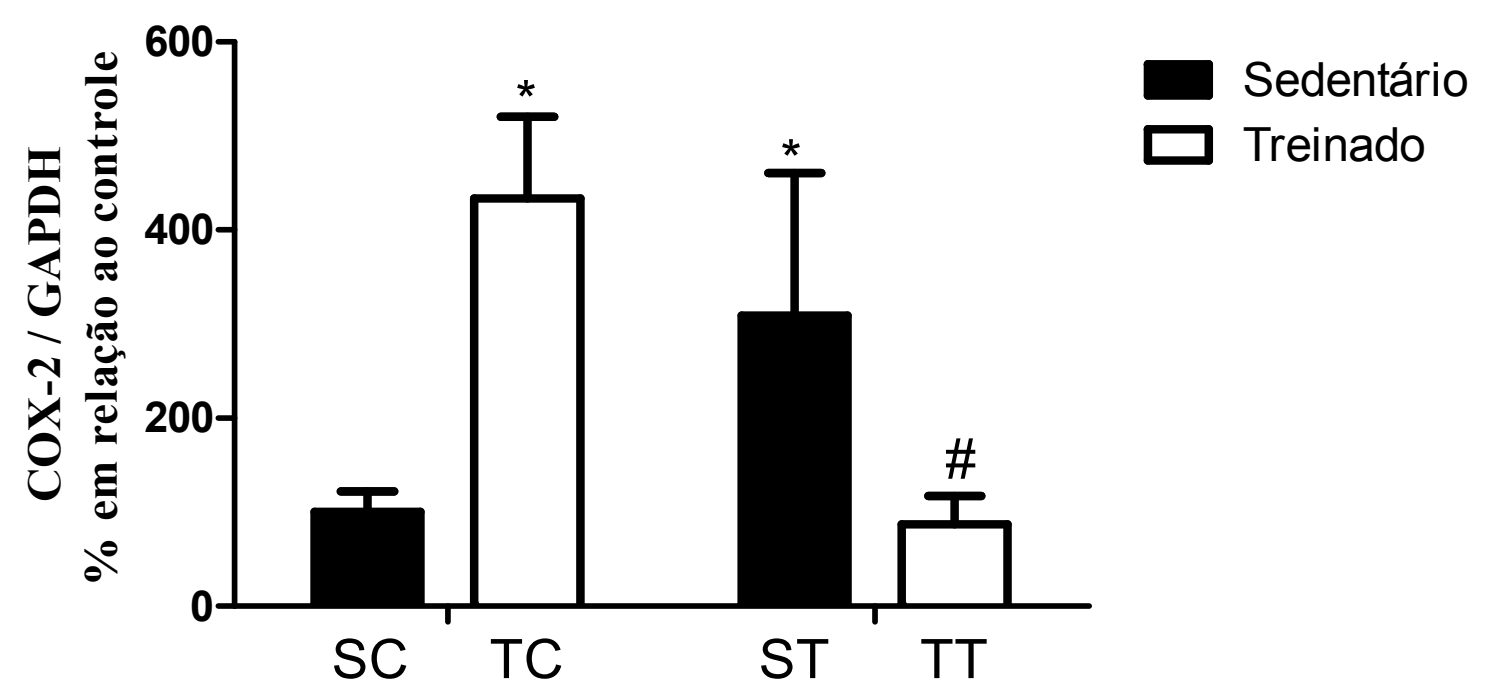

Figura 14: Expressão gênica da proteína COX-2 no fígado. Resultados expressos em média \pm EPM. $n=5$ para todos os grupos ${ }^{*} p<0,05$ vs SC e ${ }^{\#} p<0,01$ vs. ST. SC (sedentário controle), ST (sedentário tumor), TC (treinado controle), TT (treinado tumor). 


\subsubsection{Medida da expressão protéica de PPARa, CPT I/ e NFKB no fígado}

A figura 15 representa o resultado semi-quantitativo do conteúdo das proteínas PPARa, NFKB E CPT II no fígado. Assim como para a expressão gênica, a expressão protéica de PPAR- $\alpha$ apresentou aumento de $45 \% \quad\left({ }^{*} p<0.05\right)$ em TC e $104 \%\left({ }^{* *} p<0.01\right)$ in TT quando comparado com SC e ST respectivamente. A expressão protéica para ambos NF-kappaB p65 e CPT II por sua vez não apresentou diferenças entre os grupos estudados $(p>0,05)$.
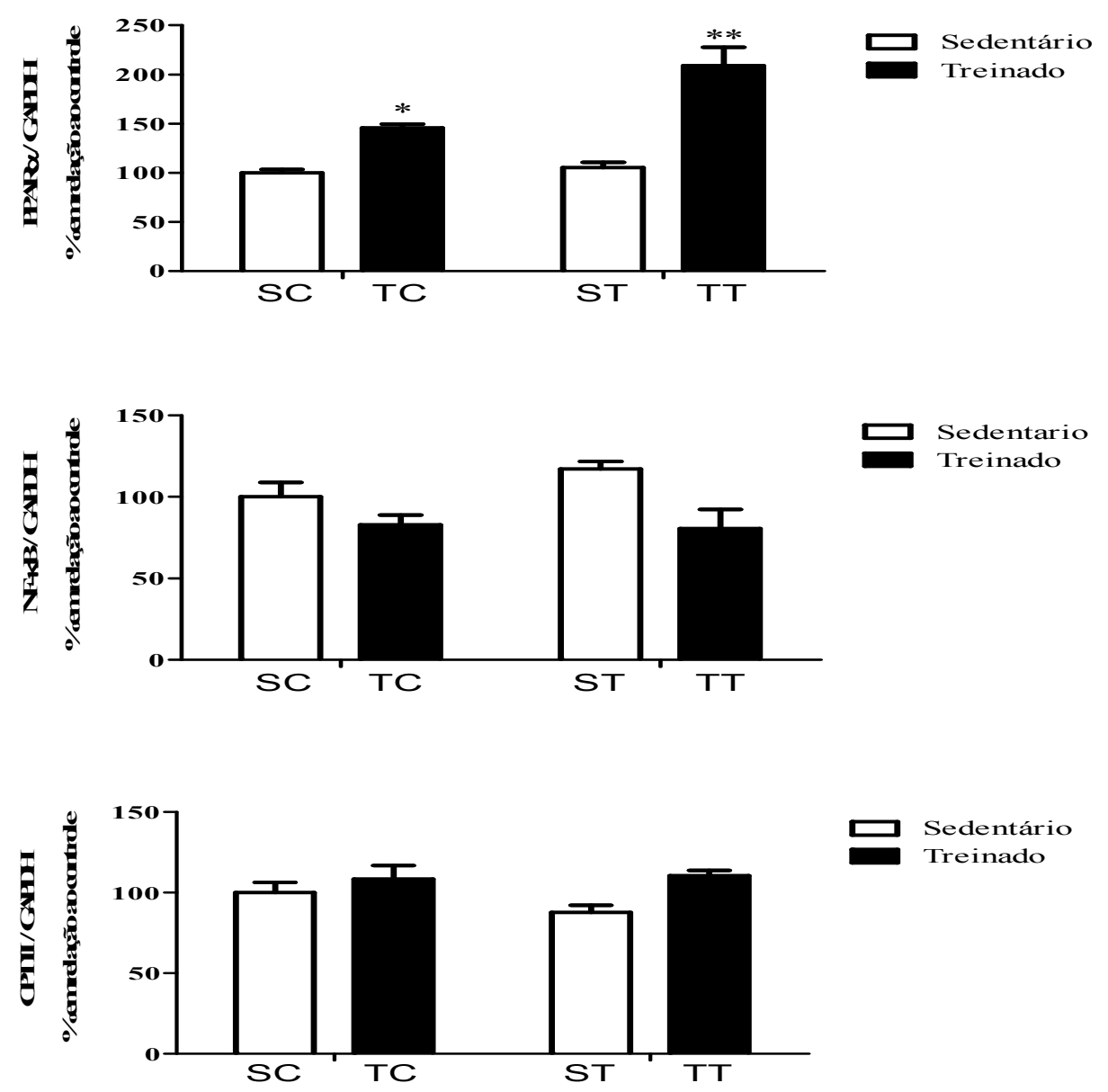

Figura 15: Expressão protéica das proteínas PPARa, CPT II, e NFkB no fígado. Resultados expressos em média \pm EPM. $n=5$ para todos os grupos. NF-kappa B p65 $(p>0,05)$ e PPAR- $\alpha .{ }^{*} p<0.05$ vs. SC $e^{* *} p<0.01$ vs. ST. SC (sedentário controle), ST (sedentário tumor), TC (treinado controle), TT (treinado tumor). 
$\mathrm{Na}$ figura 16 abaixo observa-se que $\circ$ resultado para o ensaio de ligação das unidades p50 e p65 do NFkB não apresentou diferenças entre os grupos estudados.

\section{NFkB p65}

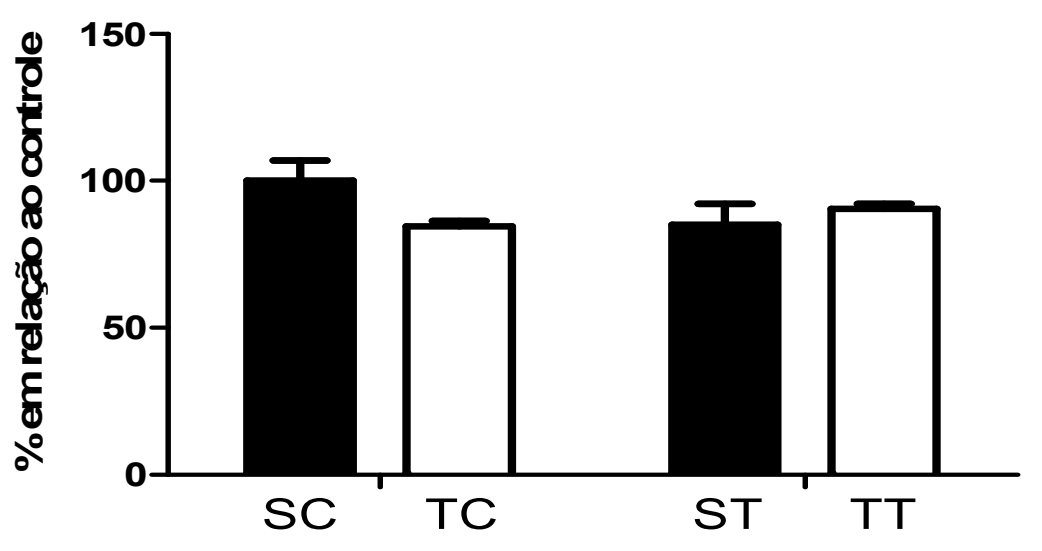

NFkB p50

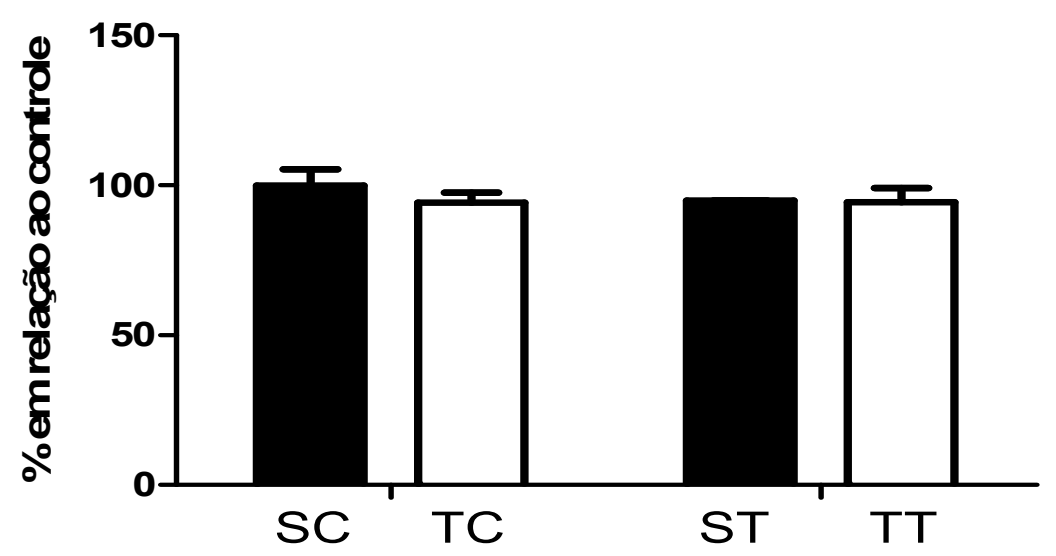

Figura 16: Ensaio de ligação ao DNA das unidades kappaB p65 e p50. Resultados expressos em média \pm EPM. $n=3$. $p>0,05$ para todos os grupos. SC (sedentário controle), ST (sedentário tumor), TC (treinado controle), TT (treinado tumor). 
$\mathrm{Na}$ tabela 3 abaixo observa-se que os resultados para a concentração de citocinas no fígado não apresentou diferenças estatísticas entre os grupos $(p>0,05)$

Tabela 3: Concentração de proteína das citocinas IL-6, IL-10, e TNF- $\alpha$ (pg/ug proteina $\left.{ }^{-1}\right)$. $P>0,05$ para todos os grupos. . Resultados expressos em média \pm EPM. $n=5$. . SC (sedentário controle), ST (sedentário tumor), TC (treinado controle), TT (treinado tumor).

\begin{tabular}{llllllllll}
\hline & SC & & ST & & TC & & TT & \\
\hline IL-6 & $18,04 \pm$ & 3,34 & $19,78 \pm$ & 3,11 & $16,69 \pm$ & 2,48 & $17,79 \pm$ & 6,14 \\
IL-10 & $9,83 \pm$ & 1,84 & $13,04 \pm$ & 2,89 & $10,97 \pm$ & 3,28 & $9,93 \pm$ & 3,06 \\
TNF- $\alpha$ & $6,55 \pm$ & 2,11 & $8,54 \pm$ & 2,32 & $7,38 \pm$ & 1,32 & $4,83 \pm$ & 1,71 \\
\hline
\end{tabular}

\subsubsection{Concentração de prostaglandina $\mathrm{E}_{2}\left(\mathrm{PGE}_{2}\right)$ no fígado.}

A concentração de $\mathrm{PGE}_{2}$ no fígado, conforme observado na figura 17 diminuiu $44 \%$ em ST $(p<0,05)$ e $90 \%$ em TT $(p<0,05)$, quando comparados com SC.

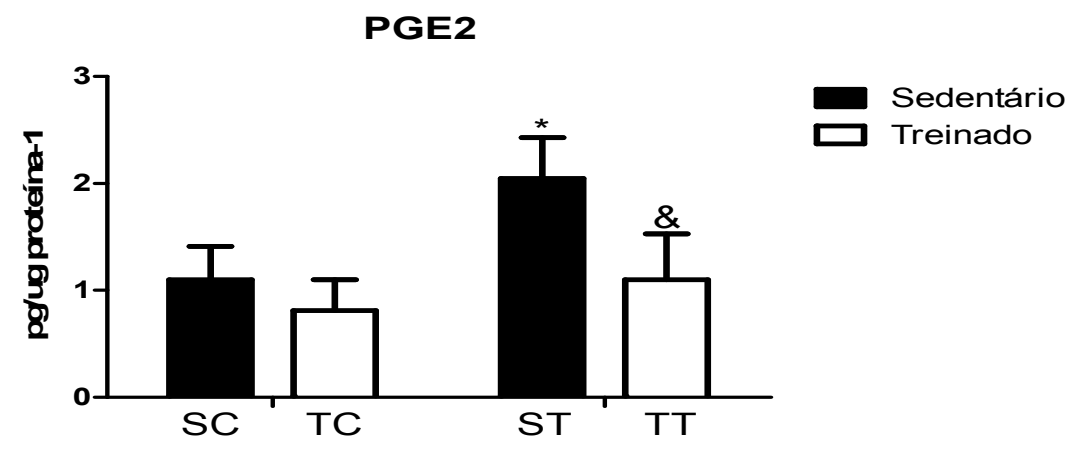

Figura 17: Concentração de $\mathrm{PGE}_{2}$ no fígado. Resultados expressos em média $\pm \mathrm{EPM}$. $\mathrm{n}=10$ para SC e ST e $n=8$ para TC e TT. ${ }^{*} p<0,05$ em relação a SC e ${ }^{*} p<0,05$ em relação a ST. SC (sedentário controle), ST (sedentário tumor), TC (treinado controle), TT (treinado tumor). 


\subsection{Músculo sóleo}

\subsubsection{Medida da atividade máxima das enzimas CPT I e CPT II no músculo sóleo}

A Figura 18 representa os resultados para atividade máxima das enzimas CPT I e CPT II para o músculo sóleo. A atividade máxima da CPT I em TC apresentou $178 \%$ de aumento comparado a SC $\left(^{* *} \mathrm{p}<0,01\right)$. Para a CPT II tanto em ST como TC observa-se aumento de $168 \%$ e $170 \%$ respectivamente em relação a SC $\left({ }^{* *} p<0,001\right)$. Ainda, o grupo TC apresentou $90 \%$ de diminuição na capacidade máxima da CPT II se comparado ao grupo SC $\left({ }^{*} p<0,05\right)$.

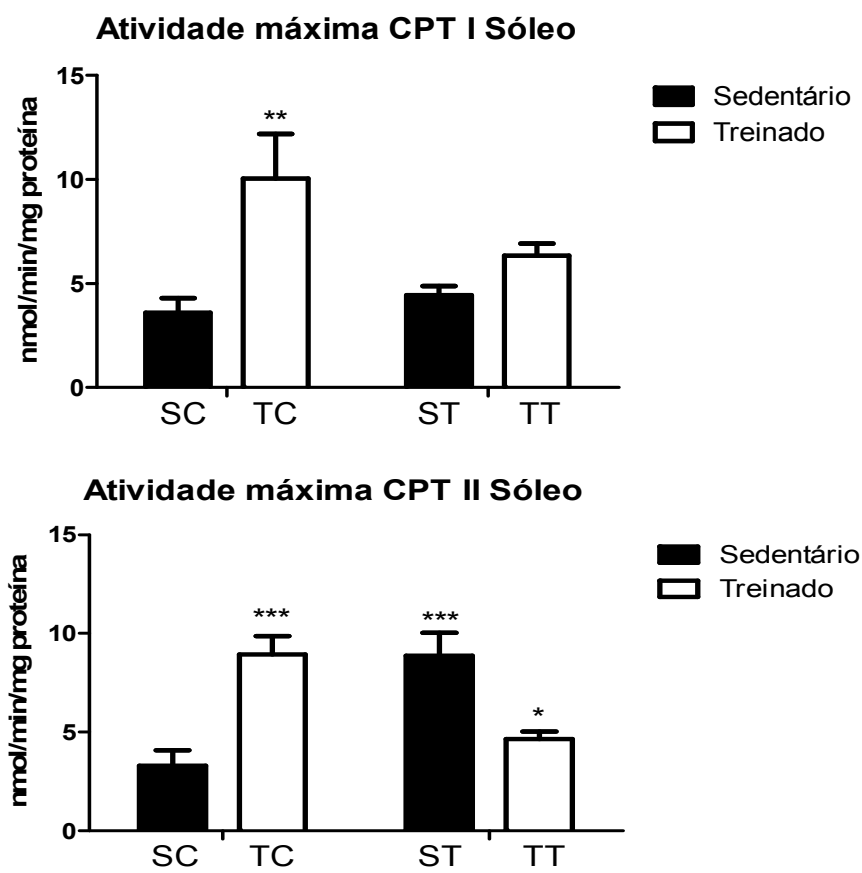

Figura 18: Atividade máxima da CPT I e CPT II no músculo sóleo. Resultados expressos em média \pm EPM. $n=7$ para todos os grupos. ${ }^{*} p<0,05$ em relação a $S T ;{ }^{* *} p<0,01$ em relação a SC e ${ }^{* * *} p<0,001$ em relação a SC. SC (sedentário controle), ST (sedentário tumor), TC (treinado controle), TT (treinado tumor). 


\subsubsection{Medida da atividade máxima da enzima Citrato Sintase (CS) no músculo sóleo}

A Figura 19 representa o resultado para atividade máxima da enzima CS para o músculo sóleo. Observa-se aumento de TC em relação a SC (407,64 \28,89 vs $183,45 \pm 26,14 ;{ }^{* * *} p<0,001$. O treinamento per se foi eficiente em aumentar a capacidade máxima da CS $\left({ }^{* * *} p<0,001\right)$.

\section{Atividade máxima CS sóleo}

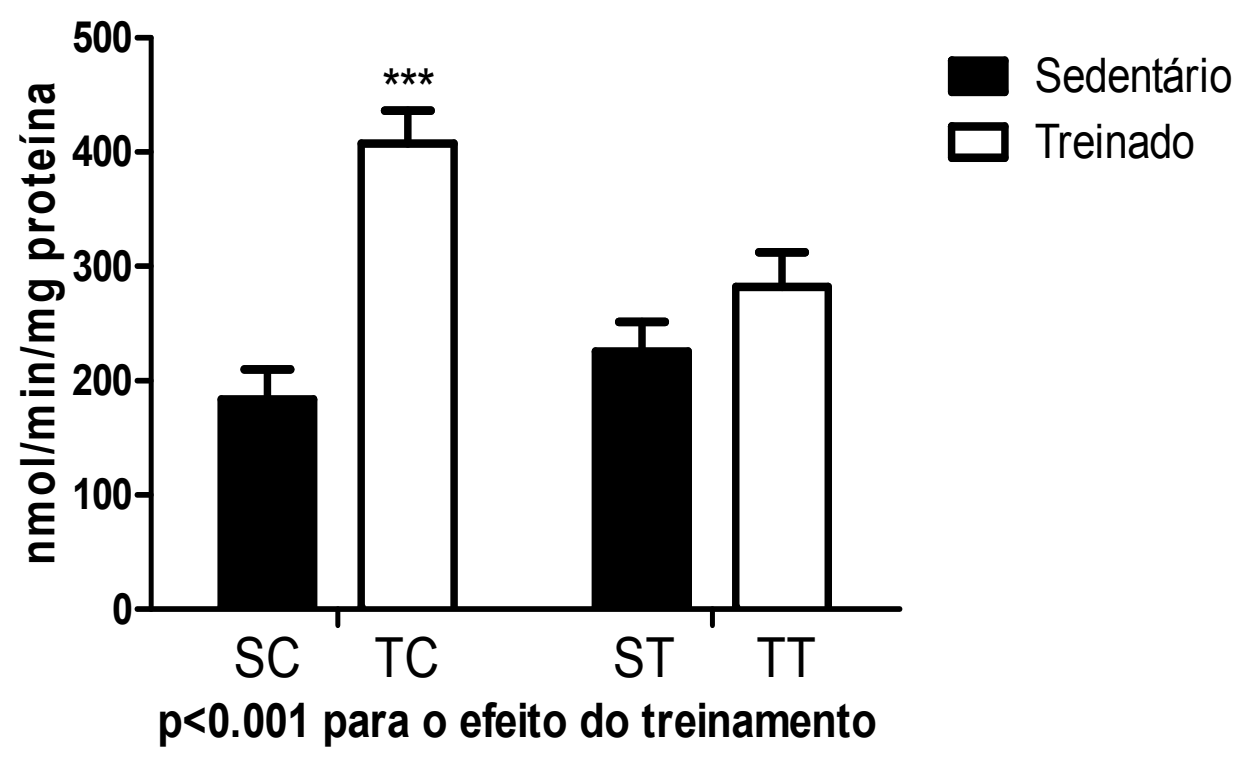

Figura 19: Atividade máxima enzima Citrato sintase no músculo sóleo. Resultados expressos em média \pm EPM. $n=7 .{ }^{* * *} p<0,001$ em relação a SC. SC (sedentário controle), ST (sedentário tumor), TC (treinado controle), TT (treinado tumor). 


\subsubsection{Medida da expressão gênica das proteínas CPT I, CPT II e FABP no músculo sóleo}

Os resultados abaixo apresentados para a expressão gênica das proteínas CPT I, CPT II e FABP no músculo sóleo (figura 20) observa-se que o treinamento aumentou a expressão gênica das três proteínas em relação ao grupo controle $\left({ }^{* * *} p<0,001\right)$.O grupo TT por sua vez aumentou a expressão gênica das proteínas CPT I e FABP se comparado à ST $\left({ }^{\&} \mathrm{p}<0,001\right)$. Ainda, se comparados a $S C$ os valores da CPT I e CPT II para TT apresentam-se elevados $\left({ }^{*} \mathrm{p}<0,05\right)$.

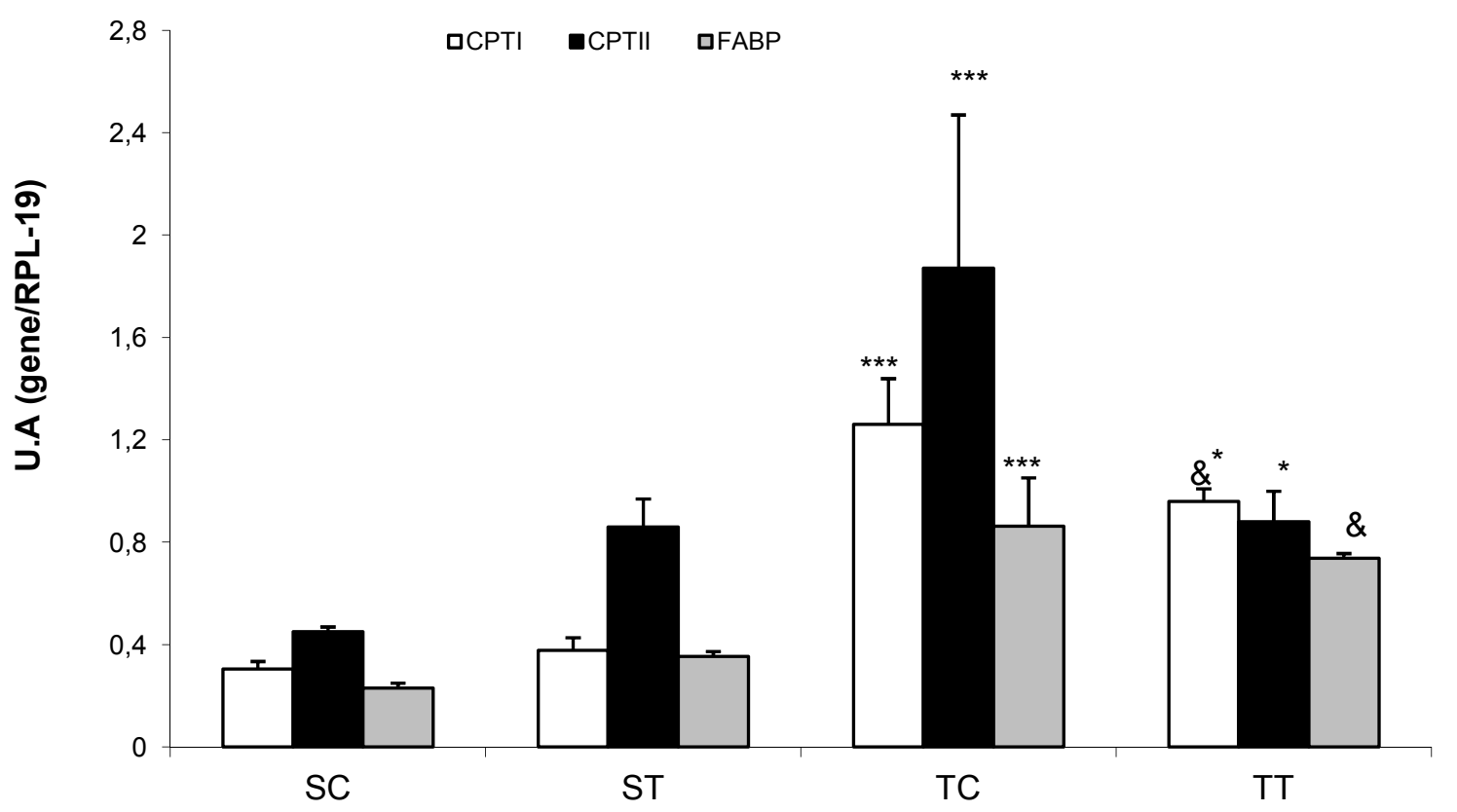

Figura 20: Expressão gênica das proteínas CPT I, CPT ॥ e FABP no músculo sóleo de ratos.. Resultados expressos em média \pm EPM. $n=5$. ${ }^{*} p<0,05$ vs. SC; ${ }^{* * *} p<0,001$ vs. SC e ${ }^{\&} p<0,001$ vs. ST. SC (sedentário controle), ST (sedentário tumor), TC (treinado controle), TT (treinado tumor). 


\subsubsection{Concentração de citocinas (IL-10. IL-6, TNF-a) no músculo sóleo}

A figura 21 abaixo apresenta os valores para a concentração de citocinas no músculo sóleo. Observa-se que as proteínas IL-6 ( $\left.{ }^{*} p<0,05\right)$, IL-1B $\left({ }^{* *} p<0,01\right)$ e IL-10 $\left({ }^{* *} p<0,01\right)$ apresentaram-se em menor concentração em TC em relação a SC. Contudo para o TNFa não foram observadas alterações nos grupos estudados $(p>0,05)$

IL-6

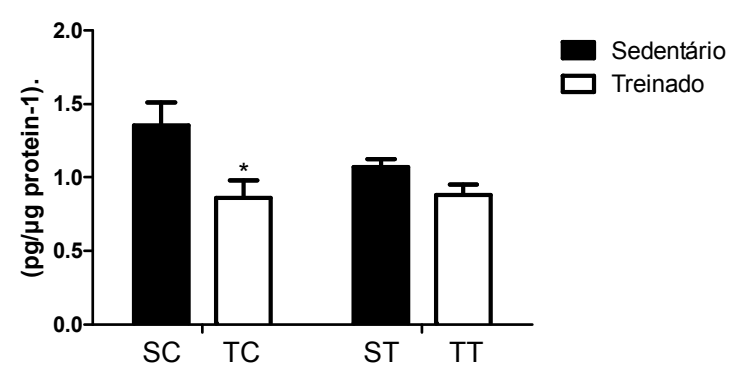

TNF alfa

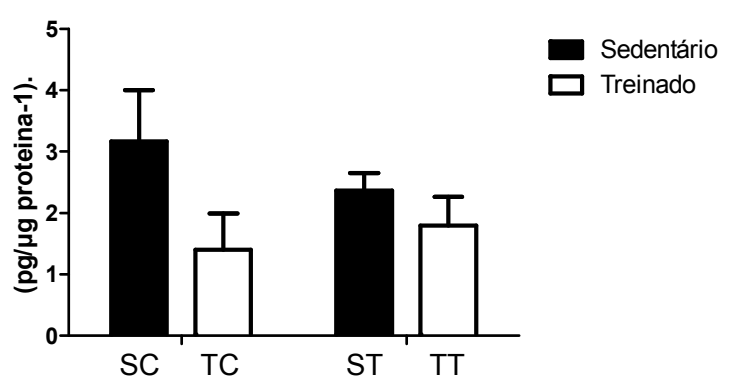

IL-1B

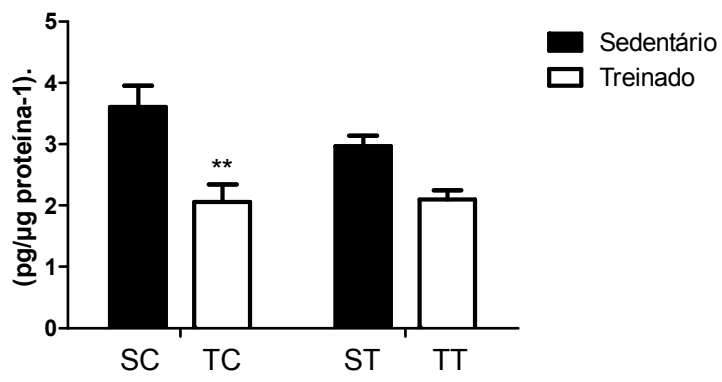

IL-10

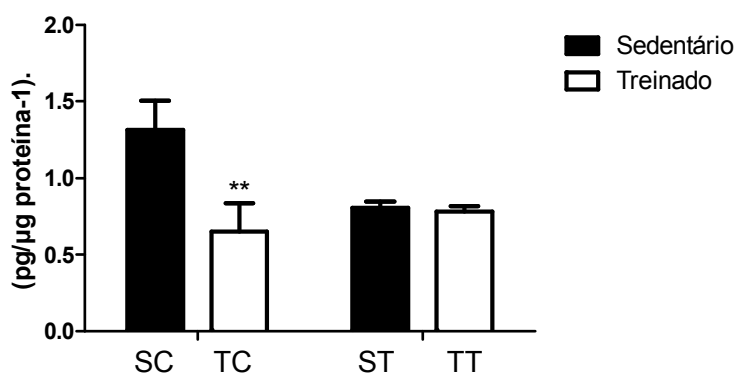

Figura 21: Concentração de proteína das citocinas IL-6, IL-10, e TNF- $\alpha$ e IL-1B(pg/ $\mu$ g proteina $\left.{ }^{-1}\right)$. Resultados expressos em média \pm EPM. $n=5$ para todos os grupos. IL-10 e IL-1B 9 ${ }^{* *} p<0,01$ entre TC e SC. IL- $6 p<0,05$ entre TC e SC e TNF $\alpha p>0,05$ para todos os grupos. SC (sedentário controle), ST (sedentário tumor), TC (treinado controle), TT (treinado tumor). 


\subsection{Tumor}

\subsection{1 peso do tumor}

A figura 22 abaixo representa os dados obtidos para o peso do tumor. Observa-se que o grupo que sofreu a intervenção do treinamento apresentou diminuiçao muito significativa no desenvolvimento do tumor no período de 14 dias antes do sacrifício $\left(17,2 \mathrm{~g} \pm 2,2\right.$ vs. $1,9 \mathrm{~g} \pm 0,3 ;{ }^{* *} \mathrm{p}<0,0001$ entre ST e TT).

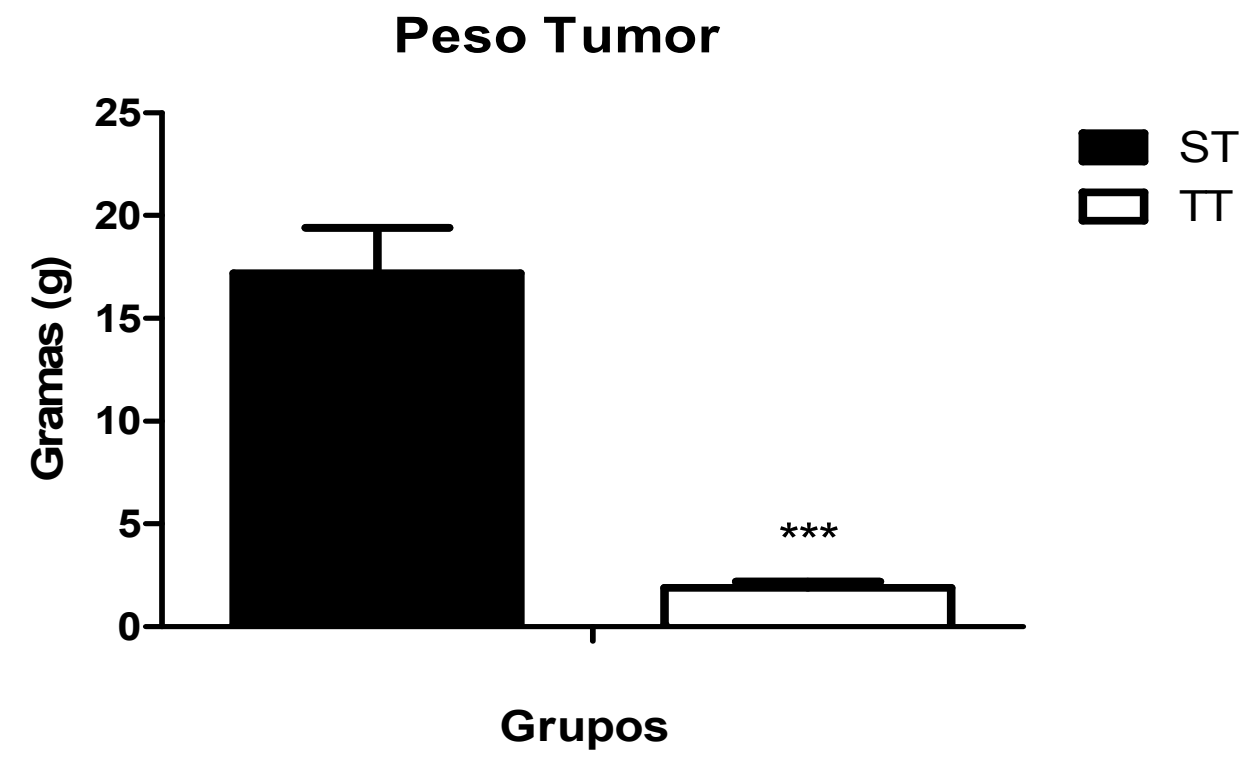

Figura 22: Peso absoluto do tumor após 14 dias de sua injeção. Resultados expressos em média \pm EPM. $n=10$ para SC e $n=8$ para $S T .{ }^{* * *} p<0,0001$ entre os grupos ST e TT. ST (sedentário tumor), TT (treinado tumor). 


\subsubsection{Concentração de $\mathrm{PGE}_{2}$ e TNFa no tecido tumoral.}

A figura 23 apresenta os valores para a concentração de $\mathrm{PGE}_{2}$ e TNFa no tecido tumoral dos ratos treinados e sedentários. Observa-se que a concentração de $\mathrm{PGE}_{2}$ nos ratos treinados diminuiu no tumor $(2,20 \pm 0,67$ vs $4,40 \pm 0,74 \mathrm{pg} / \mathrm{ug}$ proteína $^{-1}{ }^{* *} p<0,01$ entre TTe ST respectivamente). O TNFa não apresentou diferenças entre os dois grupos $(p>0,05)$.
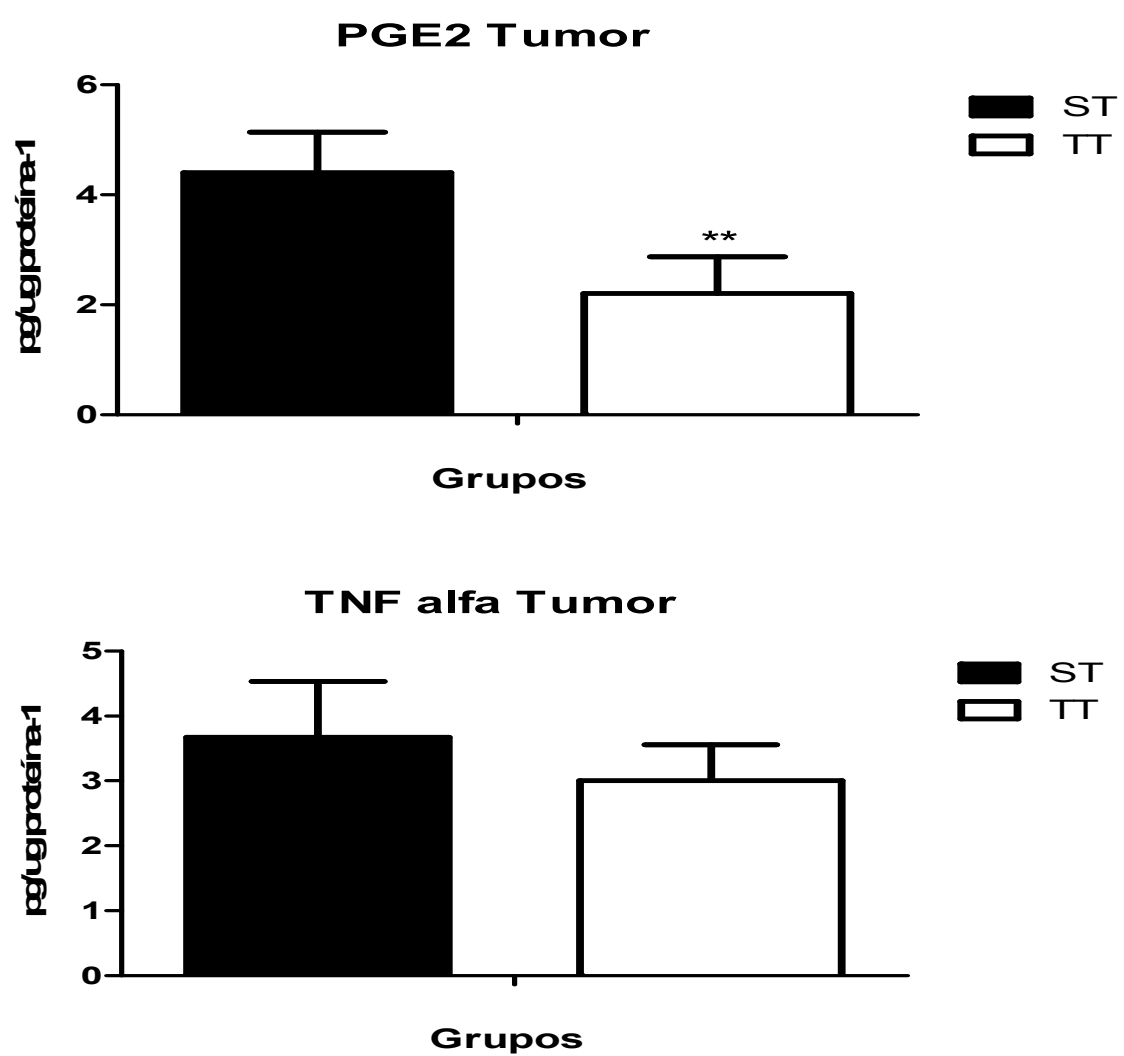

Figura 23: Concentração de $\mathrm{PGE}_{2}$ e TNFa no tecido tumoral com e sem o efeito do treinamento. ${ }^{* *} \mathrm{p}<0,01$ entre TT e ST. Resultados expressos em média \pm EPM. $n=10$ para SC e $n=8$ para ST. ST (sedentário tumor), TT (treinado tumor). 


\section{Discussão}

A caquexia associada ao câncer é uma síndrome paraneoplásica caracterizada por um "caos metabólico" e que esta associada á um baixo índice de sobrevivência. De fato, esta promove alterações prejudiciais no metabolismo energético de carboidratos, lipídios e proteínas (Argilés, 2008). Entre seus sintomas destaca-se uma marcada alteração no metabolismo lipídico (Lira et al., 2010), que leva o indivíduo a desenvolver esteatose hepática e aumento nas concentrações de lipídios séricos (Tisdale, 2009). O fígado frente ao seu papel fundamental no metabolismo intermediário, agindo como órgão central no controle de suprimento de energia para o organismo foi o foco do presente estudo.

Os resultados obtidos no presente projeto confirmam as marcadas alterações incidentes sobre o metabolismo lipídico hepático de ratos caquéticos portadores de tumor como observado em trabalhos anteriores (Kazantzis e Seelaender, 2005; Lira et al., 2010, 2008; Rosa et al., 1998; Seelaender et al., 1999, 1998, 1996).

Em um dos primeiros estudos realizados por nosso grupo de pesquisa com fígado de ratos portadores de tumor constatou-se um aumento na distribuição de lipídios em hepatócitos de ratos quando comparados com ratos controle. $\mathrm{O}$ aumento na incorporação de lipídios de acordo com o estudo ocorre em maior evidência na fase tardia do processo da caquexia, levando a instauração do processo de esteatose (Seelaender et al., 1996).

As proteínas ligadoras de ácidos graxos (FABP) são proteínas citosólicas envolvidas no transporte e metabolismo de ácidos graxos e apresentam-se em maior concentração na zona periportal dos hepatócitos (Bass, 1990). Por outro lado, no fígado de ratos caquéticos, este posicionamento inverte-se a favor da região perivenosa (Kazantzis e Seelaender, 2005). Tal preferência pela zona perivenosa esta relacionada com o aumento nas taxas de esterificação de lipídios observadas na caquexia, já que este processo ocorre preferencialmente nesta população de hepatócitos (Guzmán e Castro, 1990). Os achados de Kazantzis e Seelaender (2005) confirmam-se nos resultados obtidos no presente projeto, já que, embora as diferentes populações de hepatócitos não tenham sido isoladas, a concentração de TAG presente no fígado dos ratos ST apresentou-se elevada em comparação aos demais grupos, provavelmente devido um direcionamento da expressão gênica da 
FABP a favor da zona perivenosa, já que o modelo adotado no desenvolvimento da caquexia foi idêntico em ambos estudos.

Seelaender et al. (1998), observaram que a oxidação de lipídios, bem como a capacidade de produção de corpos cetônicos pelo fígado está diminuída em ratos portadores de tumor, enquanto a composição da lipoproteína de muito baixa densidade (VLDL) está modificada (Seelaender et al., 1996). Em outro estudo realizado mais recentemente constatou-se que a expressão gênica das proteínas apoB e MTP, ambas responsáveis pela montagem da partícula de VLDL, apresentase diminuída em ratos portadores de tumor, o que comprometeria a montagem e a composição desta partícula (Lira et al., 2008). Por fim, outro aspecto essencial a ser levado em consideração é a diminuição na taxa de secreção da VLDL presente em ratos caquéticos portadores de tumor observadas pelo nosso grupo de pesquisa a partir de experimentos realizados com Tiloxapol (Lira et al., 2008) e reforçada pelos resultados apresentados no presente projeto.

Além da diminuição na capacidade de montar e secretar a partícula de VLDL, a capacidade oxidação de lipídios pelo fígado também é diminuída quando da vigência do quadro caquético (Kazantzis e Seelaender, 2005). A etapa chave do processo de oxidação de ácidos graxos e a formação de corpos cetônicos compreendem a entrada deste substrato na mitocôndria, a qual requer contribuição fundamental de um complexo associado à membrana que envolve as enzimas CPT I e CPT II (carnitina palmitoil transferase I e II) e um transportador, a carnitina acilcarnitina translocase (CACT) (McGary e Brown, 1997 McGarry et al., 1991). Resultados obtidos por Kazantzis e Seelaender (2005) demonstraram que a atividade máxima do complexo CPT diminuiu em ratos portadores de tumor. A atividade desse complexo representa o ponto principal na oxidação de ácidos graxos de cadeia longa e os hepatócitos obtêm da oxidação de ácidos graxos a sua principal fonte de energia (Drynan et al., 1996).

Além disso, considerando-se que o modelo de desenvolvimento da caquexia utilizado no presente estudo (Walker-256) é o modelo experimental de caquexia associada ao câncer mais estudado pela ciência (Peluso et al., 2000) e que este desenvolve o quadro de anorexia, o déficit energético do hospedeiro aumenta constantemente devido ao débito imposto pelo Ciclo de Cori (no qual o fígado produz glicose a partir do lactato sintetizado em grande quantidade pelo tumor), uma maior deficiência no transporte de lipídios representada pela diminuição na atividade 
máxima do sistema CPT, representa um fornecimento de energia inadequado para o fígado, que resulta na também inadequada produção de corpos cetônicos, prejudicando não só o funcionamento do fígado, bem como, exacerbando a proteólise do músculo esquelético e agravando a caquexia (Kazantzis e Seelaender, 2005).

Considerando a importância do sistema CPT em agir diretamente na oxidação de ácidos graxos Racic et al. (2008) analisaram a participação deste sistema em 3 diferentes condições: em hepatócitos primários e in vivo no fígado de ratos obesos e não obesos. Em todos os modelos estudados verificou-se aumento na atividade da enzima CPT I capaz de reduzir substancialmente a concentração de TAG intracelular. O aumento na taxa de oxidação de palmitato verificada tanto in vitro quanto in vivo e o aumento na produção de corpos cetônicos confirma o alto grau de controle exercido pelo sistema CPT sobre a oxidação mitocondrial de ácidos graxos. Tais resultados corroboram os anteriormente encontrados por Drynan et al. (1996). Além disso, quando tratados com etomoxir (potente inibidor do complexo CPT) ratos apresentam um aumento significante no conteúdo de TAG (Dobbins et al., 2001). Portanto, o aumento na atividade máxima do complexo CPT é fundamental para reverter o processo de esteatose presente na caquexia associada ao câncer.

O metabolismo dos lipídios no músculo esquelético de acordo com a literatura é claramente prejudicado na vigência da caquexia associada ao câncer, ocasionando inclusive aumento no processo de proteólise e consequente perda de massa magra (Evans et al., 2008). De fato, o sistema proteolítico dependente de ubiquitinação é ativado no músculo esquelético de ratos portadores de tumor (Argiles e LópesSoriano, 1996; Llovera et al., 1996; Llovera et al., 1994). Diversas intervenções nutricionais através da suplementação com ácidos graxos (Tisdale, 2008; Dewey et al, 2007), aminoácidos (revisto por Argilés et al., 2008) e até mesmo a suplementação com L-carnitina (revisto por Silvério et al., 2011) descrevem bons resultados no controle do processo de proteólise da musculatura esquelética. Contudo, resultados obtidos anteriormente por nosso laboratório mostram que o aumento da capacidade de oxidar ácidos graxos no músculo sóleo por meio da atividade máxima do Complexo CPT a partir destas intervenções não apresentou diferença significativa.

A etiologia da caquexia associada ao câncer é complexa e além dos distúrbios metabólicos, fatores secretados pelo tumor em crescimento estão aparentemente 
implicados na mobilização de ácidos graxos e proteínas (Tisdale, 2010, 1999) e não existe até o momento absoluto consenso sobre os fatores que deflagram e mantêm o quadro. Contudo a concepção da síndrome como estado inflamatório, no qual a reação do hospedeiro á presença do tumor aparece como principal causa, tem desde o início da década tomado impulso (Fox et al., 2009; Lendholm et al., 2004; Fearon et al., 1998). Dentre os fatores secretados pelo tumor destacam-se as citocinas, eleitas como responsáveis pela fase aguda da inflamação, bem como pelo desenvolvimento do quadro caquético associado ao câncer (Kumar et al., 2010). Estudos realizados por nosso grupo de pesquisa (Lira et al., 2009, 2008) observaram o aumento na produção e concentração de citocinas pró-inflamatórias nos tecidos adiposo e muscular esquelético na vigência da caquexia associada ao câncer. Já no fígado tal relação ainda não fora estabelecida.

A ativação do NF-KB (fator nuclear kappa B) nos hepatócitos, responsável por controlar e estimular a expressão gênica de proteínas inflamatórias como o TNFa e IL-6, é considerado ponto chave no processo inflamatório do fígado. Os membros da família kappa $B$ regulam um grande número de genes envolvidos na resposta imune, inflamação e câncer. As proteínas da família kappa $B$ são responsivas a vários estímulos tais como citocinas, agentes infecciosos e radiação (Haecker e Karin, 2006). Segundo revisão de Haecker e Karin, (2006), em células não estimuladas, os fatores nucleares kappa B estão dimerizados com a proteína inibitória IKB e por estes razões mantidos no citoplasma. Quando estimuladas, as proteínas IkB são fosforiladas e levadas a degradação pela via dos proteassomas. Dessa maneira, os fatores kappa B são liberados e levados ao núcleo, regulando então a expressão das diversas citocinas inflamatórias supracitadas (Viatour et al., 2005).

Tal regulação leva entre outros distúrbios metabólicos a resistência e diminuição dos níveis plasmáticos de insulina (Holroyde e Reichard, 1981; Shoelson e Goldfine, 2006) e intolerância à glicose, presente em $37 \%$ de todos os pacientes com câncer (Tayek, 1995). Diversos estudos (Andreozzi et al., 2007; He et al., 2006; Rotter et al., 2003; Hirosumi et al., 2002) creditam à citocinas como IL-6, IL-1 e TNFa, efeitos parácrinos no desenvolvimento da resistência a insulina, onde o TNFa (ativador da via clássica inflamatória) seria o principal responsável (Tijerina, 2004). De fato, o TNFa tem demonstrado interferir na sinalização da insulina por meio do IRS-1 (substrato do receptor de insulina-1) (de Luca e Olefsky, 2008). 
No presente projeto, corroborando a ausência de modificação da concentração de citocinas inflamatórias no fígado, a expressão gênica e protéica da unidade p65 da família kappa B (fundamental na dimerização com a unidade p50 e na estimulação da via clássica do processo inflamatório) não apresentou modificações em nenhum dos grupos estudados. Embora seja sugestivo do não desenvolvimento do processo inflamatório no fígado, tal achado não vai de encontro às alterações metabólicas (tais como esteatose, distúrbios na montagem e secreção de VLDL e diminuição da concentração plasmática de insulina) claramente observadas nos ratos portadores de tumor e restabelecidas pelo treinamento (à ser discutido) no presente projeto. Portanto, provavelmente outra via de sinalização e modulação do processo inflamatório provavelmente está envolvida.

O exercício de intensidade moderada realizado cronicamente é conhecido por prevenir o acúmulo de lipídios no fígado, através da diminuição de fornecimento destes ao mesmo e por aumentar a incorporação de TAG na partícula de VLDL (Gauthier et al., 2003). Contudo, poucos estudos têm verificado o efeito do treinamento de intensidade moderada no metabolismo das lipoproteínas de ratos caquéticos portadores de tumor. Os resultados para a taxa de secreção de VLDL no presente projeto demonstraram que o treinamento foi capaz de reverter $o$ comprometimento da taxa secreção desta partícula, restabelecendo o metabolismo das lipoproteínas no fígado nos ratos portadores de tumor, que é claramente afetado na vigência da caquexia.

Tal resultado corrobora os anteriormente obtidos por nosso grupo de pesquisa quando o treinamento em esteira realizado por 8 semanas em ratos (protocolo igual ao utilizado no presente projeto) foi capaz de reverter a queda da expressão gênica das proteínas MTP e apoB em ratos portadores de tumor (Lira et al., 2008), o que somado ao resultado presente, reforça a capacidade do treinamento em restabelecer/preservar o metabolismo de lipoproteínas em ratos caquéticos. Tal restabelecimento da secreção de VLDL promovida pelo treinamento, diferentemente dos ratos treinados, induziu aumento na expressão gênica da FABP nos ratos portadores de tumor que sofreram a intervenção do treinamento no presente projeto, levando a uma maior incorporação de TAG e conseqüentemente maior capacidade 
de fornecimento destes para a partícula de VLDL, normalizando sua secreção, antes afetada pela vigência da caquexia.

O protocolo de treinamento adotado no presente projeto foi capaz de previnir/ restabelecer a oxidação de ácidos graxos de cadeia longa no fígado. Tal protocolo aumentou a capacidade catalítica de ambas CPT I e II e promoveu aumento na expressão gênica da CPT II. Por esta razão é possível afirmar que o efeito do treinamento gerou uma maior capacidade de oxidar lipídios em ambos os grupos treinados, mesmo nos ratos treinados portadores de tumor em comparação ao grupo controle. O aumento na capacidade de oxidar lipídios esta diretamente associada com a redução do processo de reesterificação e acúmulo de TAG no citoplasma de hepatócitos (Kazantzis e Seelaender, 2005; Stefanovic-Racic et al., 2008).

O treinamento moderado conhecidamente aumenta a atividade máxima do complexo CPT no músculo esquelético de ratos (Carnevali et al., in press), resultado este observado no presente projeto. Embora o músculo esquelético não seja o principal alvo do presente projeto, entendendo-se que metabolismo energético não pode de maneira alguma ser compreendido de maneira segmentada, sugere-se que o restabelecimento da taxa de secreção de VLDL observada no fígado (processo este fundamental no fornecimento de energia para a musculatura esquelética), somado ao aumento da expressão gênica da LPL (lipase de lipoproteínas) observado em vários estudos previamente realizados (Magkos et al,, 2007; Seip e Semenkovich, 1998) contribuem com o fornecimento de lipídios para o músculo esquelético, que a partir do aumento da atividade máxima do complexo CPT nos ratos treinados aumenta o seu gasto. De fato, no presente projeto, o treinamento foi capaz de aumentar a expressão gênica das enzimas CPT I, CPT II e FABP no músculo sóleo dos ratos TC comparados ao grupo SC. Já os ratos TT mantiveram os valores para atividade máxima da CPT I e CPT II dentro de seus valores basais e apresentaram aumento da expressão gênica da CPT I e FABP se comparados a ST, indicando que de fato, ocorreu um restabelecimento / manutenção do metabolismo lipídico não somente no fígado, bem como, no músculo esquelético dos ratos por meio do treinamento.

Ainda, sugere-se que como o presente projeto intencionou mimetizar os efeitos da caquexia nos ratos a partir do tumor de Walker-256, inserido nos ratos ao término da sexta semana de treinamento, talvez a capacidade metabólica aumentada por meio do treinamento no fígado e sóleo nas 6 semanas anteriores tenham criado 
uma resistência ao "caos" metabólico promovido pelo tumor em seus 14 dias de desenvolvimento.

A prática regular de atividades de caráter aeróbio crônico vem sendo considerada efetiva em reduzir os efeitos da inflamação crônica. A razão entre as concentrações de IL-10 (citocina anti-inflamatória) e TNFa (citocina pró-inflamatória) tem sido adotada como indicador do grau de inflamação associado aos índices de morbidade (Leonidou et al., 2007; Kaur et al., 2006). Mesmo em animais saudáveis, percebe-se que o exercício é capaz de melhorar esse parâmetro (Lira et al., 2008). Os esforços de nosso grupo de pesquisa direcionam sua atenção em verificar a capacidade do treinamento no estabelecimento desse quadro anti-inflamatório nos ratos com caquexia associada ao câncer nos diversos tecidos.

Em revisão feita por Lira et al. (2009), observou-se que embora o tecido adiposo apresente resposta heterogênea depósito-específica, o treinamento é capaz de atenuar os efeitos da inflamação neste tecido em ratos portadores de tumor, considerando o tecido adiposo mesentérico o mais afetado pelo treinamento (Lira et al., 2008), já que a prática de exercícios crônicos foi capaz de aumentar a relação IL10/TNFa neste tecido. Contudo, na literatura, faltam informações consistentes a respeito do efeito crônico do exercício no fígado em condições de distúrbio metabólico. Nos últimos anos, alguns grupos de pesquisa têm relacionado os distúrbios metabólicos no fígado como a estetatose, paralelamente ao desenvolvimento do processo inflamatório neste tecido (Bruunsgaard, 2005; Esposito e Giugliano, 2004). Cai et al (2005) demonstraram que a expressão gênica de citocinas inflamatórias aumenta no fígado de ambos ratos transgênicos ou daqueles submetidos a uma dieta rica em gorduras, demonstrando que a IL-6 está envolvida no desenvolvimento desta patologia .

Hashem et al. (2008) observaram que a razão IL-10/TNFa no fígado pode ser utilizada como um biomarcador para a investigação do grau de desenvolvimento de doenças hepáticas não alcoólicas tais como a esteatose na caquexia associada ao câncer. Mais recentemente, Pighon et al. (2011), observaram que tanto o treinamento como a reposição hormonal com 17ß-estradiol (E2) foram capazes de aumentar a razão IL-10/TNFa no fígado de ratas ovarectomizadas, indicando melhora no "status" inflamatório em ambas as condições e reduzindo o acúmulo de lipídios neste tecido. 
No presente trabalho, mudanças no perfil inflamatório representado pelo conteúdo protéico das citocinas IL-10, TNFa e IL-6 não foram observadas em nenhum dos grupos estudados. A razão IL-10/TNFa também não apresentou alterações estatisticamente significantes. Os achados de Pighon et al. (2010) diferem-se dos achados do presente projeto em alguns parâmetros. Dentre estes se destacam: a diferença entre os grupos estudados (ratas Sprague-Dawley e ratos Wistar) o modelo de inflamação adotado (ovarectomia e caquexia associada ao câncer) e principalmente o período de vigência do quadro inflamatório, uma vez que as ratas ao iniciarem as 5 semanas de treinamento já estavam ovarectomizadas, enquanto os ratos do presente projeto, treinaram por 6 semanas e então tiveram as células tumorais inseridas, para que assim verificássemos o efeito protetor do treinamento no desenvolvimento do tumor, mimetizador do processo de caquexia nos ratos.

Credita-se portanto ao treinamento, uma capacidade de adaptar o metabolismo do fígado (Lira et al., 2008) e dos diversos tecidos e criar resistência a indução do processo inflamatório neste tecido. De fato, o efeito anti-inflamatório do exercício de baixa e média intensidade já é bem documentado (Gleeson, 2007), bem como, o aumento da função imunológica que induz a uma resistência aos efeitos do tumor, que inclusive foram verificados no presente projeto e serão discutidos mais a frente.

O PPARa (receptor ativado por proliferadores de peroxissomas-alfa) é membro da família de receptores esteróides e esta envolvido em diversas funções metabólicas, respostas inflamatórias e desenvolvimento de câncer no fígado de ratos (Mei et al., 2009; Mukherjee et al., 2008). De fato, estudos realizados com ratos "knock-out" para PPARa demonstram sua importância no metabolismo energético do fígado (Pyper et al., 2010).

Observamos aumento na expressão gênica e protéica do PPARa por meio do treinamento tanto em TC quanto em TT, demonstrando claramente a sua importância na modulação do metabolismo no fígado. Realmente, muitos aspectos do metabolismo lipídico neste tecido estão sob controle do PPARa, incluindo captação de ácidos graxos pela membrana, oxidação, tráfego intracelular, cetogênese e lipólise (Rakhshandehroo et al., 2010). Contudo, além de regular vários processos metabólicos, o PPARa controla também o processo inflamatório, principalmente por interferir na ativação de fatores de transcrição pro - inflamatórios 
tais como Stat (do inglês "signal transducer and activator of transcription"), AP-1 (activator protein-1) е о NFкB (Delerive et al., 1999), regulando negativamente a expressão gênica de citocinas inflamatórias através do processo de transrepressão destes (Delerive et al., 2001).

Por esta razão propõe-se que o PPARa inibe a translocação do NFkB para o núcleo por interagir com a unidade p65 (Delerive et al., 2001). Desta maneira, o papel na regulação negativa da inflamação é o segundo efeito importante do PPARa no processo de combate a esteatose por meio do treinamento verificada no presente projeto. Através da dimerização PPARa/ NFKB previne-se a indução da expressão gênica de citocinas pro-inflamatórias tais como o TNFa, que não apresentou alterações no presente projeto. De fato, a ação protetora do PPARa recentemente foi comprovada em obesos pela regulação negativa exercida por esta isoforma na produção de citocinas pro-inflamatórias como a IL-1 (Stienstra et al., 2007a, 2007b).

O PPARa, assim como vários membros não esteróides da família dos receptores nucleares, funciona a partir da heterodimerização com outro receptor nuclear conhecido como RXR (do inglês retinoid $X$ receptor). O heterodímero PPARa/RXR liga-se a uma seqüência específica de DNA conhecido como elemento responsivo dos proliferadores de peroxissomas (PPRE), localizado na região promotora do gene (Pyper et al., 2010). Corroborando a aumento da capacidade transcricional do PPARa por meio do treinamento no presente projeto, o aumento da expressão gênica deste receptor nuclear foi acompanhado pelo aumento da expressão gênica do RXR no fígado dos ratos treinados, portadores ou não de tumor. Dessa maneira, claras evidências indicam a participação do PPARa tanto na modulação do metabolismo quanto no controle da inflamação no fígado.

Considerando a importância da inibição do NFkB por ação do PPARa, por ação do de seus ligantes (Delerive et al., 1999) e por meio do exercício como observado no presente projeto, acredita-se que mecanismos complementares estejam envolvidos (Delerive et al., 2001). Como citado anteriormente, a atividade do NFKB é intimamente controlada pela degradação do $І \kappa B \alpha$, o qual dimeriza-se e inativa as subunidades da família kappa B no citoplasma (Viatour et al., 2004). Os ativadores de PPARa são capazes de induzir a expressão gênica e protéica do ІкBa em hepatócitos (Blanquart et al., 2003). A indução da expressão gênica do IкBa não afeta a translocação nuclear da unidade p65, porém, esta associada com a diminuição da atividade do NFKB no DNA (Delerive et al., 2000). No presente projeto, 
contudo, observou-se que o treinamento foi capaz de reduzir a expressão gênica do ІкBa no fígado dos ratos.

Analises por Western blot realizadas por Delerive et al. (2000), observaram que a ação da proteína ІкBa ocorre principalmente no núcleo, reduzindo ligação do NFKB na região promotora dos genes de proteínas infamatórias. Portanto, a menor expressão gênica desta proteína observada no presente projeto nos leva a sugerir que o exercício realizado por 6 semanas antes da inserção das células tumorais foi capaz de criar uma capacidade anti-inflamatória e aumento da capacidade metabólica induzida pela maior expressão gênica do PPARa. Desta maneira a ação de controle da inflamação exercida pela proteína ІкBa não se fez necessária.

Somando-se essa análise ao não aumento no conteúdo protéico das principais citocinas inflamatórias já discutidas anteriormente no fígado de ratos treinados, supõe-se que a capacidade de ligação do $\mathrm{NF \kappa B}$, que ocorre principalmente por meio da dimerização das unidades p65 e p50 não estaria aumentada, uma vez que o processo inflamatório, pelo menos através dessa via não se desenvolveu. Interessantemente, os resultados obtidos para a atividade de ligação ao DNA das unidades p65 e p50 no presente projeto não apresentaram alterações em nenhum dos grupos estudados, corroborando a hipótese de que outra via, excluindo a via do NFкB na modulação das alterações metabólicas claramente observadas no presente projeto no metabolismo hepático de ratos com caquexia associada ao tumor estejam envolvidas.

Sabe-se que além das citocinas inflamatórias tais como TNFa e IL-6 o estresse oxidativo e a peroxidação de lipídios por este estimulada no fígado com esteatose, gera produtos que podem mediar o processo inflamatório (Kumagai et al., 2000; Leclercq et al., 2004, 2002; Lee et al., 1995). Os hepatócitos possuem receptores de prostaglandinas (Fennekohl et al., 1999) e estudos anteriores demonstram que com a progressão do processo de caquexia associada ao câncer esta associada a mudanças humorais, incluindo aumento nas concentrações plasmáticas de $\mathrm{PGE}_{2}$ (Willians e Seddiqui, 1990; Seddiqui e Willians, 1989), e também na sua produção pelas células de Kupfer. Tais alterações levam a distúrbios metabólicos que estão implicadas no desenvolvimento da caquexia e resultam em esteatose (Lira et al., 2010).

A via da cicloxigenase (COX) catalisa a conversão do ácido aracdônico em prostanóides como a $\mathrm{PGE}_{2}$ (Funk, 2001) e evidencias indicam que o PPARa pode 
ser um regulador negativo do processo inflamatório no fígado através da inibição da expressão gênica da enzima COX-2 (ciclooxigenase-2) (Nakajima et al., 2004; Devchand et al., 1996). Em hepatócitos a COX-1 é expressa constitutivamente, enquanto a COX-2 é estimulada por fatores estressores. Yu et al. (2006) ao conduzirem estudos para clarificar a significância patogênica da COX-2, observaram que a administração de Wy-14,643 (ligante sintético do PPARa) diminuição a expressão gênica e protéica da COX-2, enquanto ratos PPARa -/- apresentaram aumento nestes valores.

Uma das principais confirmações da capacidade anti-inflamatória exercida pelo treinamento nos ratos portadores de tumor observa-se a partir dos resultados para a expressão gênica da COX-2 e das concentrações hepáticas de $\mathrm{PGE}_{2}$ nos 2 grupos de ratos portadores de tumor estudados no presente projeto. Estes indicam um restabelecimento dos valores tanto da expressão gênica da COX-2, quanto da concentração de $\mathrm{PGE}_{2}$ aos níveis basais nos ratos TT, enquanto os ratos ST apresentaram aumento evidente nestes valores. Tal resultado confirma que o aumento observado nos ratos ST fora revertido por influência do treinamento realizado. Ainda, é provável que tal diminuição na expressão gênica da COX-2 tenha sido mediada pela ação indireta do PPARa, uma vez que esse fator de transcrição não é capaz de interferir na transcrição gênica da COX-2 diretamente ao nível da região promotora do gene (Yu et al., 2005). Contudo, conforme o supracitado, o PPARa tem capacidade de transrepressão ao ligar-se com a subunidade p65 do NFкB (Blanquart et al., 2003) exercendo assim uma função anti-inflamatória. Como a capacidade de ligação ao DNA das unidade p50 e p65 não sofreram alterações em nenhum dos grupos estudados no presente projeto, vias alternativas que levem ao desenvolvimento do processo inflamatório que sejam independentes do NFkB não podem ser descartadas.

A ação transcricional do PPARa é regulada por várias condições fisiológicas tais como estresse, glucocorticóides, leptina e insulina (Inoue et al., 2008). Em hepatócitos de ratos o tratamento com insulina aumenta a capacidade ativação transcricional do PPARa, através de sua fosforilação nos aminoácidos Ser12e Ser21 (Juge-Aubry et al., 1999). As concentrações de plasmáticas de insulina claramente diminuem em portadores de tumor (Holroyde e Reichard, 1981), resultado esse confirmado no presente projeto no grupo ST. Contudo, os resultados para o grupo TT não apresentaram diferenças estatísticas para o grupo controle, indicando um 
restabelecimento/ manutenção dos níveis plasmáticos de insulina e sua ação fisiológica preservada.

Em revisão realizada por Curi et al. (1995) constatou-se uma relação direta entre a diminuição das concentrações plasmáticas de insulina e o aumento das concentrações plasmáticas de $\mathrm{PGE}_{2}$ como indutores do processo de caquexia associada ao câncer. Mais recentemente, embora o modelo estudado não fosse caquexia associada ao câncer, Henkel et al. (2009) observou a capacidade da $\mathrm{PGE}_{2}$ que devido ao processo inflamatório tem sua produção aumentada pelas células de Kupfer, em atenuar os efeitos sinalizadores da insulina. Neste mesmo trabalho verificou-se que a exposição dos hepatócitos por longos períodos interrompem a capacidade de sinalização da insulina através da ativação da via ERK1/2.

Viatour et al. (2005) descrevem que além da modulação clássica do NFкB, o TNFa estimula também o processo de sinalização inflamatória pela ação da proteína MSK1 (do inglês "mitogen-and stress-activated protein kinase-1), que fosforila a unidade p65 no núcleo da célula dependente da via ERK1. Portanto os achados de Henkel et al. (2009) demonstram que a $\mathrm{PGE}_{2}$ liga-se ao receptor de prostaglandina EP3, resultando em uma ativação sustentada da via ERK1/2. Dessa maneira, alem dessa via levar a um aumento do processo inflamatório, ela guia fosforilação do grupo serina do IRS (substrato do receptor de insulina), bloqueando assim a via de sinalização de insulina e criando uma resistência a ação desta.

Como no presente projeto observou-se a não alteração na concentração das citocinas tanto pró quanto antiinflamatórias em nenhum dos grupos estudados, bem como a capacidade de ligação ao DNA das subunidades p65 e p50 do NFKB, sugere-se que a via das prostaglandinas, através do aumento da concentração de $\mathrm{PGE}_{2}$ paralelamente ao aumento da expressão gênica da COX-2 são as responsáveis por gerenciar o efeito inflamatório nos ratos portadores de tumor através de vias que não as classicamente estudadas. Contudo, mesmo que não tenha sido observado aumento na concentração hepática de TNFa e de outras citocinas em nenhum dos grupos no presente projeto, não podemos descartar completamente a sua ação sinalizadora. Certamente deve-se levar em consideração que o fígado é responsável por controlar as concentrações de citocinas na circulação e a não modificação da concentração destas neste tecido pode assim 
ocorrer a partir de citocinas advindas de outros tecidos, já que o fígado é passível de um alto grau de vascularização.

De fato, no presente projeto, verificou-se que as concentrações de citocinas no músculo sóleo dos ratos treinados foi menor nos ratos treinados em comparação aos grupos sedentários portadores ou não de tumor. Tal resultado corrobora os resultados de Lira et al. (2009), que observou a capacidade do treinamento em esteira por 8 semanas (o mesmo adotado no presente projeto) no controle da inflamação (Lira et al., 2009).

O tumor nos ratos no presente trabalho é um potente indutor dos efeitos da caquexia e por este motivo foi utilizado (Bittencourt Jr. et al., 1989). Os benefícios da administração de drogas no controle do crescimento tumoral e conseqüentemente retardo do processo de caquexia, tem sido assumido pela capacidade em reverter distúrbios metabólicos locais (Yu et al., 2005). De fato a administração de 2U/kg peso corporal de insulina mostra-se eficiente em reverter a caquexia associada ao câncer ratos portadores de tumor da linhagem Walker-256 e doses ainda maiores (5U/ kg peso corporal) diminui a taxa de crescimento do tumor em até $90 \%$.

Sabe-se que o processo de carcinogênese resulta-se a partir de dano causado ao DNA que ocorre em células normais, proporcionando crescimento e divisão acentuada destas (Radman et al., 1999). Como conseqüência de tal dano, estas células apresentam características funcionais e metabólicas diferenciadas em comparação as células encontradas no hospedeiro. Tais alterações originam-se a partir de mutações gênicas induzida por diversos fatores que tornam as mesmas resistentes à apoptose celular, formando uma massa tumoral (revisão de Muller et al., 2009). Independentemente de como o dano ao DNA se origina, o cânceres classicamente são resultados de um grupo de características comuns que se definem como marcadores para seu desenvolvimento. Entre esses se incluem: Instabilidade genética, potencial replicativo ilimitado (imortalidade), estimulação da angiogênese, evasão da capacidade de morte celular programada (apoptose) e capacidade de crescimento independente da estimulação por fatores de crescimento (Hanahan e Weinberg, 2000).

As 8 semanas de treino de endurance no presente projeto foram capazes de diminuir a progressão do crescimento tumoral (17,2 gramas para os sedentários e 1,94 gramas para os ratos treinados). Embora o mecanismo pelo qual o treinamento diminui o crescimento tumoral seja desconhecido, certamente a capacidade do 
tumor em secretar fatores que são sinalizadores para o desencadeamento do processo inflamatório no hospedeiro diminuem, amenizando assim os efeitos deletérios promovidos na vigência da caquexia.

Além disso. $\mathrm{A} \mathrm{PGE}_{2}$, que no presente projeto aparece como principal responsável pelo desenvolvimento do processo inflamatório no fígado, interessantemente diminuiu suas concentrações no tumor por meio do treinamento. Tais resultados embora ainda não totalmente esclarecedores, sem dúvida indicam a capacidade do treinamento físico em atenuar os efeitos inflamatórios e sinalizadores para o desenvolvimento da caquexia associada ao câncer não apenas no fígado, como também no próprio tumor (Lira et al., 2010) e outros tecidos como o tecido adiposo (Lira et al., 2008), hipotálamo e músculo esquelético (dados não publicados). 


\section{Conclusão}

A caquexia é uma síndrome paraneoplásica que leva ao comprometimento das funções fisiológicas do fígado, que incontestavelmente é um órgão chave na manutenção do equilíbrio do metabolismo energético. Em vários trabalhos publicados na literatura científica observa-se a capacidade do treinamento possui em otimizar as funções fisiológicas do organismo como um todo. No presente projeto foi possível observar a capacidade do treinamento moderado realizado em esteira no período de 8 semanas em reverter/amenizar os efeitos deletérios causados pela vigência da caquexia associada ao tumor, principalmente no que diz respeito a manutenção/ recuperação das funções fisiológicas do fígado.

Sabe-se que a caquexia é uma doença de origem inflamatória, onde citocinas pró-inflamatórias aumentam sua produção nos diversos tecidos estabelecendo prejuízo em suas funções. No fígado, embora a caquexia associada ao tumor tenha ocasionado alteração em seu metabolismo, o padrão de concentração das citocinas e do fator de transcrição NFKB não mudou em nenhum dos grupos estudados. A explicação para tal fenômeno se daria na atuação mais relevante da via da $\mathrm{PGE}_{2}$, claramente aumentada nos ratos portadores de tumor e revertida por efeito do treinamento. Contudo, não se pode descartar a atuação da via do NFKB. Outra possível resposta do treinamento constatou-se a partir do aumento da expressão gênica e protéica do PPARa nos ratos treinados. Este fator de transcrição além de gerenciar o metabolismo lipídico (o que explicaria o restabelecimento das funções metabólicas do fígado nos ratos TT), também supostamente age como fator antiinflamatório, porém mais estudos são necessários para entender melhor tais mecanismos.

Os mecanismos relacionados aos efeitos do treinamento ainda não estão completamente elucidados, entretanto, os resultados do presente projeto sugerem que a prática crônica de exercícios pode ser um importante agente anti-inflamatório auxiliar no controle das alterações metabólicas ocorridas no fígado na vigência da caquexia associada ao câncer. 


\section{Referências}

Adams LA, Lymp JF, St Sauver J, Sanderson SO, Lindor KD, Feldstein A, et al. The natural history of nonalcoholic fatty liver disease: a population-based cohort study. Gastroenterology. 2005;129(1):113-21.

Anderson N, Borlak J. Molecular mechanisms and therapeutic targets in steatosis and steatohepatitis. Pharmacol Rev. 2008;60(3):311-57.

Andreozzi F, Laratta E, Procopio C, Hribal ML, Sciacqua A, Perticone M, et al. Interleukin-6 impairs the insulin signaling pathway, promoting production of nitric oxide in human umbilical vein endothelial cells. Molecular and cellular biology. 2007;27(6):2372-83.

Anker SD, Coats AJ. Cardiac cachexia: a syndrome with impaired survival and immune and neuroendocrine activation. Chest. 1999;115(3):836-47.

Ardies CM. Exercise, cachexia, and cancer therapy: a molecular rationale. Nutrition and cancer. 2002;42(2):143-57.

Argiles JM, Alvarez B, Lopez-Soriano FJ. The metabolic basis of cancer cachexia. Medicinal research reviews. 1997;17(5):477-98.

Argiles JM, Anker SD, Evans WJ, Morley JE, Fearon KC, Strasser F, et al. Consensus on cachexia definitions. J Am Med Dir Assoc. 2010;11(4):229-30.

Argiles JM, Busquets S, Toledo M, Lopez-Soriano FJ. The role of cytokines in cancer cachexia. Curr Opin Support Palliat Care. 2009;3(4):263-8.

Argiles JM, Lopez-Soriano FJ, Busquets S. Apoptosis signalling is essential and precedes protein degradation in wasting skeletal muscle during catabolic conditions. Int J Biochem Cell Biol. 2008;40(9):1674-8.

Argiles JM, Lopez-Soriano FJ, Busquets S. Novel approaches to the treatment of cachexia. Drug discovery today. 2008;13(1-2):73-8.

Argiles JM, Lopez-Soriano FJ. The ubiquitin-dependent proteolytic pathway in skeletal muscle: its role in pathological states. Trends in pharmacological sciences. 1996;17(6):223-6.

Argiles JM, Moore-Carrasco R, Fuster G, Busquets S, Lopez-Soriano FJ. Cancer cachexia: the molecular mechanisms. Int J Biochem Cell Biol. 2003;35(4):405-9.

Asp L, Claesson C, Boren J, Olofsson SO. ADP-ribosylation factor 1 and its activation of phospholipase $D$ are important for the assembly of very low density lipoproteins. J Biol Chem. 2000;275(34):26285-92.

Bacurau RF, Belmonte MA, Seelaender MC, Costa Rosa LF. Effect of a moderate intensity exercise training protocol on the metabolism of macrophages and 
lymphocytes of tumour-bearing rats. Cell biochemistry and function. 2000;18(4):24958.

Baldwin C. Nutritional support for malnourished patients with cancer. Curr Opin Support Palliat Care. 2011;5(1):29-36.

Bass NM. Fatty acid-binding protein expression in the liver: its regulation and relationship to the zonation of fatty acid metabolism. Mol Cell Biochem. 1990;98:16776.

Basseres DS, Baldwin AS. Nuclear factor-kappaB and inhibitor of kappaB kinase pathways in oncogenic initiation and progression. Oncogene. 2006;25(51):6817-30.

Bharti AR, Weidner N, Ramamoorthy S. Chronic schistosomiasis in a patient with rectal cancer. Am J Trop Med Hyg. 2009;80(1):1-2.

Bing C, Trayhurn P. New insights into adipose tissue atrophy in cancer cachexia. Proc Nutr Soc. 2009;68(4):385-92.

Bjornsson OG, Duerden JM, Bartlett SM, Sparks JD, Sparks CE, Gibbons GF. The role of pancreatic hormones in the regulation of lipid storage, oxidation and secretion in primary cultures of rat hepatocytes. Short- and long-term effects. The Biochemical journal. 1992;281 ( Pt 2):381-6.

Blair SN, Cheng Y, Holder JS. Is physical activity or physical fitness more important in defining health benefits? Medicine and science in sports and exercise. 2001;33(6 Suppl):S379-99; discussion S419-20.

Blanquart C, Barbier O, Fruchart JC, Staels B, Glineur C. Peroxisome proliferatoractivated receptors: regulation of transcriptional activities and roles in inflammation. $J$ Steroid Biochem Mol Biol. 2003;85(2-5):267-73.

Bocher V, Chinetti G, Fruchart JC, Staels B. Role of the peroxisome proliferatoractivated receptors (PPARS) in the regulation of lipids and inflammation control]. Journal de la Societe de biologie. 2002;196(1):47-52.

Bozzetti F. Screening the nutritional status in oncology: a preliminary report on 1,000 outpatients. Support Care Cancer. 2009;17(3):279-84.

Bremer J. The effect of fasting on the activity of liver carnitine palmitoyltransferase and its inhibition by malonyl-CoA. Biochimica et biophysica acta. 1981;665(3):62831.

Brink M, Anwar A, Delafontaine P. Neurohormonal factors in the development of catabolic/anabolic imbalance and cachexia. Int J Cardiol. 2002;85(1):111-21, discussion 21-4.

Brown JK. A systematic review of the evidence on symptom management of cancerrelated anorexia and cachexia. Oncol Nurs Forum. 2002;29(3):517-32. 
Bruunsgaard $\mathrm{H}$. Physical activity and modulation of systemic low-level inflammation. Journal of leukocyte biology. 2005;78(4):819-35.

Bugianesi E, Leone N, Vanni E, Marchesini G, Brunello F, Carucci P, et al. Expanding the natural history of nonalcoholic steatohepatitis: from cryptogenic cirrhosis to hepatocellular carcinoma. Gastroenterology. 2002;123(1):134-40.

Cai D, Yuan M, Frantz DF, Melendez PA, Hansen L, Lee J, et al. Local and systemic insulin resistance resulting from hepatic activation of IKK-beta and NF-kappaB. Nature medicine. 2005;11(2):183-90.

Cardin S, Helie R, Bergeron R, Comte B, van de Werve G, Lavoie JM. Effect of hepatic portal infusion of pyruvate on pancreatic hormone response during exercise. The American journal of physiology. 1994;266(5 Pt 2):R1630-6.

Carnevali Jr LC, Eder R, Lira FS, Lima WP, Gonçalves DC, Zanchi NE, Nicastro H, Lavoie JM, Seelaender M. Effects of high-intensity intermittent training on carnitine palmitoyl transferase activity in the gastrocnemius muscle of rats. BJMBR, in press.

Chapados NA, Seelaender M, Levy E, Lavoie JM. Effects of exercise training on hepatic microsomal triglyceride transfer protein content in rats. Horm Metab Res. 2009;41(4):287-93.

Coker RH, Krishna MG, Lacy DB, Bracy DP, Wasserman DH. Role of hepatic alphaand beta-adrenergic receptor stimulation on hepatic glucose production during heavy exercise. The American journal of physiology. 1997;273(5 Pt 1):E831-8.

Costa G. Cachexia, the metabolic component of neoplastic diseases. Cancer Res. 1977;37(7 Pt 2):2327-35.

Courneya KS, Friedenreich CM. Relationship between exercise pattern across the cancer experience and current quality of life in colorectal cancer survivors. J Altern Complement Med. 1997;3(3):215-26.

Curi R, Homem-de-Bittencourt PI, Jr., Costa-Rosa LF, Fernandes LC, el-Razi S, Seelaender MC, et al. Insulin and prostaglandins as signals between tumor and the host immune system. Brazilian journal of medical and biological research.

Curi R, Newsholme P, Newsholme EA. Metabolism of pyruvate by isolated rat mesenteric lymphocytes, lymphocyte mitochondria and isolated mouse macrophages. The Biochemical journal. 1988;250(2):383-8.

de Luca C, Olefsky JM. Inflammation and insulin resistance. FEBS letters. 2008;582(1):97-105.

Delerive P, De Bosscher K, Besnard S, Vanden Berghe W, Peters JM, Gonzalez FJ, et al. Peroxisome proliferator-activated receptor alpha negatively regulates the vascular inflammatory gene response by negative cross-talk with transcription factors NF-kappaB and AP-1. The Journal of biological chemistry. 1999;274(45):32048-54. 
Delerive P, Fruchart JC, Staels B. Peroxisome proliferator-activated receptors in inflammation control. The Journal of endocrinology. 2001;169(3):453-9.

Delerive P, Gervois P, Fruchart JC, Staels B. Induction of IkappaBalpha expression as a mechanism contributing to the anti-inflammatory activities of peroxisome proliferator-activated receptor-alpha activators. The Journal of biological chemistry. 2000;275(47):36703-7.

Devchand PR, Keller H, Peters JM, Vazquez M, Gonzalez FJ, Wahli W. The PPARalpha-leukotriene B4 pathway to inflammation control. Nature. 1996;384(6604):39-43.

Dewey A, Baughan C, Dean T, Higgins B, Johnson I. Eicosapentaenoic acid (EPA, an omega-3 fatty acid from fish oils) for the treatment of cancer cachexia. Cochrane Database Syst Rev. 2007(1):CD004597.

Dinarello CA. Interleukin-1 and tumor necrosis factor: effector cytokines in autoimmune diseases. Seminars in immunology. 1992;4(3):133-45.

Diraison F, Dusserre E, Vidal H, Sothier M, Beylot M. Increased hepatic lipogenesis but decreased expression of lipogenic gene in adipose tissue in human obesity. American journal of physiology Endocrinology and metabolism. 2002;282(1):E46-51.

Dobbins RL, Szczepaniak LS, Bentley B, Esser V, Myhill J, McGarry JD. Prolonged inhibition of muscle carnitine palmitoyltransferase-1 promotes intramyocellular lipid accumulation and insulin resistance in rats. Diabetes. 2001;50(1):123-30.

Doyle C, Kushi LH, Byers T, et al. Nutrition, physical activity and cancer survivorship advisory committee; American Cancer Society: an American Cancer Society guide for informed choices. CA Cancer J Clin. 2006;56:323-53.

Drynan L, Quant PA, Zammit VA. Flux control exerted by mitochondrial outer membrane carnitine palmitoyltransferase over beta-oxidation, ketogenesis and tricarboxylic acid cycle activity in hepatocytes isolated from rats in different metabolic states. The Biochemical journal. 1996;317 ( Pt 3):791-5.

Durham WJ, Dillon EL, Sheffield-Moore M. Inflammatory burden and amino acid metabolism in cancer cachexia. Curr Opin Clin Nutr Metab Care. 2009;12(1):72-7.

Durstine JL, Grandjean PW, Cox CA, Thompson PD. Lipids, lipoproteins, and exercise. J Cardiopulm Rehabil. 2002;22(6):385-98.

Durstine JL, Thompson PD. Exercise in the treatment of lipid disorders. Cardiol Clin. $2001 ; 19(3): 471-88$.

Eden E, Edstrom S, Bennegard K, Schersten T, Lundholm K. Glucose flux in relation to energy expenditure in malnourished patients with and without cancer during periods of fasting and feeding. Cancer Res. 1984;44(4):1718-24. 
Esposito K, Giugliano D. The metabolic syndrome and inflammation: association or causation? Nutrition, metabolism, and cardiovascular diseases : NMCD. 2004;14(5):228-32.

Evans RD, Williamson DH. Tissue-specific effects of rapid tumour growth on lipid metabolism in the rat during lactation and on litter removal. The Biochemical journal. 1988;252(1):65-72.

Evans WJ, Morley JE, Argiles J, Bales C, Baracos V, Guttridge D, et al. Cachexia: a new definition. Clin Nutr. 2008;27(6):793-9.

Fearon K, Strasser F, Anker SD, Bosaeus I, Bruera E, Fainsinger RL, et al. Definition and classification of cancer cachexia: an international consensus. Lancet Oncol. 2011;12(5):489-95.

Fearon KC, Falconer JS, Slater C, McMillan DC, Ross JA, Preston T. Albumin synthesis rates are not decreased in hypoalbuminemic cachectic cancer patients with an ongoing acute-phase protein response. Annals of surgery. 1998;227(2):249-54.

Fearon KC, Moses AG. Cancer cachexia. International journal of cardiology. 2002;85(1):73-81.

Fearon KC, Voss AC, Hustead DS. Definition of cancer cachexia: effect of weight loss, reduced food intake, and systemic inflammation on functional status and prognosis. Am J Clin Nutr. 2006;83(6):1345-50.

Fennekohl A, Schieferdecker HL, Jungermann K, Puschel GP. Differential expression of prostanoid receptors in hepatocytes, Kupffer cells, sinusoidal endothelial cells and stellate cells of rat liver. Journal of hepatology. 1999;30(1):38-47.

Folch J, Lees M, Sloane Stanley GH. A simple method for the isolation and purification of total lipides from animal tissues. The Journal of biological chemistry. 1957;226(1):497-509.

Fox KM, Gerber Pharmd RA, Bolinder B, Chen J, Kumar S. Prevalence of inadequate glycemic control among patients with type 2 diabetes in the United Kingdom general practice research database: A series of retrospective analyses of data from 1998 through 2002. Clin Ther. 2006;28(3):388-95.

Funk CD. Prostaglandins and leukotrienes: advances in eicosanoid biology. Science. 2001;294(5548):1871-5.

Gauthier MS, Couturier K, Latour JG, Lavoie JM. Concurrent exercise prevents highfat-diet-induced macrovesicular hepatic steatosis. J Appl Physiol. 2003;94(6):212734.

Gibbons GF, Wiggins D, Brown AM, Hebbachi AM. Synthesis and function of hepatic very-low-density lipoprotein. Biochemical Society transactions. 2004;32(Pt 1):59-64. 
Gibbons GF. Assembly and secretion of hepatic very-low-density lipoprotein. The Biochemical journal. 1990;268(1):1-13.

Gilmore TD, Herscovitch M. Inhibitors of NF-kappaB signaling: 785 and counting. Oncogene. 2006;25(51):6887-99.

Gleeson M. Immune function in sport and exercise. J Appl Physiol. 2007;103(2):6939.

Guzman M, Castro J. Zonal heterogeneity of the effects of chronic ethanol feeding on hepatic fatty acid metabolism. Hepatology. 1990;12(5):1098-105.

Guzman M, Castro J. Zonation of fatty acid metabolism in rat liver. The Biochemical journal. 1989;264(1):107-13.

Hacker H, Karin M. Regulation and function of IKK and IKK-related kinases. Science's STKE : signal transduction knowledge environment. 2006;2006(357).

Hashem RM, Mahmoud MF, El-Moselhy MA, Soliman HM. Interleukin-10 to tumor necrosis factor-alpha ratio is a predictive biomarker in nonalcoholic fatty liver disease: interleukin-10 to tumor necrosis factor-alpha ratio in steatohepatitis. European journal of gastroenterology \& hepatology. 2008;20(10):995-1001.

Hayden MS, Ghosh S. Signaling to NF-kappaB. Genes Dev. 2004;18(18):2195-224.

He Q, Suzuki H, Sharma N, Sharma RP. Ceramide synthase inhibition by fumonisin B1 treatment activates sphingolipid-metabolizing systems in mouse liver. Toxicological sciences : an official journal of the Society of Toxicology. 2006;94(2):388-97.

Hebbachi AM, Seelaender MC, Baker BW, Gibbons GF. Decreased secretion of very-low-density lipoprotein triacylglycerol and apolipoprotein $B$ is associated with decreased intracellular triacylglycerol lipolysis in hepatocytes derived from rats fed orotic acid or n-3 fatty acids. The Biochemical journal. 1997;325 ( Pt 3):711-9.

Henkel J, Neuschafer-Rube F, Neuschafer-Rube AP, Pueschel GP. Aggravation by Prostaglandin $E_{2}$ of interleukin-6-dependent insulin resistance in hepatocytes. Hepatology, 2009; 50: 781-90.

Henriksson J. Training induced adaptation of skeletal muscle and metabolism during submaximal exercise. The Journal of physiology. 1977;270(3):661-75.

Hirosumi J, Tuncman G, Chang L, Gorgun CZ, Uysal KT, Maeda K, et al. A central role for JNK in obesity and insulin resistance. Nature. 2002;420(6913):333-6.

Holloszy JO, Booth FW. Biochemical adaptations to endurance exercise in muscle. Annual review of physiology. 1976;38:273-91.

Holroyde CP, Reichard GA. Carbohydrate metabolism in cancer cachexia. Cancer treatment reports. 1981;65 Suppl 5:55-9. 
Homem-de-Bittencourt Junior PI, Pontieri V, Curi R, Lopes OU. Effects of aspirin-like drugs on Walker 256 tumor growth and cachexia in rats. Brazilian journal of medical and biological research, 1989;22(8):1039-42.

Horowitz JF, Klein S. Lipid metabolism during endurance exercise. The American journal of clinical nutrition. 2000;72(2 Suppl):558S-63S.

Hsu H, Xiong J, Goeddel DV. The TNF receptor 1-associated protein TRADD signals cell death and NF-kappa B activation. Cell. 1995;81(4):495-504.

Hyltander A, Drott C, Unsgaard B, Tolli J, Korner U, Arfvidsson B, et al. The effect on body composition and exercise performance of home parenteral nutrition when given as adjunct to chemotherapy of testicular carcinoma. Eur $\mathrm{J}$ Clin Invest. $1991 ; 21(4): 413-20$.

Inoue J, Satoh S, Kita M, Nakahara M, Hachimura S, Miyata M, et al. PPARalpha gene expression is up-regulated by LXR and PXR activators in the small intestine. Biochemical and biophysical research communications. 2008;371(4):675-8.

Juge-Aubry C, Pernin A, Favez T, Burger AG, Wahli W, Meier CA, et al. DNA binding properties of peroxisome proliferator-activated receptor subtypes on various natural peroxisome proliferator response elements. Importance of the 5 '-flanking region. The Journal of biological chemistry. 1997;272(40):25252-9.

Jungermann K, Kietzmann T. Zonation of parenchymal and nonparenchymal metabolism in liver. Annual review of nutrition. 1996;16:179-203.

Kaur K, Sharma AK, Dhingra S, Singal PK. Interplay of TNF-alpha and IL-10 in regulating oxidative stress in isolated adult cardiac myocytes. Journal of molecular and cellular cardiology. 2006;41(6):1023-30.

Kazantzis M, Seelaender MC. Cancer cachexia modifies the zonal distribution of lipid metabolism-related proteins in rat liver. Cell Tissue Res. 2005;321(3):419-27.

Kerner J, Hoppel C. Fatty acid import into mitochondria. Biochim Biophys Acta. 2000;1486(1):1-17.

Kim JH, Kim B, Cai L, Choi HJ, Ohgi KA, Tran C, et al. Transcriptional regulation of a metastasis suppressor gene by Tip60 and beta-catenin complexes. Nature. 2005;434(7035):921-6.

Kimber NE, Heigenhauser GJ, Spriet LL, Dyck DJ. Skeletal muscle fat and carbohydrate metabolism during recovery from glycogen-depleting exercise in humans. The Journal of physiology. 2003;548(Pt 3):919-27.

Kolden GG, Strauman TJ, Ward A, Kuta J, Woods TE, Schneider KL, et al. A pilot study of group exercise training (GET) for women with primary breast cancer: feasibility and health benefits. Psycho-oncology. 2002;11(5):447-56. 
Kumagai T, Kawamoto Y, Nakamura Y, Hatayama I, Satoh K, Osawa T, et al. 4hydroxy-2-nonenal, the end product of lipid peroxidation, is a specific inducer of cyclooxygenase-2 gene expression. Biochemical and biophysical research communications. 2000;273(2):437-41.

Kumar NB, Kazi A, Smith T, Crocker T, Yu D, Reich RR, et al. Cancer cachexia: traditional therapies and novel molecular mechanism-based approaches to treatment. Curr Treat Options Oncol. 2010;11(3-4):107-17.

Latos $\mathrm{P}$, Wojtczak $A B$. Use of the glucose oxidase/peroxidase method for glucose assay leads to overestimation of the inhibition of gluconeogenesis by aminopyrine. Biochimica et biophysica acta. 1989;991(1):152-4.

Leclercq IA, Farrell GC, Schriemer R, Robertson GR. Leptin is essential for the hepatic fibrogenic response to chronic liver injury. Journal of hepatology. 2002;37(2):206-13.

Leclercq IA, Farrell GC, Sempoux C, dela Pena A, Horsmans Y. Curcumin inhibits NF-kappaB activation and reduces the severity of experimental steatohepatitis in mice. Journal of hepatology. 2004;41(6):926-34.

Lee KS, Buck M, Houglum K, Chojkier M. Activation of hepatic stellate cells by TGF alpha and collagen type $\mathrm{I}$ is mediated by oxidative stress through c-myb expression. The Journal of clinical investigation. 1995;96(5):2461-8.

Leonidou L, Mouzaki A, Michalaki M, DeLastic AL, Kyriazopoulou V, Bassaris HP, et al. Cytokine production and hospital mortality in patients with sepsis-induced stress hyperglycemia. The Journal of infection. 2007;55(4):340-6.

Levine B, Kalman J, Mayer L, Fillit HM, Packer M. Elevated circulating levels of tumor necrosis factor in severe chronic heart failure. N Engl J Med. 1990;323(4):236-41.

Lima WP, Carnevali LC, Jr., Eder R, Costa Rosa LF, Bacchi EM, Seelaender MC. Lipid metabolism in trained rats: effect of guarana (Paullinia cupana Mart.) supplementation. Clin Nutr. 2005;24(6):1019-28.

Lira FS, Koyama CH, Yamashita AS, Rosa JC, Zanchi NE, Batista ML, Jr., et al. Chronic exercise decreases cytokine production in healthy rat skeletal muscle. Cell biochemistry and function. 2009;27(7):458-61.

Lira FS, Rosa JC, Yamashita AS, Koyama CH, Batista ML, Jr., Seelaender M. Endurance training induces depot-specific changes in IL-10/TNF-alpha ratio in rat adipose tissue. Cytokine. 2009;45(2):80-5.

Lira FS, Rosa JC, Zanchi NE, Yamashita AS, Lopes RD, Lopes AC, et al. Regulation of inflammation in the adipose tissue in cancer cachexia: effect of exercise. Cell Biochem Funct. 2009;27(2):71-5. 
Lira FS, Tavares FL, Yamashita AS, Koyama CH, Alves MJ, Caperuto EC, et al. Effect of endurance training upon lipid metabolism in the liver of cachectic tumourbearing rats. Cell Biochem Funct. 2008;26(6):701-8.

Lira FS, Yamashita A, Carnevali LC, Jr., Goncalves DC, Lima WP, Rosa JC, et al. Exercise training reduces PGE2 levels and induces recovery from steatosis in tumorbearing rats. Horm Metab Res. 2010;42(13):944-9.

Llovera M, Garcia-Martinez C, Agell N, Lopez-Soriano FJ, Argiles JM. Muscle wasting associated with cancer cachexia is linked to an important activation of the ATP-dependent ubiquitin-mediated proteolysis. International journal of cancer Journal international du cancer. 1995;61(1):138-41.

Llovera M, Garcia-Martinez C, Agell N, Marzabal M, Lopez-Soriano FJ, Argiles JM. Ubiquitin gene expression is increased in skeletal muscle of tumour-bearing rats. FEBS letters. 1994;338(3):311-8.

Loberg RD, Bradley DA, Tomlins SA, Chinnaiyan AM, Pienta KJ. The lethal phenotype of cancer: the molecular basis of death due to malignancy. CA Cancer $\mathrm{J}$ Clin. 2007;57(4):225-41.

Lopez-Soriano J, Argiles JM, Lopez-Soriano FJ. Lipid metabolism in rats bearing the Yoshida AH-130 ascites hepatoma. Mol Cell Biochem. 1996;165(1):17-23.

Lundholm K, Daneryd P, Bosaeus I, Korner U, Lindholm E. Palliative nutritional intervention in addition to cyclooxygenase and erythropoietin treatment for patients with malignant disease: Effects on survival, metabolism, and function. Cancer. 2004;100(9):1967-77.

Machado AP, Costa Rosa LF, Seelaender MC. Adipose tissue in Walker 256 tumourinduced cachexia: possible association between decreased leptin concentration and mononuclear cell infiltration. Cell and tissue research. 2004;318(3):503-14.

Magkos F, Patterson BW, Mohammed BS, Mittendorfer B. A single 1-h bout of evening exercise increases basal FFA flux without affecting VLDL-triglyceride and VLDL-apolipoprotein B-100 kinetics in untrained lean men. American journal of physiology Endocrinology and metabolism. 2007;292(6):E1568-74.

Mantovani A. Molecular pathways linking inflammation and cancer. Curr Mol Med. 2010;10(4):369-73.

Marin-Corral J, Fontes CC, Pascual-Guardia S, Sanchez F, Olivan M, Argiles JM, et al. Redox balance and carbonylated proteins in limb and heart muscles of cachectic rats. Antioxid Redox Signal. 2010;12(3):365-80.

Marok R, Winyard PG, Coumbe A, Kus ML, Gaffney K, Blades S, et al. Activation of the transcription factor nuclear factor-kappaB in human inflamed synovial tissue. Arthritis Rheum. 1996;39(4):583-91. 
Martinez-Outschoorn UE, Whitaker-Menezes D, Pavlides S, Chiavarina B, Bonuccelli G, Casey T, et al. The autophagic tumor stroma model of cancer or "battery-operated tumor growth": A simple solution to the autophagy paradox. Cell Cycle. 2010;9(21):4297-306.

McCarthy DO. Rethinking nutritional support for persons with cancer cachexia. Biol Res Nurs. 2003;5(1):3-17.

McGarry JD, Brown NF. The mitochondrial carnitine palmitoyltransferase system. From concept to molecular analysis. European journal of biochemistry / FEBS. $1997 ; 244(1): 1-14$.

McGarry JD, Foster DW. Regulation of hepatic fatty acid oxidation and ketone body production. Annual review of biochemistry. 1980;49:395-420.

McGarry JD, Sen A, Esser V, Woeltje KF, Weis B, Foster DW. New insights into the mitochondrial carnitine palmitoyltransferase enzyme system. Biochimie. $1991 ; 73(1): 77-84$.

McMillan DC. Systemic inflammation, nutritional status and survival in patients with cancer. Curr Opin Clin Nutr Metab Care. 2009;12(3):223-6.

Mei CL, He P, Cheng B, Liu W, Wang YF, Wan JJ. Chlamydia pneumoniae induces macrophage-derived foam cell formation via PPAR alpha and PPAR gammadependent pathways. Cell biology international. 2009;33(3):301-8.

Mukherjee R, Locke KT, Miao B, Meyers D, Monshizadegan H, Zhang R, et al. Novel peroxisome proliferator-activated receptor alpha agonists lower low-density lipoprotein and triglycerides, raise high-density lipoprotein, and synergistically increase cholesterol excretion with a liver $X$ receptor agonist. The Journal of pharmacology and experimental therapeutics. 2008;327(3):716-26.

Mulligan HD, Tisdale MJ. Effect of the lipid-lowering agent bezafibrate on tumour growth rate in vivo. Br J Cancer. 1991;64(6):1035-8.

Murthy MS, Pande SV. Malonyl-CoA-sensitive and -insensitive carnitine palmitoyltransferase activities of microsomes are due to different proteins. J Biol Chem. 1994;269(28):18283-6.

Muscaritoli M, Anker SD, Argiles J, Aversa Z, Bauer JM, Biolo G, et al. Consensus definition of sarcopenia, cachexia and pre-cachexia: joint document elaborated by Special Interest Groups (SIG) "cachexia-anorexia in chronic wasting diseases" and "nutrition in geriatrics". Clin Nutr. 2010;29(2):154-9.

Mustafa I, Leverve X. Metabolic and nutritional disorders in cardiac cachexia. Nutrition. 2001;17(9):756-60.

Nakajima T, Kamijo Y, Tanaka N, Sugiyama E, Tanaka E, Kiyosawa K, et al. Peroxisome proliferator-activated receptor alpha protects against alcohol-induced liver damage. Hepatology. 2004;40(4):972-80. 
Pearsall D, Palmer WK. Triacylglycerol metabolism in rat skeletal muscle after exercise. J Appl Physiol. 1990;68(6):2451-6.

Pedersen BK, Hoffman-Goetz L. Exercise and the immune system: regulation, integration, and adaptation. Physiological reviews. 2000;80(3):1055-81.

Peluso G, Nicolai R, Reda E, Benatti P, Barbarisi A, Calvani M. Cancer and anticancer therapy-induced modifications on metabolism mediated by carnitine system. Journal of cellular physiology. 2000;182(3):339-50.

Petersen AM, Pedersen BK. The anti-inflammatory effect of exercise. J Appl Physiol. 2005;98(4):1154-62.

Pighon A, Gutkowska J, Jankowski M, Rabasa-Lhoret R, Lavoie JM. Exercise training in ovariectomized rats stimulates estrogenic-like effects on expression of genes involved in lipid accumulation and subclinical inflammation in liver. Metabolism. 2011;60(5):629-39.

Pond CM. Long-term changes in adipose tissue in human disease. Proc Nutr Soc. 2001;60(3):365-74.

Pyper SR, Viswakarma N, Yu S, Reddy JK. PPARalpha: energy combustion, hypolipidemia, inflammation and cancer. Nucl Recept Signal. 2010;8:e002.

Rakhshandehroo M, Knoch B, Muller M, Kersten S. Peroxisome proliferator-activated receptor alpha target genes. PPAR Res. 2010;2010.

Ramos EJ, Suzuki S, Marks D, Inui A, Asakawa A, Meguid MM. Cancer anorexiacachexia syndrome: cytokines and neuropeptides. Curr Opin Clin Nutr Metab Care. $2004 ; 7(4): 427-34$.

Reddy JK, Rao MS. Lipid metabolism and liver inflammation. II. Fatty liver disease and fatty acid oxidation. American journal of physiology Gastrointestinal and liver physiology. 2006;290(5):G852-8.

Rosa LF, Kazantzis M, Seelaender MC. The effect of Walker-256 tumour development upon Kupffer cell metabolism. Cell biochemistry and function. 1998;16(3):195-202.

Rosa Neto JC, Lira FS, Oyama LM, Zanchi NE, Yamashita AS, Batista ML, Jr., et al. Exhaustive exercise causes an anti-inflammatory effect in skeletal muscle and a proinflammatory effect in adipose tissue in rats. European journal of applied physiology. 2009;106(5):697-704.

Rosa Neto JC, Lira FS, Zanchi NE, Oyama LM, Pimentel GD, Santos RV, et al. Acute exhaustive exercise regulates IL-2, IL-4 and MyoD in skeletal muscle but not adipose tissue in rats. Lipids Health Dis. 2011;10:97. 
Rotter V, Nagaev I, Smith U. Interleukin-6 (IL-6) induces insulin resistance in 3T3-L1 adipocytes and is, like IL-8 and tumor necrosis factor-alpha, overexpressed in human fat cells from insulin-resistant subjects. The Journal of biological chemistry. 2003;278(46):45777-84.

Saggerson ED, Carpenter CA. Carnitine palmitoyltransferase in liver and five extrahepatic tissues in the rat. Inhibition by DL-2-bromopalmitoyl-CoA and effect of hypothyroidism. The Biochemical journal. 1986;236(1):137-41.

Saggerson ED, Carpenter CA. Malonyl CoA inhibition of carnitine acyltransferase activities: effects of thiol-group reagents. FEBS letters. 1982;137(1):124-8.

Sakurai $H$, Chiba H, Miyoshi $H$, Sugita $T$, Toriumi W. IkappaB kinases phosphorylate NF-kappaB p65 subunit on serine 536 in the transactivation domain. J Biol Chem. 1999;274(43):30353-6.

Schoonjans K, Staels B, Auwerx J. The peroxisome proliferator activated receptors (PPARS) and their effects on lipid metabolism and adipocyte differentiation. Biochimica et biophysica acta. 1996;1302(2):93-109.

Schwartz AL. Fatigue mediates the effects of exercise on quality of life. Quality of life research : an international journal of quality of life aspects of treatment, care and rehabilitation. 1999;8(6):529-38.

Seelaender MC, Curi R, Colquhoun A, Williams JF, Zammitt VA. Carnitine palmitoyltransferase II activity is decreased in liver mitochondria of cachectic rats bearing the Walker 256 carcinosarcoma: effect of indomethacin treatment. Biochemistry and molecular biology international. 1998;44(1):185-93.

Seelaender MC, Kazantzis M, Costa Rosa LF. The effect of adrenaline and Walker256 tumour-induced cachexia upon Kupffer cell metabolism. Cell biochemistry and function. 1999;17(3):151-6.

Seelaender MC, Nascimento CM, Curi R, Williams JF. Studies on the lipid metabolism of Walker 256 tumour-bearing rats during the development of cancer cachexia. Biochemistry and molecular biology international. 1996;39(5):1037-47.

Segal R, Evans W, Johnson D, Smith J, Colletta S, Gayton J, et al. Structured exercise improves physical functioning in women with stages I and II breast cancer: results of a randomized controlled trial. Journal of clinical oncology : official journal of the American Society of Clinical Oncology. 2001;19(3):657-65.

Seip RL, Semenkovich CF. Skeletal muscle lipoprotein lipase: molecular regulation and physiological effects in relation to exercise. Exercise and sport sciences reviews. 1998;26:191-218.

Sheperd J. Analysis of training needs of qualified nurse practitioners. $\mathrm{Br} \mathrm{J}$ Nurs. 1992;1(6):310-3. 
Shoelson SE, Lee J, Goldfine AB. Inflammation and insulin resistance. The Journal of clinical investigation. 2006;116(7):1793-801.

Siddiqui RA, Williams JF. The regulation of fatty acid and branched-chain amino acid oxidation in cancer cachectic rats: a proposed role for a cytokine, eicosanoid, and hormone trilogy. Biochemical medicine and metabolic biology. 1989;42(1):71-86.

Silverio R, Laviano A, Rossi Fanelli F, Seelaender M. I-carnitine and cancer cachexia: Clinical and experimental aspects. J Cachex Sarcopenia Muscle. $2011 ; 2(1): 37-44$

Skipworth RJ, Stewart GD, Dejong CH, Preston T, Fearon KC. Pathophysiology of cancer cachexia: much more than host-tumour interaction? Clin Nutr. 2007;26(6):667-76.

Smiechowska J, Utech A, Taffet G, Hayes T, Marcelli M, Garcia JM. Adipokines in patients with cancer anorexia and cachexia. J Investig Med. 2010;58(3):554-9.

Smith SA. Peroxisome proliferator-activated receptors and the regulation of mammalian lipid metabolism. Biochemical Society transactions. 2002;30(Pt 6):108690.

Soop M, Soop A, Sundqvist KG. Spontaneous lymphocyte proliferation during trauma and infection. Scandinavian journal of immunology. 1988;28(6):659-65.

Spassiani NA, Kuk JL. Exercise and the fatty liver. Appl Physiol Nutr Metab. 2008;33(4):802-7.

Springer J, von Haehling S, Anker SD. The need for a standardized definition for cachexia in chronic illness. Nat Clin Pract Endocrinol Metab. 2006;2(8):416-7.

Staels B, Dallongeville J, Auwerx J, Schoonjans K, Leitersdorf E, Fruchart JC. Mechanism of action of fibrates on lipid and lipoprotein metabolism. Circulation. 1998;98(19):2088-93.

Stefanick ML, Mackey S, Sheehan M, Ellsworth N, Haskell WL, Wood PD. Effects of diet and exercise in men and postmenopausal women with low levels of HDL cholesterol and high levels of LDL cholesterol. N Engl J Med. 1998;339(1):12-20.

Stefanovic-Racic M, Perdomo G, Mantell BS, Sipula IJ, Brown NF, O'Doherty RM. A moderate increase in carnitine palmitoyltransferase 1a activity is sufficient to substantially reduce hepatic triglyceride levels. American journal of physiology Endocrinology and metabolism. 2008;294(5):E969-77.

Stienstra R, Mandard S, Patsouris D, Maass C, Kersten S, Muller M. Peroxisome proliferator-activated receptor alpha protects against obesity-induced hepatic inflammation. Endocrinology. 2007;148(6):2753-63.

Stienstra R, Mandard S, Tan NS, Wahli W, Trautwein C, Richardson TA, et al. The Interleukin-1 receptor antagonist is a direct target gene of PPARalpha in liver. Journal of hepatology. 2007;46(5):869-77. 
Tayek JA. A review of cancer cachexia and abnormal glucose metabolism in humans with cancer. Journal of the American College of Nutrition. 1992;11(4):445-56.

Tessitore L, Vizio B, Jenkins O, De Stefano I, Ritossa C, Argiles JM, et al. Leptin expression in colorectal and breast cancer patients. Int J Mol Med. 2000;5(4):421-6.

Thompson MP, Koons JE, Tan ET, Grigor MR. Modified lipoprotein lipase activities, rates of lipogenesis, and lipolysis as factors leading to lipid depletion in C57BL mice bearing the preputial gland tumor, ESR-586. Cancer Res. 1981;41(8):3228-32.

Thompson PD, Cullinane EM, Sady SP, Flynn MM, Chenevert CB, Herbert PN. High density lipoprotein metabolism in endurance athletes and sedentary men. Circulation. $1991 ; 84(1): 140-52$.

Thoren P, Floras JS, Hoffmann P, Seals DR. Endorphins and exercise: physiological mechanisms and clinical implications. Medicine and science in sports and exercise. 1990;22(4):417-28.

Tijerina AJ. The biochemical basis of metabolism in cancer cachexia. Dimensions of critical care nursing : DCCN. 2004;23(6):237-43.

Tilley SL, Coffman TM, Koller BH. Mixed messages: modulation of inflammation and immune responses by prostaglandins and thromboxanes. $J$ Clin Invest. $2001 ; 108(1): 15-23$.

Tisdale MJ. Cancer cachexia. Current opinion in gastroenterology. 2010;26(2):14651.

Tisdale MJ. Catabolic mediators of cancer cachexia. Curr Opin Support Palliat Care. 2008;2(4):256-61.

Tisdale MJ. Mechanisms of cancer cachexia. Physiol Rev. 2009;89(2):381-410.

Tisdale MJ. Wasting in cancer. The Journal of nutrition. 1999;129(1S Suppl):243S$6 \mathrm{~S}$.

Tracey KJ, Lowry SF, Cerami A. Cachetin/TNF-alpha in septic shock and septic adult respiratory distress syndrome. Am Rev Respir Dis. 1988;138(6):1377-9.

van Bilsen M, van der Vusse GJ, Gilde AJ, Lindhout M, van der Lee KA. Peroxisome proliferator-activated receptors: lipid binding proteins controling gene expression. Molecular and cellular biochemistry. 2002;239(1-2):131-8.

Van Dijk G, Balkan B, Lindfeldt J, Bouws G, Scheurink AJ, Ahren B, et al. Contribution of liver nerves, glucagon, and adrenaline to the glycaemic response to exercise in rats. Acta physiologica Scandinavica. 1994;150(3):305-13.

Viatour P, Merville MP, Bours V, Chariot A. Phosphorylation of NF-kappaB and IkappaB proteins: implications in cancer and inflammation. Trends Biochem Sci. 2005;30(1):43-52. 
von Haehling S, Genth-Zotz S, Anker SD, Volk HD. Cachexia: a therapeutic approach beyond cytokine antagonism. Int J Cardiol. 2002;85(1):173-83.

Warnold I, Lundholm K, Schersten T. Energy balance and body composition in cancer patients. Cancer Res. 1978;38(6):1801-7.

Wasserman DH, Spalding JA, Bracy D, Lacy DB, Cherrington AD. Exercise-induced rise in glucagon and ketogenesis during prolonged muscular work. Diabetes. 1989;38(6):799-807.

Weinstein I, Cook GA, Heimberg M. Regulation by oestrogen of carnitine palmitoyltransferase in hepatic mitochondria. The Biochemical journal. $1986 ; 237(2): 593-6$.

Williams JA, Shacter E. Regulation of macrophage cytokine production by prostaglandin E2. Distinct roles of cyclooxygenase-1 and -2 . J Biol Chem. 1997;272(41):25693-9.

Windmueller HG, Spaeth AE. Regulated biosynthesis and divergent metabolism of three forms of hepatic apolipoprotein B in the rat. Journal of lipid research. $1985 ; 26(1): 70-81$.

Witters LA, Watts TD, Daniels DL, Evans JL. Insulin stimulates the dephosphorylation and activation of acetyl-CoA carboxylase. Proc Natl Acad Sci $U S A$. 1988;85(15):5473-7.

Woeltje KF, Esser V, Weis BC, Cox WF, Schroeder JG, Liao ST, et al. Inter-tissue and inter-species characteristics of the mitochondrial carnitine palmitoyltransferase enzyme system. J Biol Chem. 1990;265(18):10714-9.

Woeltje KF, Kuwajima M, Foster DW, McGarry JD. Characterization of the mitochondrial carnitine palmitoyltransferase enzyme system. II. Use of detergents and antibodies. The Journal of biological chemistry. 1987;262(20):9822-7.

Yu J, Ip E, Dela Pena A, Hou JY, Sesha J, Pera N, et al. COX-2 induction in mice with experimental nutritional steatohepatitis: Role as pro-inflammatory mediator. Hepatology. 2006;43(4):826-36.

Zammit VA, Corstorphine CG. Altered release of carnitine palmitoyltransferase activity by digitonin from liver mitochondria of rats in different physiological states. The Biochemical journal. 1985;230(2):389-94.

Zammit VA. Role of insulin in hepatic fatty acid partitioning: emerging concepts. The Biochemical journal. 1996;314 ( Pt 1):1-14.

Zhong H, May MJ, Jimi E, Ghosh S. The phosphorylation status of nuclear NF-kappa $B$ determines its association with CBP/p300 or HDAC-1. Mol Cell. 2002;9(3):625-36. 
Zhong H, Voll RE, Ghosh S. Phosphorylation of NF-kappa B p65 by PKA stimulates transcriptional activity by promoting a novel bivalent interaction with the coactivator CBP/p300. Mol Cell. 1998;1(5):661-71. 